\title{
Investigating the Potential of Waste Heat Recovery as a Pathway for Heavy-Duty Exhaust Aftertreatment Thermal Management
}

\author{
Saroj Pradhan
}

Follow this and additional works at: https://researchrepository.wvu.edu/etd

\section{Recommended Citation}

Pradhan, Saroj, "Investigating the Potential of Waste Heat Recovery as a Pathway for Heavy-Duty Exhaust Aftertreatment Thermal Management" (2014). Graduate Theses, Dissertations, and Problem Reports. 6445.

https://researchrepository.wvu.edu/etd/6445

This Thesis is protected by copyright and/or related rights. It has been brought to you by the The Research Repository @ WVU with permission from the rights-holder(s). You are free to use this Thesis in any way that is permitted by the copyright and related rights legislation that applies to your use. For other uses you must obtain permission from the rights-holder(s) directly, unless additional rights are indicated by a Creative Commons license in the record and/ or on the work itself. This Thesis has been accepted for inclusion in WVU Graduate Theses, Dissertations, and Problem Reports collection by an authorized administrator of The Research Repository @ WVU. For more information, please contact researchrepository@mail.wvu.edu. 
Investigating the Potential of Waste Heat Recovery as a Pathway for Heavy-Duty Exhaust Aftertreatment Thermal Management

\author{
Saroj Pradhan
}

\author{
Thesis submitted \\ to the College of Engineering and Mineral Resources \\ at West Virginia University \\ in partial fulfillment of requirements for the degree of \\ Master of Science in \\ Mechanical Engineering
}

\author{
Committee Members: \\ Dr. Arvind Thiruvengadam, Ph.D., Chair \\ Dr. Gregory Thompson, Ph.D. \\ Dr. Hailin Li, Ph.D. \\ Department of Mechanical and Aerospace Engineering
}

Morgantown, West Virginia, USA

2014

Keywords: Waste Heat Recovery, Heavy-Duty Diesel Engines, SCR, Aftertreatment Thermal Management

Copyright 2014 Saroj Pradhan 


\section{ABSTRACT \\ Investigating the Potential of Waste Heat Recovery as a Pathway for Heavy-Duty Exhaust Aftertreatment Thermal Management}

\section{Saroj Pradhan}

Heavy-duty diesel (HDD) engines are the primary propulsion source for most heavy-duty vehicle freight movement and have been equipped with an array of aftertreatment devices to comply with more stringent emissions regulations. In light of concerns about the transportation sector's influence on climate change, legislators are introducing requirements calling for significant reductions in fuel consumption and thereby, greenhouse gas (GHG) emission over the coming decades. Advanced engine concepts and technologies will be needed to boost engine efficiencies. However, increasing the engine's efficiency may result in a reduction in thermal energy of the exhaust gas, thus contributing to lower exhaust temperature, potentially affecting after-treatment activity, and consequently emissions rate of regulated pollutants.

As an aftertreatment thermal management for selective catalytic reduction (SCR) system, this study investigates the possible utilization of waste heat recovered from a HDD engine as a means to offset fuel penalty incurred during thermal management of SCR system. Experiments were aimed at conducting detailed energy audit of a MY 2011 heavy-duty diesel engine equipped with a DPF and SCR. A MATLAB ${ }^{\circledR}$ based steady-state simulation tool was developed to simulate a waste heat recovery system (WHRS) based on an Organic Rankine Cycle (ORC), working with three different organic fluids, and primarily harvesting energy from combinations of the engine's heat dissipating circuits. The simulations were based on experimental data obtained through a comprehensive characterization of engine energy distribution using a heavy-duty engine dynamometer.

Results obtained from the ORC-WHRS simulation over the engine operating points showed that the working fluids, R123 and R245fa with utilizing post-SCR exhaust stream, and exhaust gas recirculation (EGR) cooler as the two heat sources provided the optimum performance. As the primary goal of this study was to understand the utilization of a WHRS as a strategy for thermal management of an after-treatment system in reducing NOx levels, the study further investigates into the dynamic operation of a heavy-duty diesel engine from an actual vehicle testing. Assessment on magnitude of the energy generated for the transient vehicle operation does show ORC-WHRS as a feasible application in reaching the desired thermal state of a typical HDD engine SCR system. 


\section{ACKNOWLEDGEMENT}

I would like to express my appreciation and thanks to my advisor Dr. Arvind, who has not only been an excellent mentor but also as a good friend for me. Your support and encouragement has been a tremendous guidance in this journey of mine. I also thank Dr. Mridul Gautam for giving me an opportunity to work with CAFEE and giving me your motivational talks to help me grow my confidence in this challenging and exciting field of study.

Furthermore, a special thanks to Marc and Pragalath for your guidance in this research work and in all the other projects. I also thank all my CAFEE colleagues for helping me out in the lab and giving me two years of fun filled moments in CAFEE. I greatly thank Dan for all the support and inspiration. I thank my committee members, Dr. Gregory Thompson and Dr. Hailin Li for giving valuable feedbacks.

To my dear mom and dad, thank you for your love, support, and believing in me. I am very grateful to my sister and Selina for the source of inspiration. 


\section{TABLE OF CONTENTS}

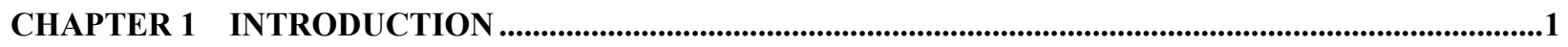

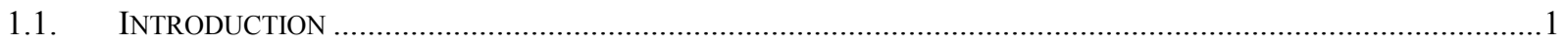

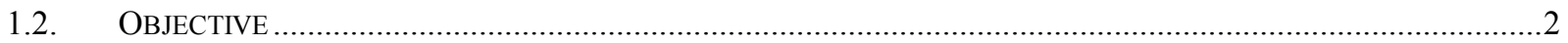

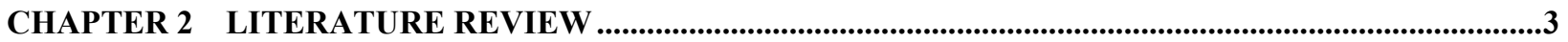

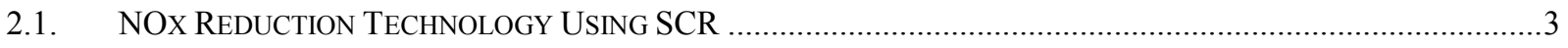

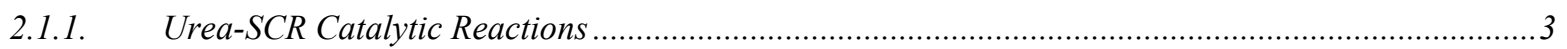

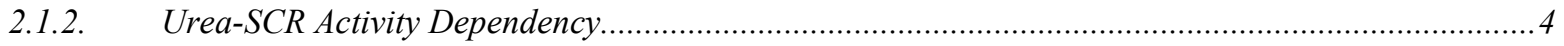

2.1.3. Real-World Heavy-Duty Low Exhaust Temperature Activity ...................................................... 8

2.2. THERMAL MANAGEMENT STRATEGIES FOR IMPROVED SCR ACTIVITY ……......................................... 10

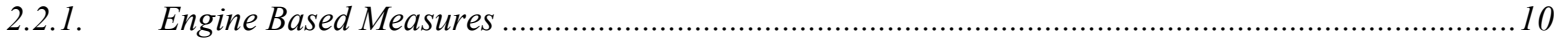

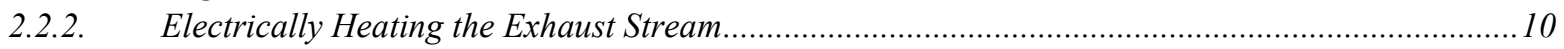

2.3. WASTE HEAT ReCOVERY SYSTEM AS Potential PowER GENERATOR ...............................................11

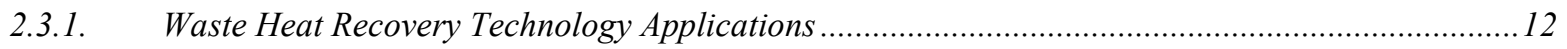

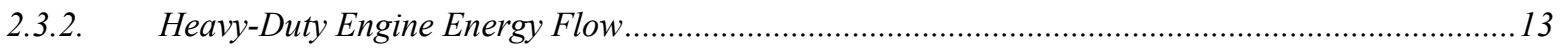

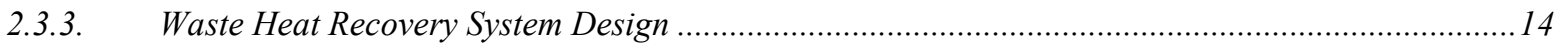

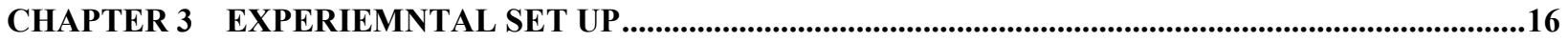

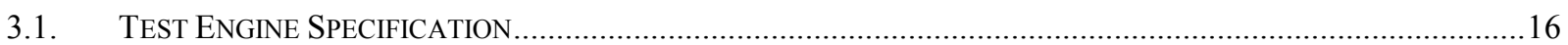

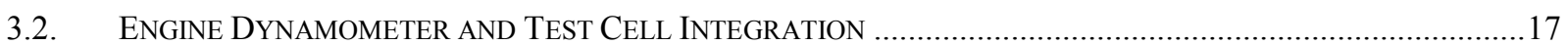

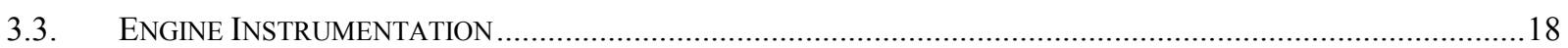

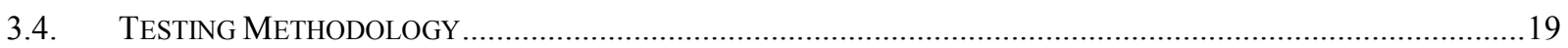

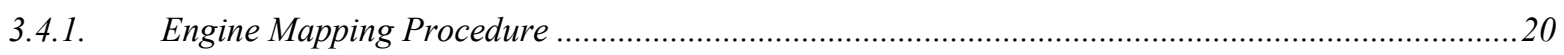

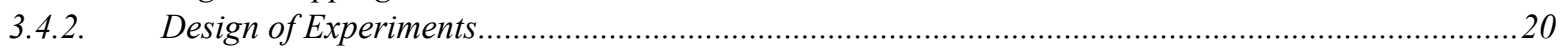

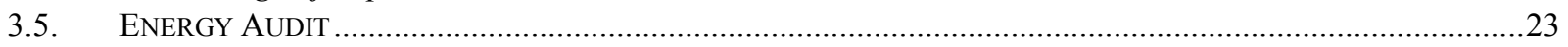

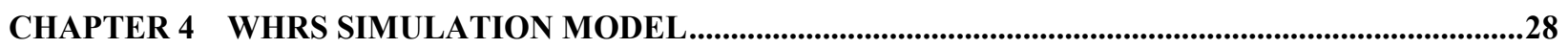

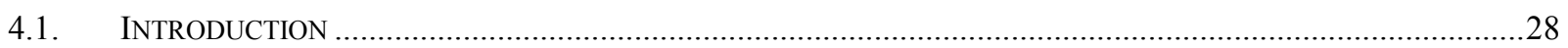

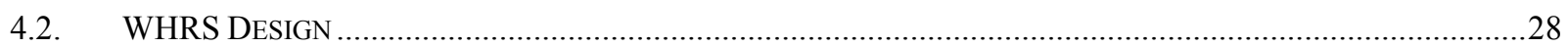

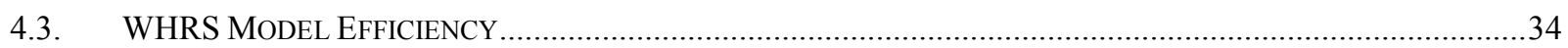

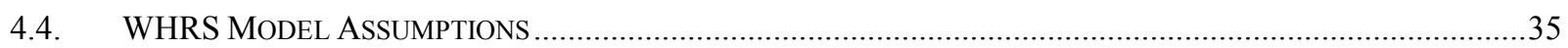

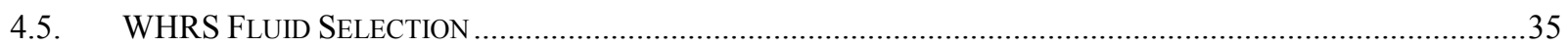

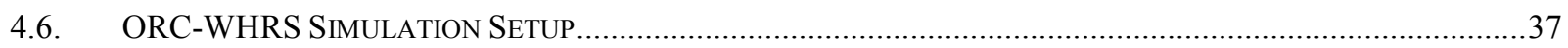

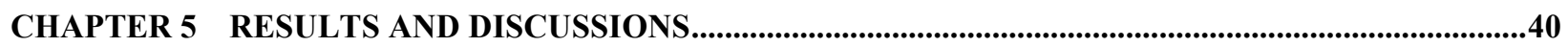

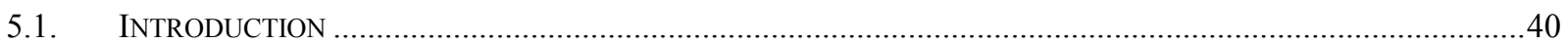

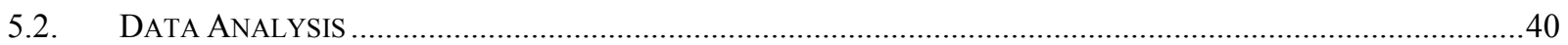

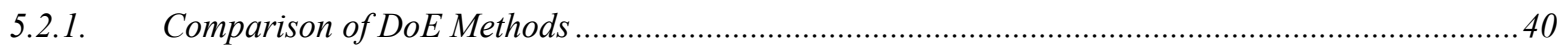

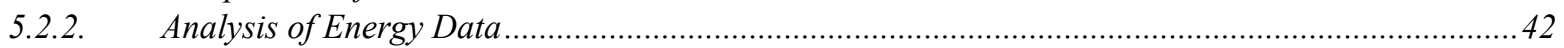

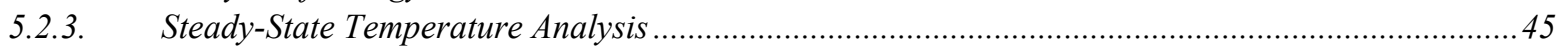

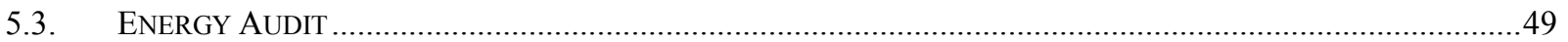

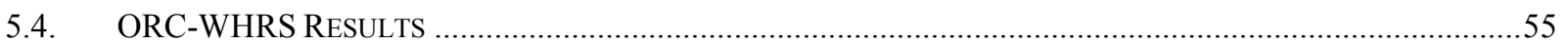

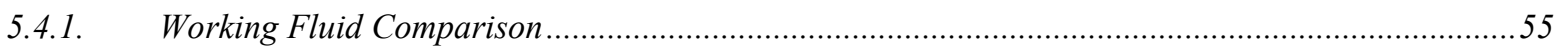

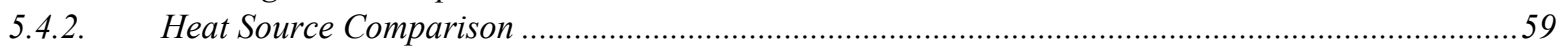

CHAPTER 6 THERMAL MANAGEMENT POTENTIAL ....................................................................................62

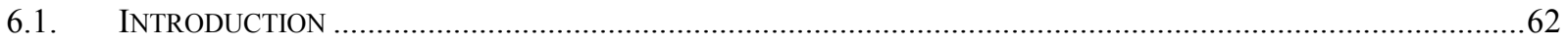

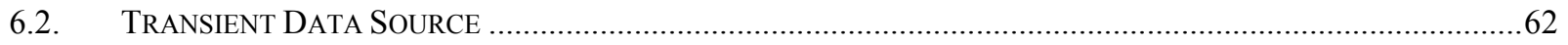




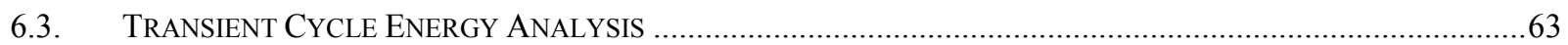

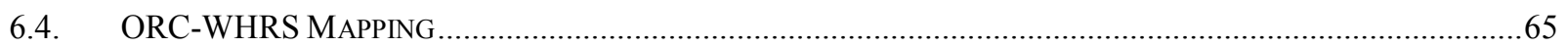

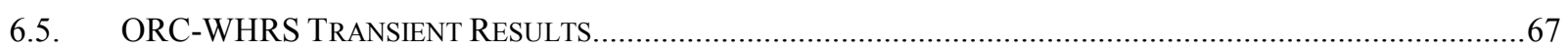

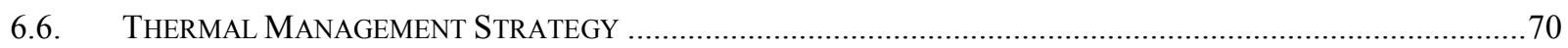

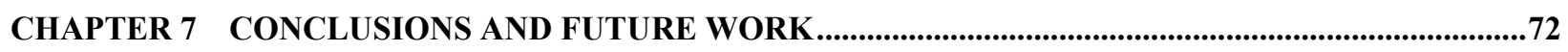

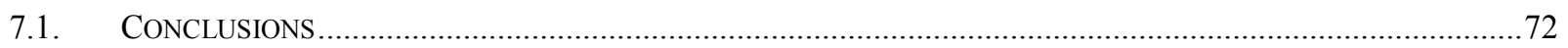

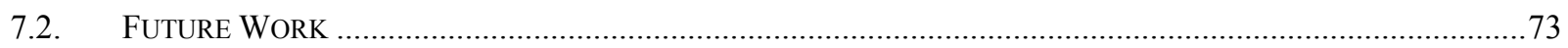

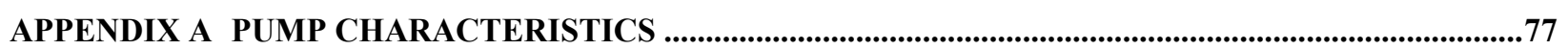

APPENDIX B ORC-WHRS RESPONSE SURFACE RESULTS...................................................................78 


\section{LIST OF TABLES}

TABLE 1. ENERGY FLOW IN TYPICAL MODERN HD DIESEL ENGINE OPERATED AT HIGH LOAD CONDITION.....................13

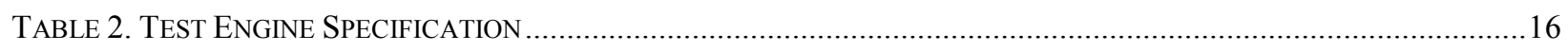

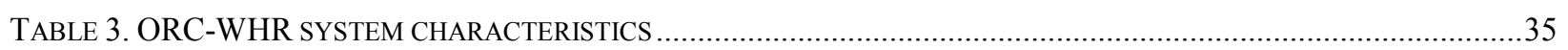

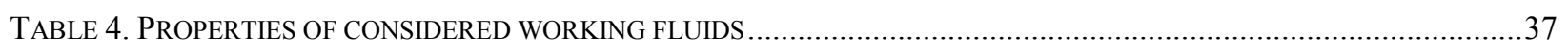

TABLE 5. ORC-WHRS MODEL HEAT SOURCE AND WORKING FLUID CONFIGURATION ………….................................39

TABLE 6. SUMMARY OF THE $2^{\text {ND }}$ ORDER CURVE FITTING MODEL FOR THE TWO DESIGN METHODS.................................40

TABLE 7. SUMMARY OF TEMPERATURE FOR THE SELECT (2 MINUTES) MODES …….................................................47

TABLE 8. SUMMARY OF TEMPERATURE FOR THE SELECT (FIRST 20 SECONDS) MODES.................................................48

TABLE 10. SUMMARY OF TEMPERATURE FOR THE SELECT (LAST 20 SECONDS) MODES ..............................................49

TABLE 11. THERMAL CYCLE EFFICIENCY OF ORC-WHRS MODEL ……..............................................................59

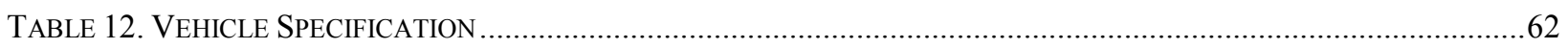

TABLE B-1. PARAMETER ESTIMATE FOR SECOND ORDER RESPONSE MODEL OF R123 DATA .........................................79

TABLE B-2. PARAMETER ESTIMATE FOR SECOND ORDER RESPONSE MODEL OF R245FA DATA ……..............................80 


\section{LIST OF FIGURES}

FIGURE 1. NOX CONVERSION FOR VANADIA-BASED AND METAL-EXCHANGED ZEOLITE-BASED SCR ACTIVITY AT

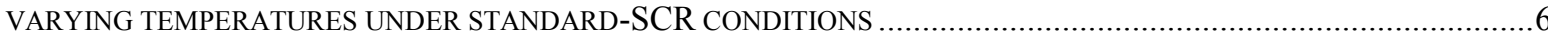

FIGURE 2. NOX CONVERSION OF A STANDARD SCR CATALYST AS FUNCTION OF EXHAUST GAS TEMPERATURE USING

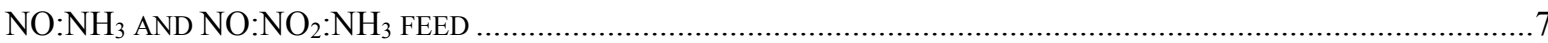

FIGURE 3. INFLUENCE OF THE $\mathrm{NO}_{2} / \mathrm{NO}_{\mathrm{x}}$ FRACTION ON NO $\mathrm{N}_{\mathrm{X}}$ CONVERSION .......................................................

FIGURE 4. NO2 FRACTION IN NOX AFTER A PT-BASED OXIDATION CATALYST WITH VARYING INLET TEMPERATURE ....8

FIGURE 5. EXHAUST DEPENDENT CUMULATIVE $\mathrm{NO}_{\mathrm{x}}$ EMISSION PROFILE FROM A CU-ZEOLITE BASED SCR EQUIPPED TEST VEHICLE DRIVEN IN A CITY ROUTE

FIGURE 6. EMICAT ${ }^{\circledR}$ 'S ELECTRICALLY HEATED CATALYST SYSTEM BEFORE SCR CATALYST IN LIGHT DUTY APPLICATION.

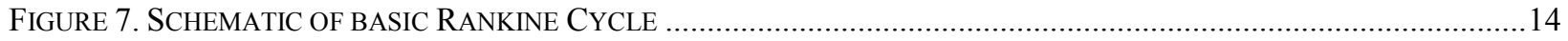

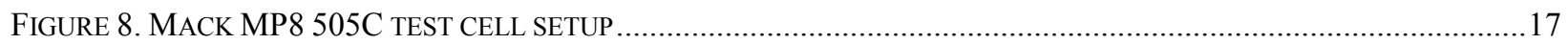

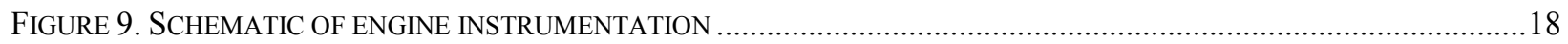

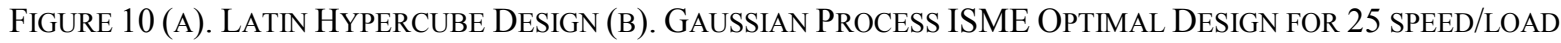

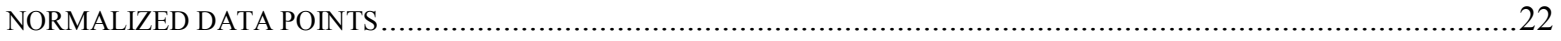

FIGURE 11. SPEED AND TORQUE COMBINATION OF 53 TEST POINTS UNDER THE LUG CURVE ....................................23

FIGURE 12. SCHEMATIC OF THE ENGINE ENERGY FLOW FOR THE SPECIFIED CONTROL VOLUME ................................24

FIGURE 13. CONTROL VOLUME CHOSEN FOR CALCULATING EGR FRACTION AT THE INTAKE MANIFOLD ....................27

FIGURE 14. LAYOUT OF PROPOSED RANKINE CYCLE WASTE HEAR RECOVERY SYSTEM WITH ENERGY RECOVERY FROM

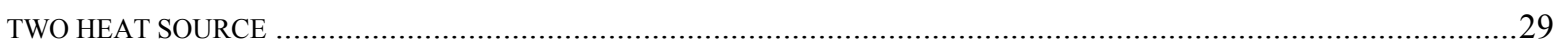

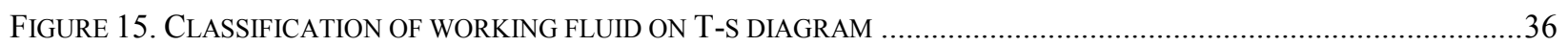

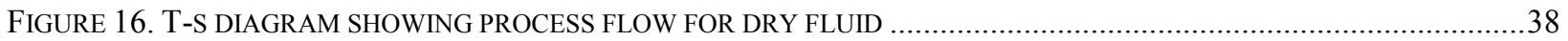

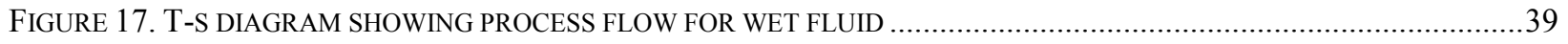

FIGURE 18. COMPARISON OF THE PREDICTED FUEL [G/S] FOR TWO DOE DESIGNS ............................................41

FIGURE 19. PERCENT DIFFERENCE OF THE PREDICTION FUEL [G/S] FOR TWO DOE DESIGNS....................................42

FigurE 20. DATA ANALYSIS OF EXHAUST ENERGY RATE BY ENGINE POWER DEMAND ..........................................43

FIGURE 21. DATA ANALYSIS OF COOLANT ENERGY RATE BY ENGINE POWER DEMAND.........................................44

FIGURE 22. DATA ANALYSIS OF CAC ENERGY RATE BY ENGINE POWER DEMAND ...........................................44

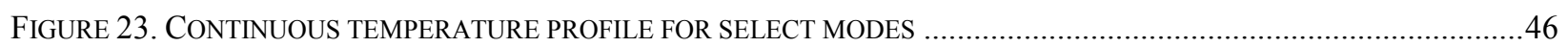

FIGURE 24. RELATIVE ENERGY DISTRIBUTION WITH RESPECT TO TOTAL FUEL ENERGY ..........................................50

FIGURE 25. RELATIVE ENERGY DISTRIBUTION WITH RESPECT TO TOTAL FUEL ENERGY FOR SELECT OPERATING POINTS . .51

FIGURE 26. ENERGY DISTRIBUTION OF THE TOTAL ACCOUNTED HEAT LOSS FROM EXHAUST, COOLANT AND CAC .......52 FIGURE 27 COMPARISON OF TEMPERATURE PROFILE FOR ALL OPERATING POINTS ................................................53

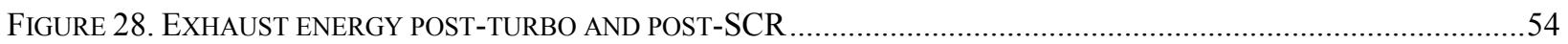


FIGURE 29. TOTAL COOLANT ENERGY INCLUDING EGR ENERGY

FIGURE 30. HX1 [EXHAUST] - HX2 [EGR] WASTE HEAT RECOVERY FOR DIFFERENT WORKING FLUIDS ...................55

FIGURE 31. HX1 [EGR] - HX2 [EXHAUST] WASTE HEAT RECOVERY FOR DIFFERENT WORKING FLUIDS ...................56

FIGURE 32. HX1 [CAC] - HX2 [EXHAUST] WASTE HEAT RECOVERY FOR DIFFERENT WORKING FLUIDS ..................57

FIGURE 33. HX1 [CAC] - HX2 [EGR] WASTE HEAT RECOVERY FOR DIFFERENT WORKING FLUIDS .......................58

FIGURE 34. WHRS CYCLE OUTPUT FOR DIFFERENT HEAT SOURCE CONFIGURATION USING R123 ............................60

FIGURE 35. ORC-WHRS CYCLE OUTPUT FOR DIFFERENT HEAT SOURCE CONFIGURATION USING R245FA.................60

FIGURE 36. ORC-WHRS CYCLE OUTPUT FOR DIFFERENT HEAT SOURCE CONFIGURATION USING R134A..................61

FIGURE 37. PRE-SCR TEMPERATURE PROFILE FROM A COLD-START UDDS CYCLE VEHICLE-CHASSIS TEST RESULTS..64

FIGURE 38. PRE-SCR EXHAUST ENERGY THERMAL ANALYSIS ON THE UDDS CYCLE VEHICLE-CHASSIS TEST RESULTS

FIGURE 39. ORC-WHRS CYCLE OUTPUT POWER MAP FOR HX1(EXHAUST POST-SCR) AND HX2(EGR) USING R123 66 FIGURE 40. ORC-WHRS CYCLE OUTPUT POWER MAP FOR HX1(EXHAUST POST-SCR) AND HX2(EGR) USING R245FA

FIGURE 41. TRANSIENT INPUT FACTOR PROFILES . .68

FIGURE 42. ORC-WHRS POWER GENERATED FOR HX1 [EXHAUST] - HX2 [EGR] WHRS ON UDDS CYCLE .............68

FIGURE 43. CUMULATIVE ENERGY RESULTS USING ORC-WHRS OUTPUT ON UDDS CYCLE ................................69

FIGURE 44. SCHEMATIC OF A THERMAL MANAGEMENT USING ORC-WHRS AS THE POWER SOURCE.........................70

FIGURE 45. CATALYST PRE-HEATING STRATEGY BEFORE AND AFTER ENGINE KEY-ON..........................................71

FIGURE A-1. PERFORMANCE CURVE FOR THE SELECTED POSITIVE DISPLACEMENT PUMP ..........................................77

FIGURE B-1. ACTUAL BY PREDICTED PLOT FOR SECOND ORDER RESPONSE MODEL FOR ORC-WHRS (R123) ............78

FIGURE B-2. ACTUAL BY PREDICTED PLOT FOR SECOND ORDER RESPONSE MODEL FOR ORC-WHRS (R245FA) .........80 


\section{CHAPTER 1 INTRODUCTION}

\subsection{Introduction}

In recent years, modern heavy-duty $(\mathrm{HD})$ vehicles have demonstrated leading progress in achieving stringent emission standards put forward by federal emission regulators in US and Europe. Particularly in the area of reducing vehicle oxides of nitrogen $\left(\mathrm{NO}_{\mathrm{x}}\right)$ emission, the selective catalytic reduction (SCR) technology has been a viable after-treatment solution. However, significant challenges are seen in $\mathrm{NO}_{\mathrm{x}}$ conversion efficiency of a SCR catalyst during the real world on-road applications (Stanton, 2013).

Implication of lower SCR activity during low exhaust temperature operations such as cold start, low load/speed, and initial driving phase has shown to result in significantly elevated NOx emission during such period, and consequently contributing greatly to overall vehicle emission (Misra et al., 2013). Initiating the NOx conversion reaction in a SCR catalyst system greatly depends upon the type of catalyst coating used, and the light-off temperature of the catalyst (Kröcher, 2007). According to studies, catalyst deactivation are seen to occur for temperatures below $200^{\circ} \mathrm{C}$ due to decomposition of the reducing agent over the substrate surface and pores (Koebel et al., 2002).

Engine manufactures have utilized combinations of multiple strategies and mechanisms to provide thermal management for proper SCR activation and urea injections during cold start and low load/speed driving operations (Johnson, 2009). Strategically controlling different engine based parameters to warm-up the exhaust gas stream during low temperature operation has been an effective approach but at the same time exhibits penalties in fuel consumption, emissions and system costs (Cavina et al., 2013). 
An alternative approach is to employ a thermal strategy by means of actively heating the catalyst substrate or the column of exhaust stream just before the inlet of the SCR system to target light-off temperatures. Such strategy has been seen in few engine research studies, and commonly in light-duty diesel vehicle application where the entrance of the SCR catalyst is electrically heated to target faster light-off time in order to maintain proper temperatures during vehicle warm-up periods (Wang et al., 2011, Talus et al., 2011).

\subsection{Objective}

The global objective of this thesis is to investigate potential thermal management strategies for selective catalytic reduction (SCR) aftertreatment system performance during low exhaust temperature operations. This study primarily looks into harvesting wasted heat from the HDD engine, and in order to understand the potential practicality of achieving such strategy this study splits into three objectives:

1. Conduct an engine dynamometer testing to perform an energy analysis on a modern HDD engine in order to understand the recoverable wasted energy.

2. Develop a waste heat recovery system (WHRS) model using Organic Rankine Cycle, and simulate using recoverable heat energy from the same HDD engine to generate useful mechanical work out from the ORC- turbine.

3. Perform an assessment of the ORC-WHRS generated output work as potential energy source in electrically heating exhaust stream for SCR thermal management. 


\section{CHAPTER 2 LITERATURE REVIEW \\ 2.1. NOx Reduction Technology Using SCR}

SCR systems have proven to be effective in controlling the $\mathrm{NO}_{\mathrm{x}}$ emissions over most operating conditions. This technology has been widely adopted by the heavy duty vehicle industry along with or without other engine based strategies such as exhaust gas recirculation (EGR), incylinder modifications and more in order to reduce total vehicle-out $\mathrm{NO}_{\mathrm{x}}$ emissions (Stanton, 2013). As an alternative approach, SCR has aided manufactures in meeting USEPA $2010 \mathrm{NO}_{\mathrm{x}}$ emissions compared to in-cylinder based high EGR strategy. Additionally, use of aqueous urea as the reducing agent coupled with a SCR catalyst has shown to be an efficient pathway in reducing $\mathrm{NO}_{\mathrm{x}}$ under wide range of engine operations. Low exhaust temperature conditions, however, result in the inactivity of SCR aftertreatment systems. This section addresses on the urea-based SCR catalyst activity mechanisms and activity dependencies.

\subsubsection{Urea-SCR Catalytic Reactions}

Oxides of nitrogen in heavy-duty diesel exhaust are composed mostly of NO, which is typically greater than $90 \%$; the remainder of the $\mathrm{NO}_{\mathrm{x}}$ is in the form of $\mathrm{NO}_{2}$. Thus, most of the $\mathrm{SCR}$ activity is required in reducing the NO compound (Koebel et al., 2001).

Ammonia $\left(\mathrm{NH}_{3}\right)$ is used as the primary reducing agent to mitigate $\mathrm{NO}$; the gaseous reaction with the aid of SCR catalysts is provided by Equation (1). The reaction is interpreted as "standard SCR" (Koebel et al., 2001), where 4 mole of ammonia reacts with 4 mole of nitrogen monoxide and only 1 mole of oxygen to produce nitrogen and water. Due to low concentration of oxygen, the reaction occurs at much slower rate. This standard type of reaction is considered less relevant to diesel engine application due to lean (high oxygen content) combustion processes where there is abundance of oxygen in the exhaust stream (Koebel et al., 2000). 


$$
4 \mathrm{NH}_{3}+4 \mathrm{NO}+\mathrm{O}_{2} \rightarrow 4 \mathrm{~N}_{2}+6 \mathrm{H}_{2} \mathrm{O}
$$

Subsequently, a faster known reaction (Bosch and Janssen, 1988) between the reducing agent $\mathrm{NH}_{3}$, and mixture of $\mathrm{NO}_{2}$ and $\mathrm{NO}$ in even ratio of 1:1 is given by the Equation (2). This reaction is also recognized as "fast $\mathrm{SCR}$ " reaction.

$$
4 \mathrm{NH}_{3}+2 \mathrm{NO}+2 \mathrm{NO}_{2} \rightarrow 4 \mathrm{~N}_{2}+6 \mathrm{H}_{2} \mathrm{O}
$$

Conversely, the reaction is slower when $\mathrm{NO}_{2} / \mathrm{NO}_{\mathrm{x}}$ ratio exceeds over $50 \%$ (Bosch and Janssen, 1988). Such reaction, solely with $\mathrm{NO}_{2}$ is given by the following Equation (3).

$$
8 \mathrm{NH}_{3}+6 \mathrm{NO}_{2} \rightarrow 7 \mathrm{~N}_{2}+12 \mathrm{H}_{2} \mathrm{O}
$$

Widely used in the heavy-duty SCR application, urea, typically at $32.5 \%$ by weight with water, is considered to be the safest method to obtain $\mathrm{NH}_{3}$ (Sluder et al., 2005). Adequate physical decomposition is required to convert liquid stored urea to extract $\mathrm{NH}_{3}$ for $\mathrm{SCR}$ activity. The three main processes that undergo this conversion of aqueous urea to obtain $\mathrm{NH}_{3}$ are evaporation, thermolysis, and hydrolysis, which are provided below by Equation (4), Equation (5) and Equation (6), respectively (Koebel et al., 2001).

$$
\begin{gathered}
\mathrm{NH}_{2}-\mathrm{CO}-\mathrm{NH}_{2}(\text { aqueous }) \rightarrow \mathrm{NH}_{2}-\mathrm{CO}-\mathrm{NH}_{2}(\text { solid })+x \mathrm{H}_{2} \mathrm{O} \text { (gas) } \\
\mathrm{NH}_{2}-\mathrm{CO}-\mathrm{NH}_{2} \text { (solid) } \rightarrow \mathrm{NH}_{3} \text { (gas) }+\mathrm{HNCO}(\text { gas }) \\
\mathrm{HNCO}(\text { gas })+\mathrm{H}_{2} \mathrm{O} \text { (gas) } \rightarrow \mathrm{NH}_{3}(\text { gas })+\mathrm{CO}_{2} \text { (gas) }
\end{gathered}
$$

\subsubsection{Urea-SCR Activity Dependency}

The main target of the SCR system is the conversion efficiency of $\mathrm{NO}_{\mathrm{x}}$, and this efficiency highly depends upon multiple factors such as type of urea decomposition, catalyst material, NO- 
to- $\mathrm{NO}_{2}$ ratio, and most importantly the catalyst temperatures at which the reaction takes place inside the SCR system (Keuper et al., 2011). Additionally, it presents that above mentioned parameters have interdependency within each other for SCR functionality (Keuper et al., 2011).

As the catalyst temperature is directly related to the exhaust temperatures entering the SCR system, the SCR activity is predominately linked to the engine operating conditions. According to a study by Koebel for exhaust stream temperatures below $200^{\circ} \mathrm{C}$, the process gets critical in SCR conversion efficiency between the decomposition of the reducing agent and the catalyst activation (Koebel et al., 2002). In the same paper, the author mentions at such low temperatures, ammonia nitrates in solid or liquid form tends to get deposited into the pores of the catalyst, and could potentially lead to catalyst deactivation. Hence, limiting urea dosing at low temperature conditions is usually implemented as a control strategy for preventing SCR substrate fouling, and the cut-off point for urea injection typically ranges between $200-250^{\circ} \mathrm{C}$ (Majewski, 2014).

As mentioned earlier, the effect of temperature on SCR efficiency also depends on the type of catalyst coating used. Different catalysts-based material within the SCR system have varying light-off temperatures along with different temperature ranges for optimum catalyst activity. Figure 1 compares the catalytic activity of iron-based (Fe), copper-based $(\mathrm{Cu})$ and vanadium-based (V) coated catalysts given by the symbols $(\bullet),(\boldsymbol{\bullet})$ and $(\bullet)$, respectively. 


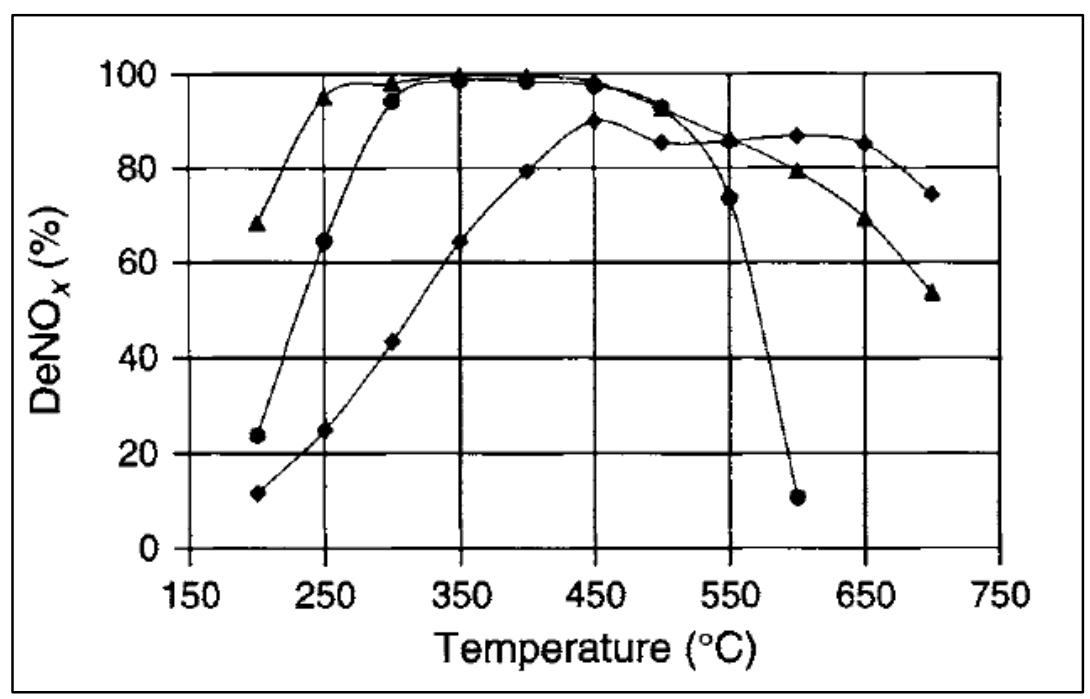

Figure 1. NOx conversion for vanadia-based and metal-exchanged zeolite-based SCR
activity at varying temperatures under standard-SCR conditions (Kröcher, 2007)

Based on a catalyst performance study (Kröcher, 2007), copper-based catalysts are most active for $\mathrm{SCR} \mathrm{NO}_{\mathrm{x}}$ conversion in comparison to iron or vanadium-based catalysts for temperatures below $300^{\circ} \mathrm{C}$. Activities characterized by lower and wider temperature ranges seem to be more suitable for copper-based catalysts. Due to this suitability, copper-based catalysts have proven to become the common catalyst material in SCR systems for heavy-duty diesel applications for reducing diesel NOx emissions (Kamasamudram et al., 2010).

Maintaining "fast-SCR" or optimum $\mathrm{NO}_{2} / \mathrm{NO}_{\mathrm{x}}$ ratios has further potential to increase the SCR performance, even at lower temperatures (Koebel et al., 2002). From a study performed by Chandler, shows that the control of SCR catalyst activity can be significantly varied by having $\mathrm{NO}_{2}$ in the exhaust gas, especially at low exhaust temperatures (Chandler et al., 2000). Figure 2, illustrates such catalyst activities where at lower temperature ranges $\left(175\right.$ to $\left.300^{\circ} \mathrm{C}\right), \mathrm{NO}_{\mathrm{x}}$ conversion efficiency tends to remain above $90 \%$ when feeding $\mathrm{NO}_{2}$ as a feed gas than compared to not having any $\mathrm{NO}_{2}$ at all in the exhaust stream. 


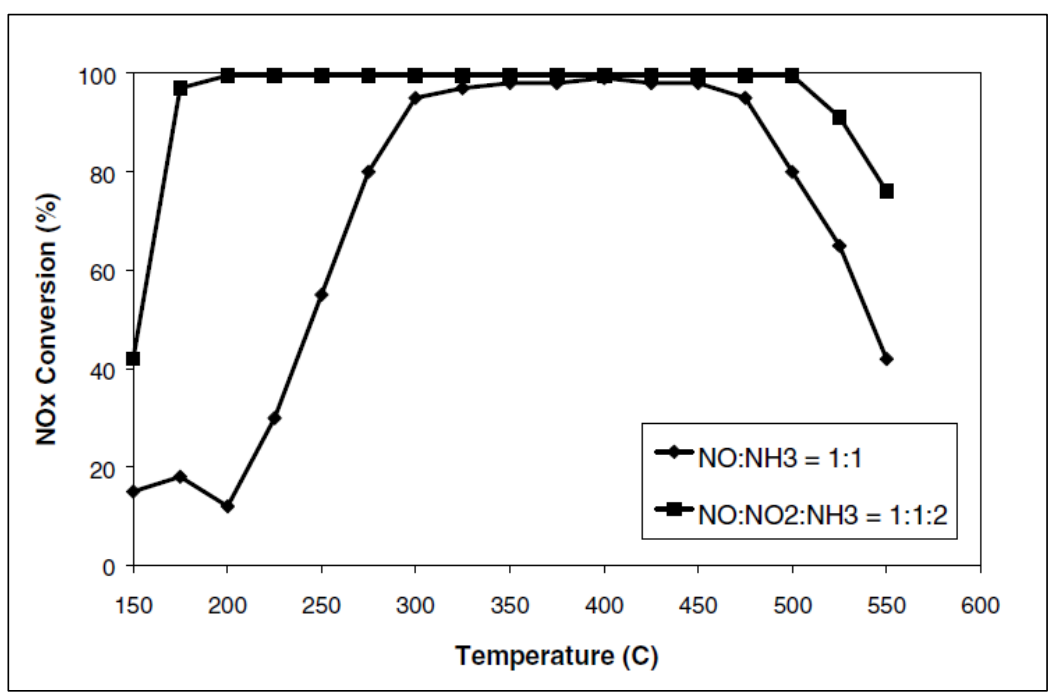

Figure 2. NOx conversion of a standard SCR catalyst as function of exhaust gas temperature using NO: $\mathbf{N H}_{3}$ and NO: $\mathbf{N O}_{2}: \mathbf{N H}_{3}$ feed (Chandler et al., 2000)

Figure 3, illustrates the influence of percentage of $\mathrm{NO}_{2}$ for the SCR's ability to reduce overall $\mathrm{NO}_{\mathrm{x}}$. It shows that the optimum conversion efficiency is seen at $50 \% \mathrm{NO}_{2}$-to- $\mathrm{NO}_{\mathrm{x}}$ ratio, and starts to rapidly decrease as the proportion increases (Koebel et al., 2002).

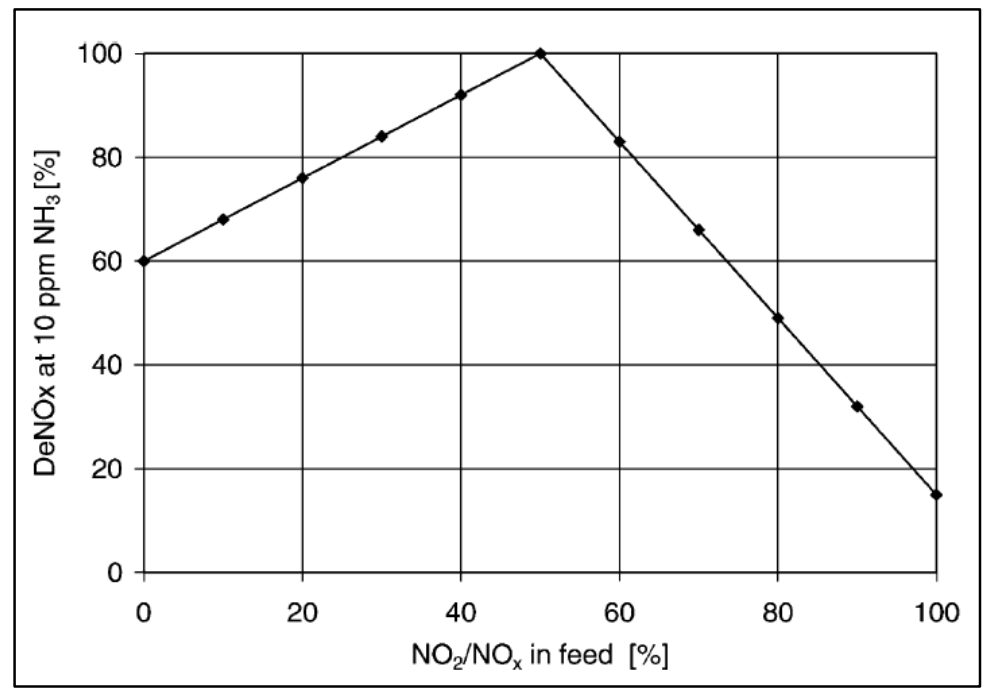

Figure 3. Influence of the $\mathrm{NO}_{2} / \mathrm{NO}_{\mathbf{x}}$ fraction on $\mathrm{NO}_{\mathbf{x}}$ conversion (Koebel et al., 2002)

Use of pre-oxidation catalyst located upstream of the SCR have been shown to facilitate the performance of the SCR catalyst activity. The diesel oxidation catalyst (DOC) systems which 
are primarily used for controlling carbon monoxide (CO), hydrocarbons ( $\mathrm{HC})$, and organic fraction of diesel particulates (SOF) emissions, are shown to produce representative amount of $\mathrm{NO}_{2}$ during the oxidation reaction in presence of NO in the exhaust (Majewski, 2014). Likewise, the performance of the oxidation catalyst also varies with temperature and is shown to be inactive under certain temperatures ranges. From a relevant DOC performance study (Gieshoff et al., 2000), on a platinum-based (Pt) oxidation catalyst, the $\mathrm{NO}_{2}$ fraction in NOx peaks $(80 \%)$ at temperatures around 250 to $300^{\circ} \mathrm{C}$, also depicted in Figure 4. It is also observed that $50 \%$ of $\mathrm{NO}_{2-}$ to-NO fraction is seen around 150 to $200^{\circ} \mathrm{C}$.

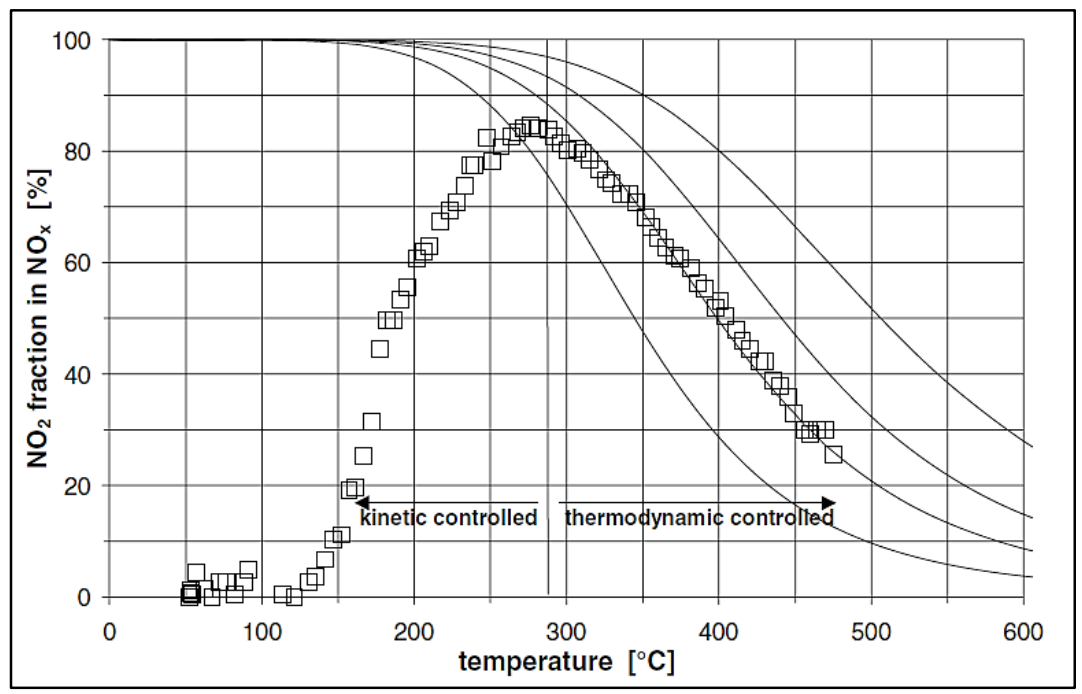

Figure 4. NO2 fraction in NOx after a Pt-based oxidation catalyst with varying inlet temperature (Gieshoff et al., 2000)

\subsubsection{Real-World Heavy-Duty Low Exhaust Temperature Activity}

Heavy-duty vehicles are used for wide range of day to day activities. The daily operational routes can range from low speed/load - stop and go vocational driving schedule to long haul interstate driving. From a SCR thermal activity study, a typical HDD engine requires about 1 to 2 minutes to obtain a proper SCR activity condition with exhaust temperature reaching above $250^{\circ} \mathrm{C}$ (Ettireddy et al., 2014). 
Similarly, a recent study published by the California Air Resources Board (CARB), have clearly shown complications of low temperature activity on $\mathrm{NO}_{\mathrm{x}}$ emissions out of a Class- 8 heavyduty diesel vehicles equipped with SCR technology. The HDD vehicles for the study were tested on-road under diverse driving conditions. Figure 5 presents data for a vehicle with EGR and SCR, illustrating the $\mathrm{NO}_{\mathrm{x}}$ emissions over the cycle dependent on the vehicle operation leading to variation in exhaust temperature. The results from this study showed that the SCR aftertreatment was effective in reducing the $\mathrm{NO}_{\mathrm{x}}$ emissions typically for highway driving conditions when the SCR inlet temperatures are shown to be above the proper catalyst activation temperatures, but exhibits low SCR performance during operations such as cold start, low load/speed, and initial driving phases (Misra et al., 2013). The study also presents that during the cold start period, when the SCR inlet temperature are relatively low (considered $<150^{\circ} \mathrm{C}$ in the study), the rate of vehicle $\mathrm{NO}_{\mathrm{x}}$ accumulated tend to rise rapidly, and then begins to gradually slow down as the vehicle exhaust approaches the optimum SCR activity temperatures.

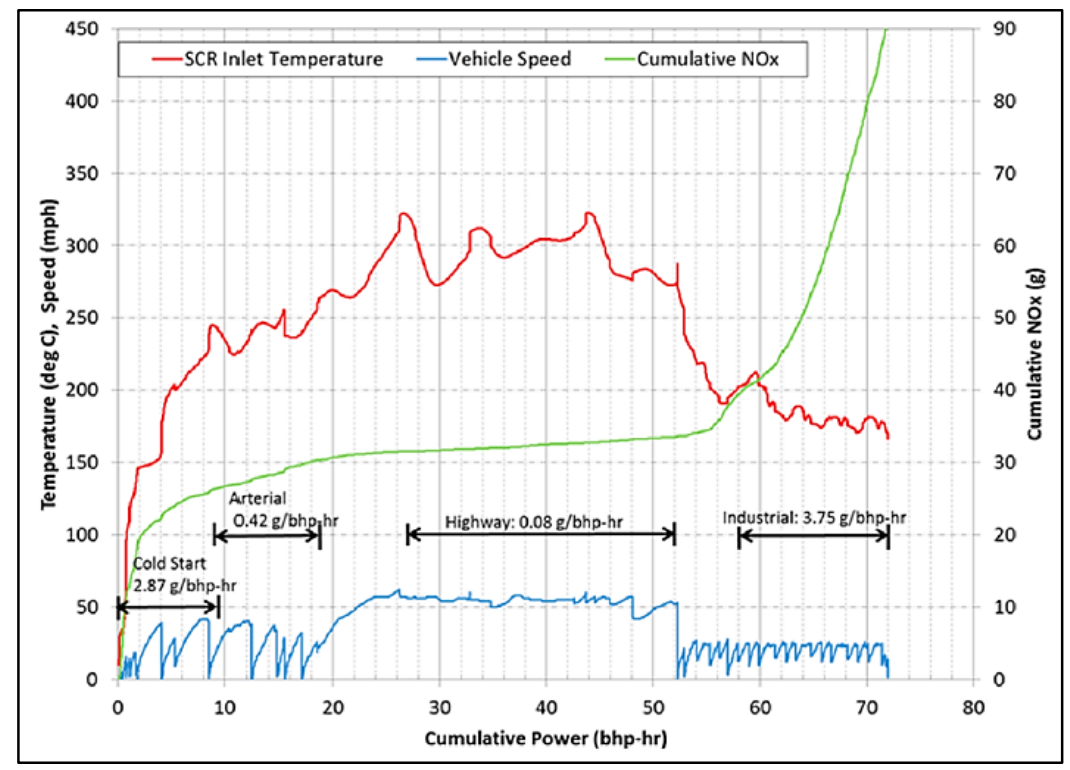

Figure 5. Exhaust dependent cumulative $\mathrm{NO}_{\mathrm{x}}$ emission profile from a $\mathrm{Cu}$-zeolite based SCR equipped test vehicle driven in a city route (Misra et al., 2013) 


\subsection{Thermal Management Strategies for Improved SCR Activity}

Engine manufactures have utilized combinations of multiple strategies and mechanisms to provide thermal management for proper SCR activation along with urea dosing during cold start and low load/speed driving operation (Johnson, 2009). The desired exhaust thermal conditions at such vehicle operations can either be reached actively with the assist of engine-based control measures or by using a medium, for example a heating coil to locally increase the temperature of the exhaust gas volume entering the SCR substrate. This section reviews two approaches of thermal management strategies.

\subsubsection{Engine Based Measures}

Strategically controlling different engine based parameters to warm-up the exhaust gas stream during cold start and under low load-speed engine conditions has been an effective approach (Stanton, 2013). Experimental work on thermal management strategies based on engine control strategies implemented individually or in a combined effort of parameters such as start of injection (SOI), throttle valve actuation (TVA) system, variable geometry turbocharger (VGT) actuation, and variable valve train (VVT) have shown to provide faster light-off temperatures of the catalytic reactions on SCR systems (Cavina et al., 2013). Such studies also show that enginebased measures tend to negatively affect in producing $\mathrm{HC}, \mathrm{CO}$ and PM emissions along with fuel consumption.

\subsubsection{Electrically Heating the Exhaust Stream}

Another approach for aftertreatment thermal management is directly heating the catalyst substrate or the volume of exhaust stream just before the inlet of the SCR system. An example related to similar strategy using electrically heated catalyst $\left(\mathrm{E}^{-\mathrm{SCR}^{\mathrm{TM}}}\right)$ provide by $\mathrm{EMICAT}^{\circledR}$ has proven be an effective technology in light-duty diesel application (Ulrich et al., 2012). The device 
utilizes a heating disc as an integrated part of the SCR system, providing necessary thermal energy into the exhaust stream passing through the SCR substrate. The heater works on the principle of resistive heating coil element, and also contains catalyst coating for reducing $\mathrm{NO}_{\mathrm{x}}$ immediately. The amount of energy required to raise the exhaust stream to a certain temperature directly depends on the power supplied to the resistive coil. From the study, the electrically heated catalyst utilizes energy reclaimed from mechanical work of the engine. Figure 6 shows a schematic of the EMICAT $^{\circledR}$ electrically heating system before the SCR catalyst.

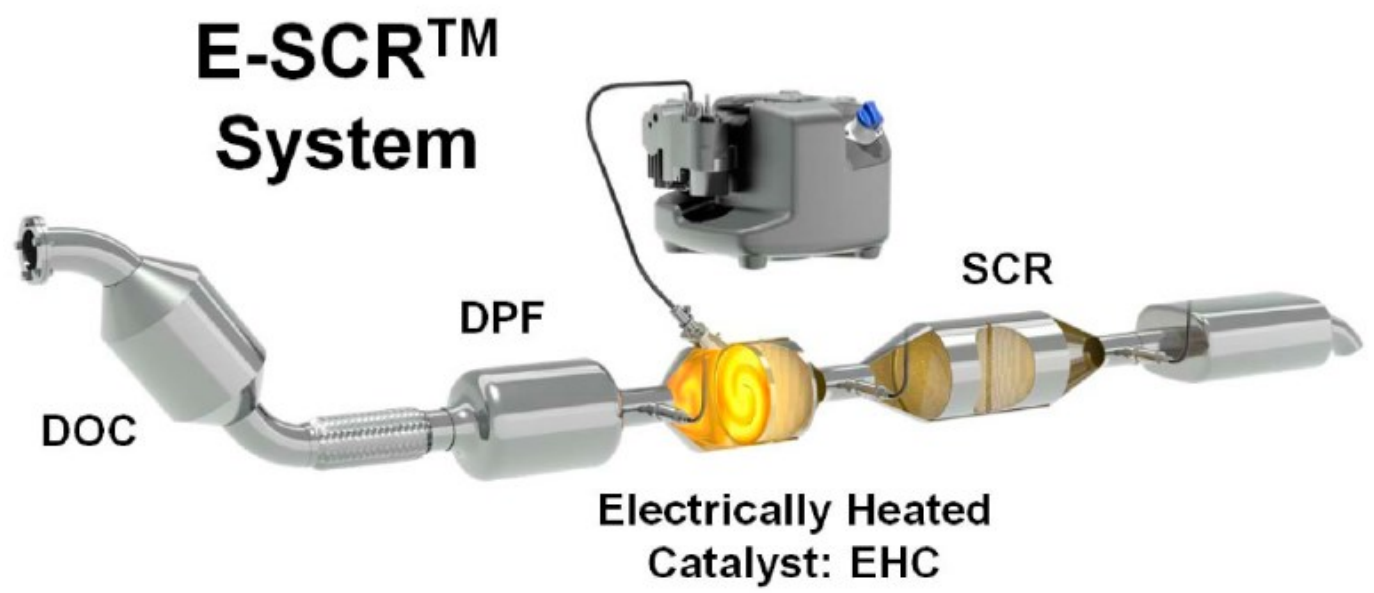

Figure 6. EMICAT $^{\circledR}$ 's electrically heated catalyst system before SCR catalyst in Light Duty Application (Ulrich et al., 2012)

\subsection{Waste Heat Recovery System as Potential Power Generator}

In this proposed context, the most important constraint is the source of energy required in order to add sufficient energy into the exhaust stream without compromising potential fuel consumption. This section reviews waste heat recovery as a viable application in extracting wasted heat from heavy-duty vehicles in the means of achieving thermal energy. 


\subsubsection{Waste Heat Recovery Technology Applications}

Utilizing wasted energy converted to electrical energy in automotive applications dates as early as 1988, when the first exhaust-based Automotive Thermoelectric Electric Generator (ATEG) was applied on a Porsche 944 exhaust system to produce tens of Watts (Birkholz, 1988). In 1990, the same ATEG technology with different material design, a diesel truck exhaust system was capable of producing $1 \mathrm{~kW}$. It also shows that TEGs perform well only at higher temperatures ranges, which would provide disadvantages for temperatures ranges seen in a heavy-duty vehicle operations (Avadhanula et al., 2013).

Turbochargers are the most known examples of waste heat recovery within heavy-duty and higher performance light duty engines. Having been around for nearly a century, the use of conventional turbochargers utilizes exhaust energy to boost intake air and significantly improves engine efficiency (Arnold et al., 2001). Similar to the concept of turbochargers, mechanical and electrical turbo-compounding has also been recognized as a potential source to generate useful work, where the recovered energy from the exhaust is mechanically or electrically added back to the engine flywheel (Noor et al., 2014). Major heavy-duty truck manufacturers such as Volvo, Detroit Diesel, Iveco and Scania have already utilized such technology for long-hauled applications (Noor et al., 2014).

There has been increasing interest and extensive research on recovering waste energy for heavy-duty diesel vehicles using Rankine Cycle working with environmentally friendly, organic fluids (Stanton, 2013). Such approach has potentially shown to improve diesel engine's overall efficiency just by utilizing wasted energy from different heat sources. The ORC-WHR system with

using two major heat sources, EGR and exhaust stream, have demonstrated beneficial levels of fuel consumption reduction: for example, providing reduction as high as $6.0 \%$ during a highway 
operation from Class-8 HD vehicle. Other similar analysis have also shown that up to 5\% fuel improvement can be achieved implementing from WHRS utilizing only the EGR (Teng et al., 2011). In a popular event, the Department of Energy Supertruck Program, major OEMs have developed and demonstrated WHR system using ORC as a technological pathway in targeting higher brake thermal efficiency (Gravel, 2013).

\subsubsection{Heavy-Duty Engine Energy Flow}

In modern on-road heavy-duty vehicles, about $40-42 \%$ of the total fuel energy consumed in the engine is utilized to generate useful work while the rest of the energy is lost in the form of heat and friction (Talus et al., 2011). For typical heavy-duty diesel engines, experimental results have shown that most of the input energy from the fuel is discharged in the form of heat to the ambient air (Latz et al., 2013).

A study aimed specifically in the analysis and development of a waste heat recovery system for Class-8 diesel vehicles shows that an engine operated at high EGR at B100 steady state point (mode from the European Stationary Cycle-ESC) rejects about 20\% of the total input energy through the exhaust flow after the turbocharger, while $18 \%$ of the engine heat is taken by coolant (Teng et al., 2011).

Table 1. Energy flow in typical modern HD diesel engine operated at high load condition (Teng et al., 2011)

\begin{tabular}{|l|c|}
\hline \multicolumn{1}{|c|}{ Energy Flow Path } & \% of Total Fuel Energy \\
\hline Brake Power [Shaft-Mechanical Work] & $41 \%$ \\
\hline Exhaust Energy [Post-Turbo] & $20 \%$ \\
\hline Coolant Energy & $18 \%$ \\
\hline Exhaust Gas Recirculation (EGR) & $11 \%$ \\
\hline Charge Air Cooler (CAC) & $9 \%$ \\
\hline Other [Ambient] & $1 \%$ \\
\hline
\end{tabular}




\subsubsection{Waste Heat Recovery System Design}

\subsubsection{Rankine Power Cycle}

Considering the quality (tendency of energy to convert from one form to another) of wasted energy in a normal engine operation, utilization of a Rankine power cycle are commonly accessed as a basic approach for waste heat recovery potential (Cozzolini et al., 2012). From the basic introduction regarding the thermodynamic analysis of power-generating systems, the Rankine cycle consist of four major components to complete the cycle and generate useful work (Moran and Shapiro, 2008). Figure 7 illustrates a basic schematic of a Rankine cycle consisting of system pump, evaporator/boiler (heat exchanger), expander/turbine, and condenser (heat exchanger). Detailed explanation on individual components and thermodynamic analysis of the processes are described in Chapter 4.

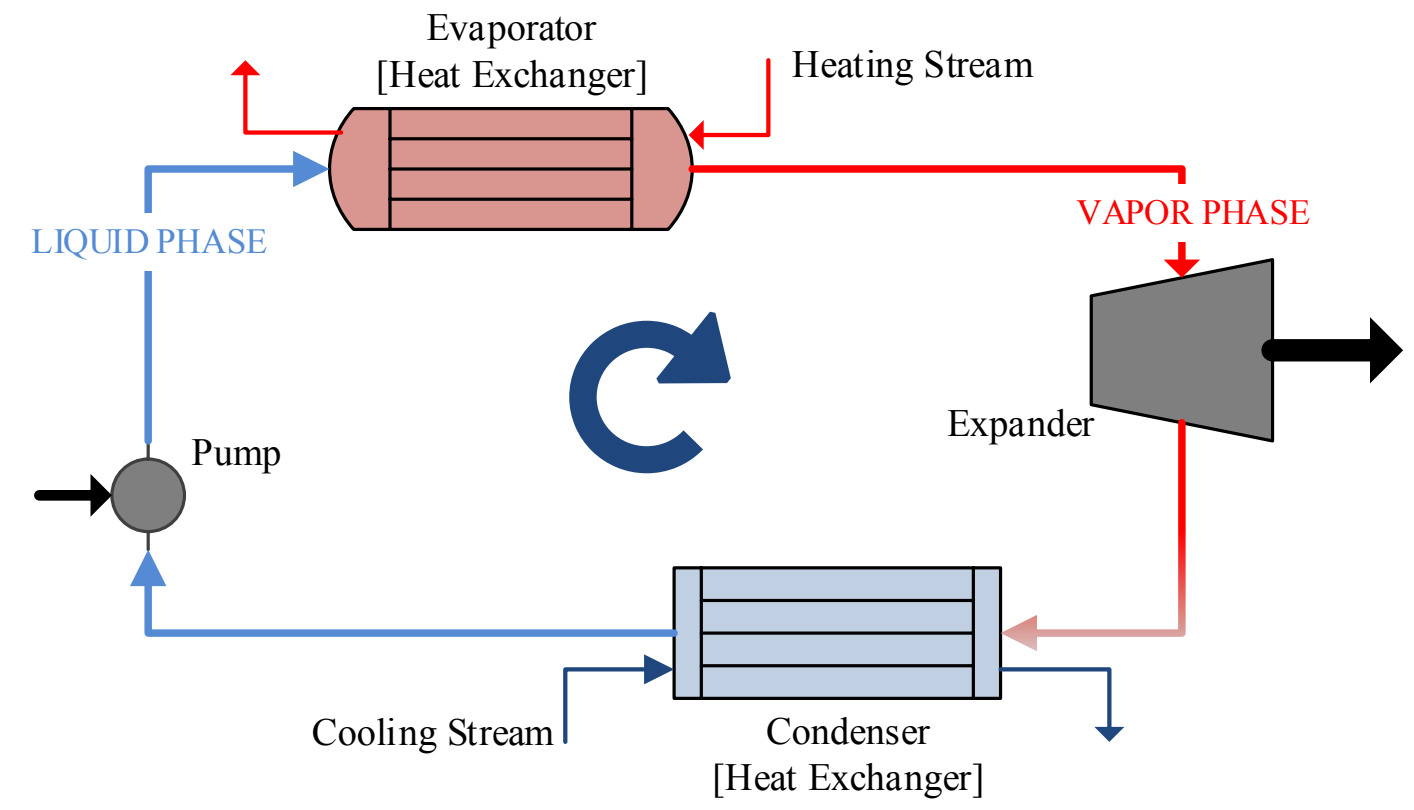

Figure 7. Schematic of basic Rankine Cycle

From numerous studies and publications it can be noted that manufactures and institutional researchers have approached WHRS design in multiple paths, taking advantage of different 
available energy source for gaining the optimum results at different engine operation conditions. The WHR system built by Cummins Inc. demonstrates the utilization of charge air cooler (CAC), exhaust gas stream downstream of the aftertreatment and EGR circuit. Similarly, AVL investigates WHR systems utilizing only the EGR cooler as the primary heat source (Teng and Regner, 2009).

\subsubsection{WHRS Working Fluids}

Considering the system's component size along with keeping system cost and environmental aspects in mind, selecting the right working fluid for the Rankine cycle is an important step in overall performance of the WHR system (Bae et al., 2011). Numerous studies related to engine waste heat recovery have been investigated with comparing the performance of different organic fluid types for ORC-WHRS implemented on heavy-duty diesel vehicle applications (Arunachalam et al., 2012). Selection of the organic fluid for this study are discussed in the ORC-WHR system design section. 


\section{CHAPTER 3 EXPERIEMNTAL SET UP}

All measurement of the study presented herein were conducted at the Engine and Emissions Research Laboratory (EERL) at West Virginia University. The EERL is a part of West Virginia University's Center for Alternative Fuels, Engines and Emissions (CAFEE) and the transient engine dynamometer test cell is designed and operated according to recommendations set forth by Code of Federal Regulations (CFR), Title 40, Part 1065 (USEPA)

\subsection{Test Engine Specification}

In order to perform a comprehensive energy analysis on a modern, on-road heavy-duty engine, a 12.8L Mack MP8 505C representing US EPA 2010 emissions compliant engine was tested on an engine dynamometer test bench. Table 2 summarizes the test engine specifications.

Table 2. Test Engine Specification

\begin{tabular}{|l|l|}
\hline Manufacturer & Mack \\
\hline Model year & 2011 \\
\hline Model & MP8 - 505C \\
\hline Displacement (L) & 12.8 \\
\hline Rated Horsepower (HP) & 505 \\
\hline Rated Speed (RPM) & 1800 \\
\hline Peak Torque @Speed & $1810 \mathrm{ft}-1 \mathrm{~b} @ 1100 \mathrm{rpm}$ \\
\hline After-treatment system & DPF-SCR \\
\hline EGR & High pressure cooled EGR \\
\hline Turbocharger & VGT \\
\hline Fuel Injection & Electronic unit injectors (2400 Bar) \\
\hline Compression Ratio & $16: 1$ \\
\hline Bore and Stroke & $131 \mathrm{~mm}$ x 158 mm \\
\hline
\end{tabular}




\subsection{Engine Dynamometer and Test Cell Integration}

The Mack MP8 engine was removed from a Class-8 tractor along with its after-treatment system. The after-treatment system included the diesel particulate filter (DPF), selective catalytic reduction (SCR) and a urea tank. The engine with its aftertreatment unit was installed in the WVU ERC engine test cell as shown in Figure 8. A procured chassis harness was used to link the engine control unit (ECU) with the aftertreatment ECU, and necessary communication was insured within the ECU's and vehicle interface.

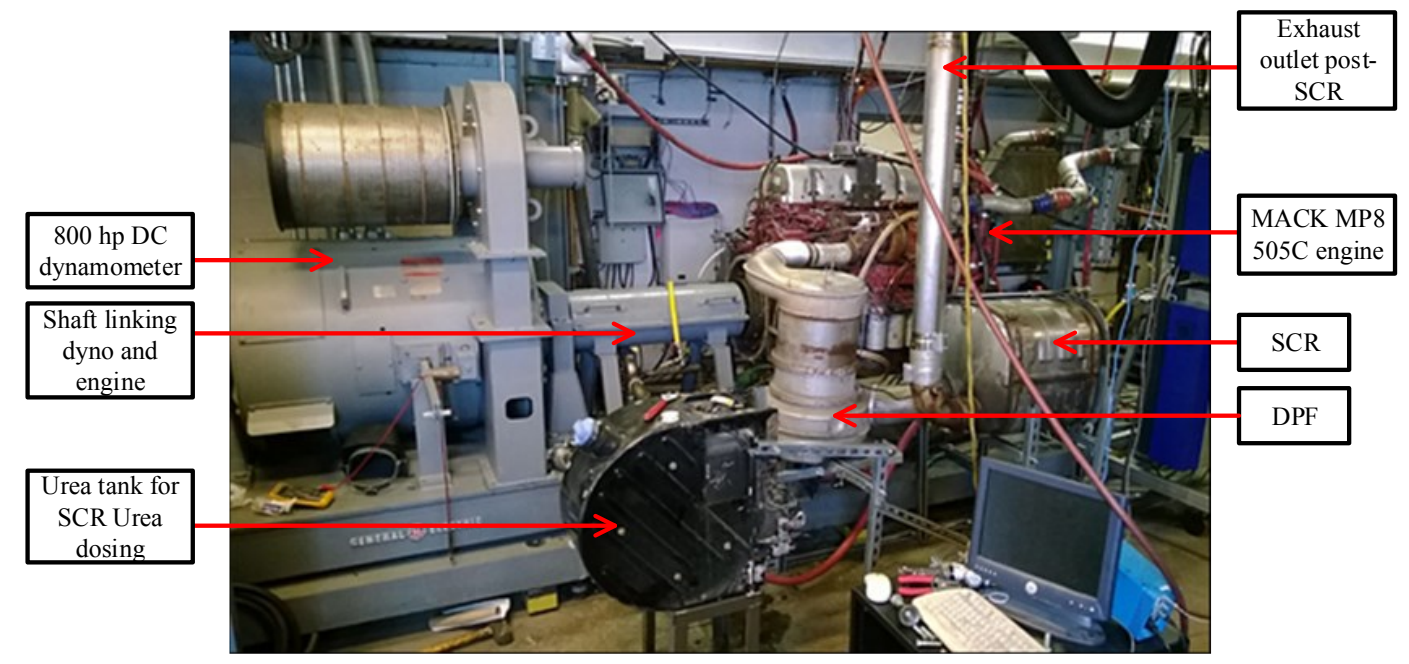

Figure 8. Mack MP8 505C test cell setup

A General Electric (GE) 800hp direct current (DC) heavy-duty platform dynamometer, capable of providing and absorbing power at engine speeds up to 2500 RPM, was used for testing the Mack MP8 engine rated at 505hp at 1800 RPM. The engine was coupled with the test cell DC dynamometer via a universal joint dynamometer shaft adapted to the engine flywheel. Throttle input and speed control were provided using WVU CAFEE's in-house engine dynamometer test cell software. CAN bus communication with SAE J1939 protocol was used between the test cell controller and the engine control unit ECU. Constant monitoring of the engine and aftertreatment fault codes were made for fault detection to insure proper functionality of the integrated systems. 


\subsection{Engine Instrumentation}

In order to examine and quantify the energy flows on all fluid flows, the test engine was instrumented for temperature, pressure and flow rates. The intake air, exhaust, coolant, and oil fluid flow paths were instrumented using ungrounded Omega K-type thermocouples to measure temperatures. Figure 9 provides a detailed schematic of the temperature instrumentation conducted on the test engine. The K-type thermocouples have a temperature range of -200 to $1250^{\circ} \mathrm{C}$, suitable for measuring within operating temperatures ranges seen on similar engine models based on a relevant studies conducted by CAFEE. All thermocouples sensors along with the thermocouple lines were checked using linearity verification according to 40 CFR Part 1065 Subpart D. For each thermocouple verification process, an input temperature measure is simulated using a NISTtraceable thermocouple calibrator, and verified against the response value observed in the data acquisition monitor.

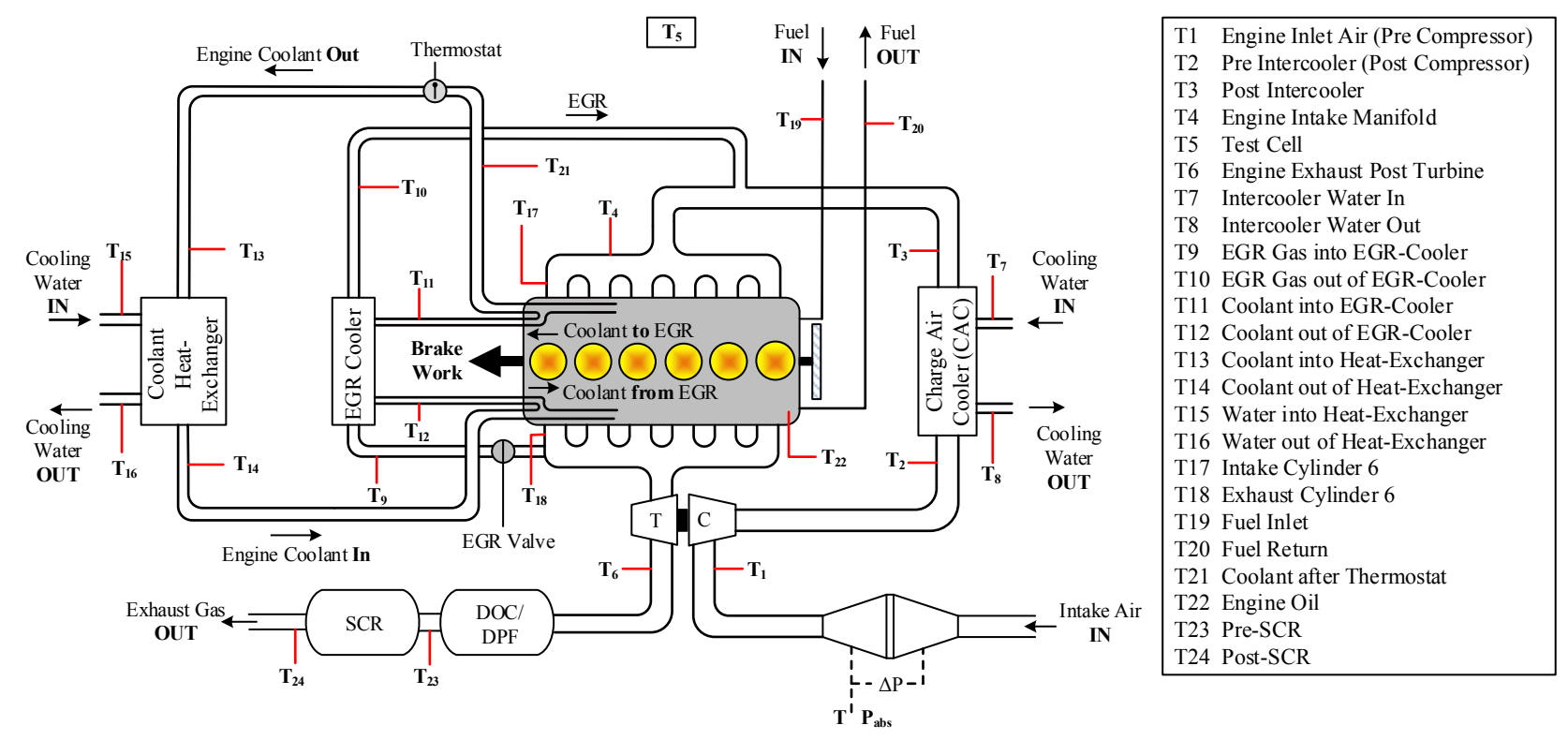

Figure 9. Schematic of engine instrumentation

The coolant flow rate was measured using a turbine flowmeter from Omega (Model No:

FTB-109). The flowmeter was connected inlet flow of the engine coolant circuit. Intake air flow 
rates were measured using the Meriam's Laminar Flow Element (LFE) (Model No. Z50MC2-6). The absolute pressure measurements of pre-charge air cooler (CAC), intake manifold, exhaust manifold, and post-turbine were taken using the pressure transducers from Omega (Model No: PX613). For depression pressure measurement of the intake air before the turbocharger's compressor, a pressure transducer from Validyne (Model No: P55D) was used. All the flowmeter measurement devices and the pressure transducers were calibrated by the manufactures. Additional, the fuel outlet line along with the engine oil were also monitored during engine testing as part of test procedure.

The inlet fuel supply to the engine was installed with an AVL Fuel Mass Flow Meter (Model No: AVL735) and AVL Fuel Temperature Control (Model No: AVL753C) system combined for continuous fuel consumption measurement and fuel conditioning, respectively. All the data channels were recorded at a sampling rate of $10 \mathrm{~Hz}$ by the test cell's data acquisition system. A WVU CAFEE's in-house reduction program was used to convert the acquired data by the data acquisition system from raw data in the form of analog-to-digital code to proper engineering units.

\subsection{Testing Methodology}

This section discusses the testing approach and methodologies applied in operating the test engine in order to collect instrumented data. The primary focus of this work was to understand the engine's availability of waste heat energy by characterizing energy flows under maximum numbers of the engine's speed and load combinations. The mapped curve was later used for developing the design of experiments (DOE) for the intent of gathering sufficient information from the engine. 


\subsubsection{Engine Mapping Procedure}

As an initial step, engine mapping was performed to obtain the engine's operating boundaries. The process provides in locating the peak torque and peak power curves of the engine as a function of engine speed. The lug curve, is a common term given to such curve. In engine dynamometer testing, conducting engine mapping also helps in monitoring proper functionality of all the engine components under the engine's operating limits.

Prior to the engine mapping procedure, the engine is warmed up until the engine coolant and oil temperatures were stabilized. WVU CAFEE's engine control and monitoring software was used for carrying out the automated engine mapping process. The control software initiates a "wide-open-throttle" by demanding a 100\% throttle, and then increases the engine speed from idle to governed speed point, continuously at a rate of $4 \mathrm{rpm}$ per second. Three engine mapping tests were taken to validate the final torque and power curves. The validation process was based on comparing the coefficient of determination ( $r$-squared statistics) for the repeatability of the three obtained lug curves. The mapping curves were also used to verify the maximum torque and power as per manufacturer's provided power ratings at specified engine speed, in order to see if the engine is operating as it's supposed to be or in a "de-rate" mode where the engine control unit (ECU) limits in power as a control strategy for various performance and emission reasons.

\subsubsection{Design of Experiments}

In order to evaluate energy analysis along with the waste heat recovery potential under the engine operating boundaries, gathering maximum information under the lug curve was important. To efficiently characterize operating points for a wide area of interest under the operating region, DoE methodology with space-filling design was used for developing the test matrix. JMP ${ }^{\circledR}$, a 
statistical software developed from SAS (Statistical Analysis System) was used for generating and analyzing the DoE designs.

In the space-filling design, two input parameters (speed and torque) were considered as the DoE factors which were segmented down into multiple levels. The speed and torque levels were normalized in creating the DoE design in $\mathrm{JMP}^{\circledR}$. The speed levels are bounded on the lower end by the engine idle point (650rpm, normalized to 0.3 ), and on the upper end by the high idle point (governed speed of $2200 \mathrm{rpm}$, normalized to 1). When generating the space-filling design, an upper boundary speed of $0.9(1980 \mathrm{rpm})$ was only taken in order avoid the engine control cut-off at the governed speed. The torque levels at each speed were bounded by $0 \%$ of peak torque at that speed and $100 \%$ torque at current speed.

Two different methods known as Latin Hypercube and Gaussian Process IMSE Optimal were used for the space-filling design for generating the combinations of speed/load test runs for each design. Due to test cell availability and budget limitations, a total of 25 (speed/load) data points were chosen for each method. These two methods are described as follows (JMP, 2012):

\section{I) Latin Hypercube Method:}

In this method, the specified numbers of combination points are chosen in a way to maximize the minimum distance between design points while constraining even spacing throughout the boundaries for the factor levels, as shown in Figure 10 (a). The method also randomly selects the sequence from the set points, to eliminate potential run order bias.

\section{II) Gaussian Process IMSE Optimal Method:}

This method minimizes the integrated mean squared error of the normalized points on the selected factor's boundary, shown in Figure 10 (b). The method does not include 
boundary values from the two factors as compared to a Latin Hypercube design which could possibly have a boundary value.

In total, 50 speed/load combination points were generated by the two DoE designs under the engine lug curve obtained from the engine mapping procedure, as shown in Figure 11. Data capturing for each selected design were performed using a transient ramp-modal cycle, allowing 2 minutes for each steady-state operation at each engine operating point, and 20 seconds for transitioning between points. Time period of two minute per test point were intently given for stabilization of the engine's control parameters and the temperatures. It is to be noted based on relevant engine studies and CAFEE's engine testing experiments that two minutes of stabilization time would not have been sufficient for certain operating points but due limited test cell availability and budget constraints, such timings were considered for obtaining the entire test matrix. The effect of stabilization time has been reviewed and discussed in the result section. Three more points at $100 \%$ of the A, B, and C speed from the European Stationary Cycle (ESC) were also used in the test matrix (symbol ' $\mathrm{X}$ ' in Figure 11) to include conditions at full load operation.

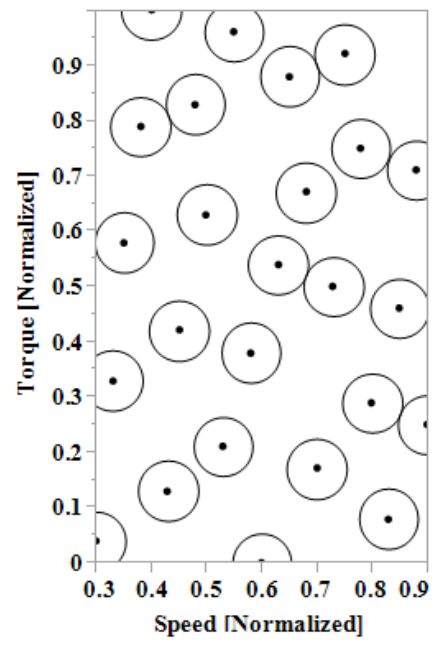

(a)

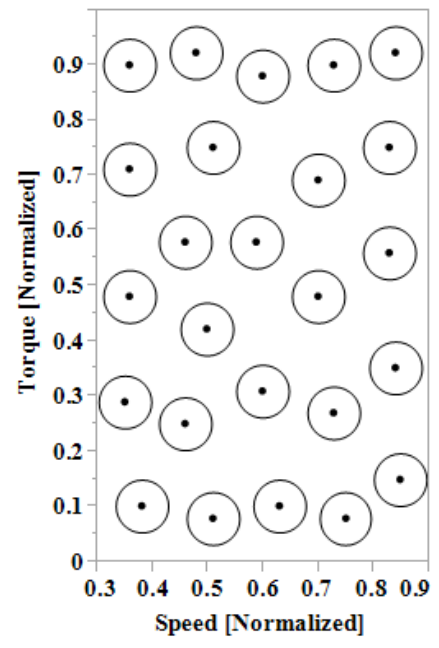

(b)

Figure 10 (a). Latin Hypercube Design (b). Gaussian Process ISME Optimal Design for 25 speed/load normalized data points 


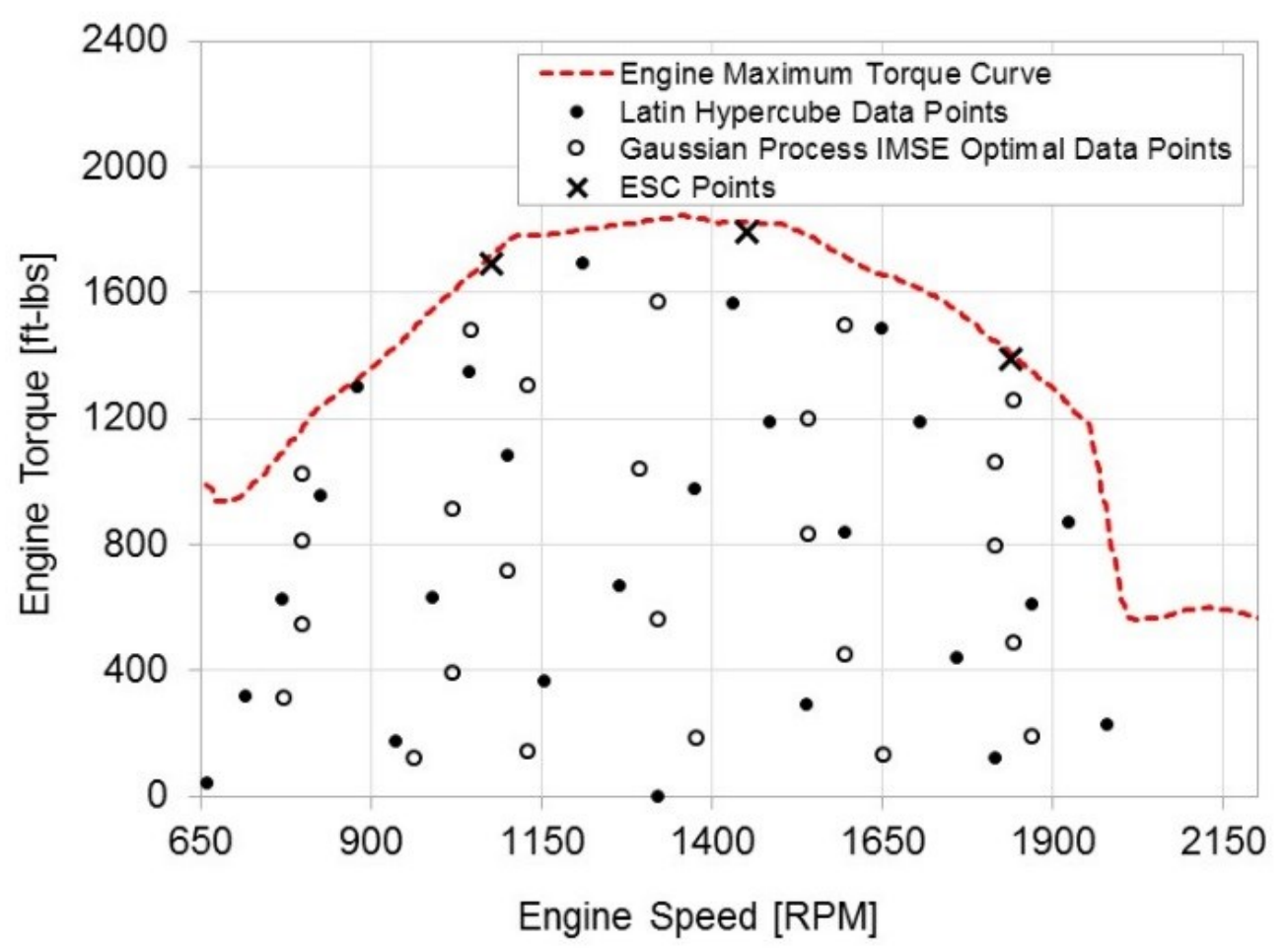

Figure 11. Speed and torque combination of 53 test points under the lug curve

\subsection{Energy Audit}

The methods for analyzing the energy balances for the test engine are based on basic thermodynamic principles (Moran and Shapiro, 2008). Defining the control volume in enclosing the engine subsystems assist in adequately characterizing energies flowing in and out of the system. Figure 12 displays the control volume surrounding the engine region. For energy balance, the control volume does not include the aftertreatment system.

Evaluating the first law of thermodynamics for a typical turbo-charged heavy-duty diesel, a steady-state energy balance performed over a controlled boundary is given by Eq. (7) (Heywood, 1988).

$$
\dot{Q}_{\text {intakeair }}+\dot{Q}_{\text {fuel }}=\dot{Q}_{\text {exhaust }}+\dot{Q}_{\text {coolant }}+\dot{Q}_{C A C}+\dot{Q}_{\text {misc }}+\dot{W}_{\text {shaft }}
$$




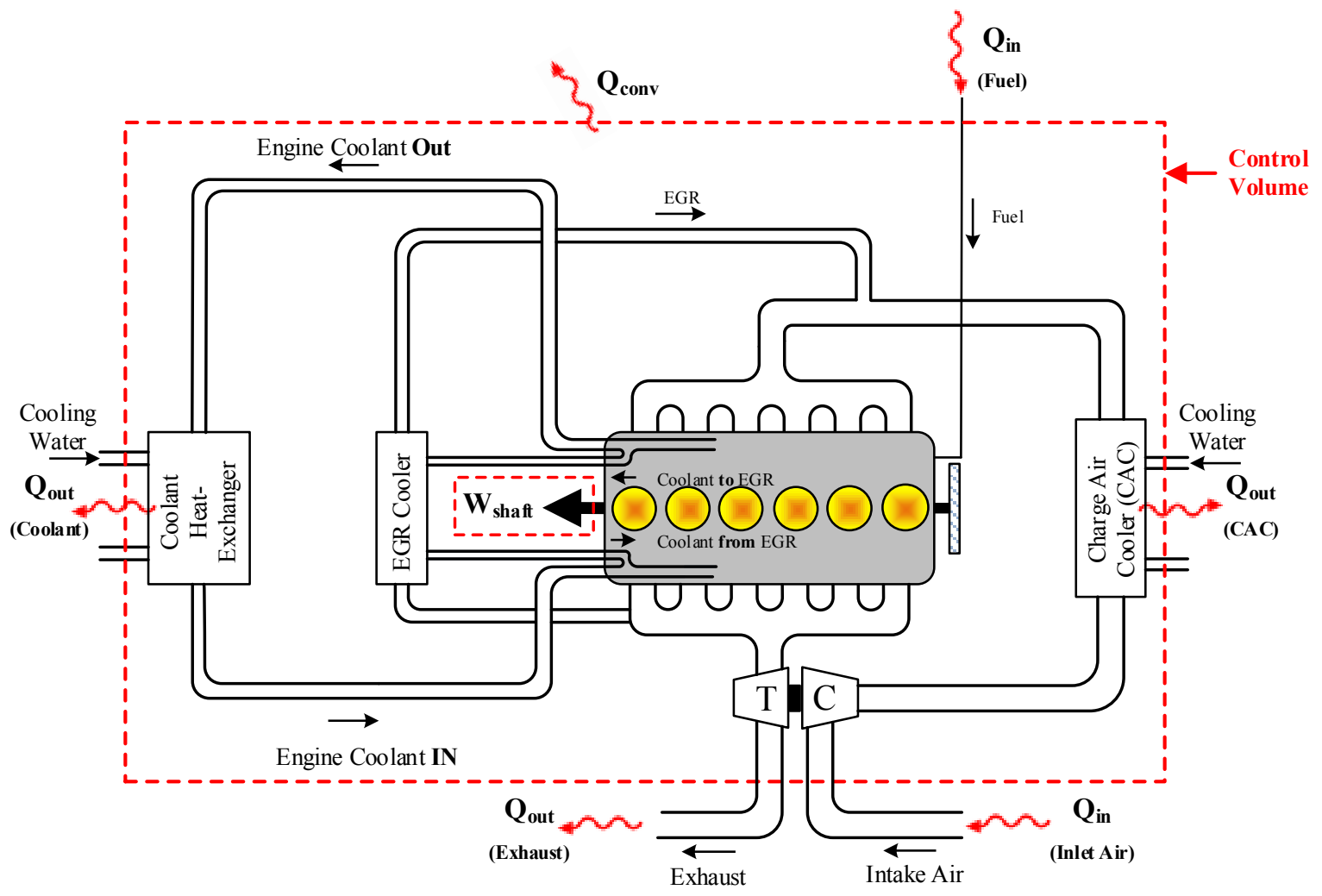

Figure 12. Schematic of the engine energy flow for the specified control volume

The total rate of input energy entering the control volume are accounted by the intake air and the fuel. The input energy carried in by the intake air is calculated using the mass flow rate of the intake air, $\dot{m}_{\text {intakeair }}$ and the enthalpy of air at respective intake temperature. The rate of fuel energy supplied to the engine is calculated based on the mass flow rate of the fuel, $\dot{m}_{f u e l}$, and energy content of a diesel fuel provided by the lower heating value (LHV) taken as $43 \mathrm{MJ} / \mathrm{kg}$ (Giannelli et al., 2005).

$$
\dot{Q}_{f u e l}=\dot{m}_{f u e l} \cdot L H V
$$

With depicting the major recoverable waste heat with respect to the rate of input energy from the fuel, $\dot{Q}_{\text {exhaust }}, \dot{Q}_{\text {coolant }}$ and $\dot{Q}_{C A C}$ energy terms accounts for the rate of output energy 
distribution taken by the exhaust gases, engine coolant and compressed charge air cooling, respectively. The remainder of the unaccounted energy which were not measured for in this study were lumped into miscellaneous losses, $\dot{Q}_{\text {misc }}$ considered to be such as pumping losses, engine friction, engine surface heat transfer, auxiliary loadings, etc.

The rate of energy loss carried by the exhaust stream $\dot{Q}_{\text {exhaust }}$, in Eq. (7) is calculated using the exhaust mass flow rate, $\dot{m}_{\text {exhaust }}$ and enthalpy of exhaust at respective exhaust temperature. Since, individual exhaust constituents were not measured in this study, the properties of exhaust flow were evaluated as air (idle air assumption). In order to estimate the energy transported solely by the exhaust gases, the exhaust energy is also corrected for the energy at intake condition which is provided by Eq. (9) (Heywood, 1988).

$$
\dot{Q}_{\text {exhaust }}=\dot{m}_{\text {exhaust }} h_{\text {exhaust }}-\dot{m}_{\text {intakeair }} h_{\text {intake }}
$$

where, $\dot{m}_{\text {exhaust }}$ is the exhaust mass flow rate calculated from summing the fuel and intake air mass flow rates. Enthalpies were calculated at respective exhaust and intake air temperatures and pressures.

Likewise, the engine coolant fluid carries the heat transferred from the engine's cylinder head and walls through the process of thermal conduction. The engine coolant energy also incorporates the EGR and oil cooling subsystems since it's an internal fluid circuit included inside the selected control volume. The rate of thermal energy loss dissipated by the total engine coolant is calculated as:

$$
\dot{Q}_{\text {coolant }}=\dot{m}_{\text {coolant }} C_{p \text { coolant }}\left(T_{\text {engine_coolant_out }}-T_{\text {engine_coolant_in }}\right)
$$


where $\dot{\mathrm{m}}_{\text {coolant }}$ is the measured coolant mass flow rate, and $c_{p_{-} \text {coolant }}$ is the specific heat of the coolant. The $c_{p_{-} \text {coolant }}$ was calculated for a temperature based on a look up table provided for ethylene glycol solution of $50 \%$ by volume water at (TheEngineeringToolBox). Temperatures are measured at the inlet and outlet of the engine's coolant paths.

Eq. (11) gives the rate of energy loss $\dot{Q}_{C A C}$, dissipated through charge air cooler, where $\dot{m}_{\text {air }}$ the mass flow rate of air, and enthalpies is are calculated for post and pre charge air cooler at respective temperature and pressure.

$$
\dot{Q}_{C A C}=\dot{m}_{\text {intakeair }}\left(h_{\text {postCAC }}-h_{\text {preCAC }}\right)
$$

Although the EGR cooler system is considered inside the control volume and combined within the engine coolant energy, the rate of EGR heat energy provided by Eq. (12) were also evaluated separately.

$$
\dot{Q}_{E G R}=\dot{m}_{E G R} c_{p_{-} E G R}\left(T_{E G R \_g a s_{-} o u t}-T_{E G R \_g a s_{\_} \text {in }}\right)
$$

where, $c_{p_{-} E G R}$ is the specific heat capacity at constant pressure calculated at respective temperature and pressure. For simplicity, the exhaust gas was assumed as air, since individual exhaust constituents were not measured as a part of the engine testing and the scope of this study. The temperatures are measured at inlet and outlet of the EGR cooler's gas path. The mass flow rate of the EGR was obtained from performing an energy balance for a control volume underlying the EGR gas path outlet of the EGR cooler, intake air post CAC, and charge air in intake manifold (shown in Figure 13). 


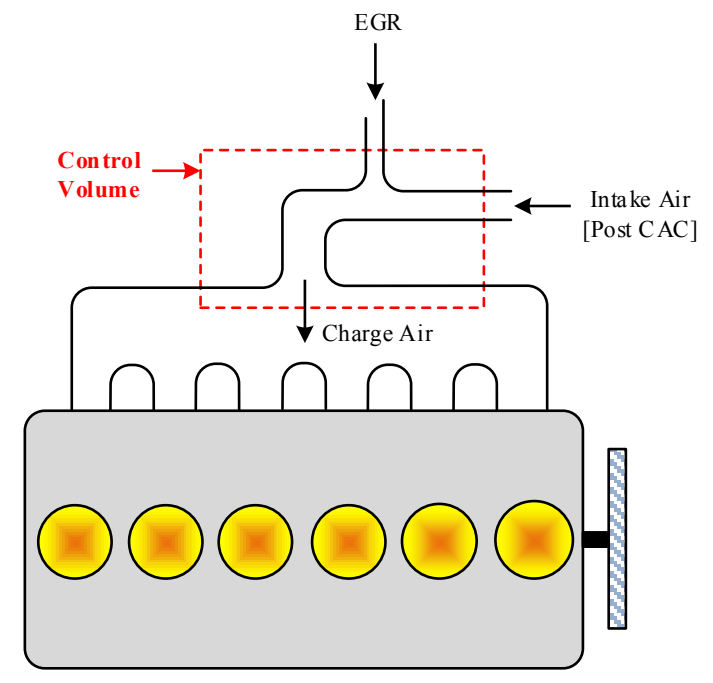

Figure 13. Control volume chosen for calculating EGR fraction at the intake manifold

Assuming adiabatic mixing of the fluids, Eq. (13) provides the calculation of EGR mass flow rate at respective engine operating point.

$$
\dot{m}_{E G R}=\frac{\dot{m}_{\text {intakeair }}\left(h_{\text {intake charge }}-h_{\text {postCAC }}\right)}{h_{E G R \_g a s \_o u t}-h_{\text {intake charge }}}
$$

where, $\dot{m}_{\text {intakeair }}$ is the intake mass flow rate. The enthalpy properties, $h_{\text {intake charge were }}$ calculated for the intake manifold temperature and pressure air condition, $h_{\text {postCAC }}$ using temperature and pressure outlet of the charge air cooler, and $h_{E G R_{-} g a s_{-} o u t}$ using temperature and pressure of the EGR gas outlet of the EGR cooler.

All of the thermodynamic properties for the fluids at respective states were obtained from Reference Fluid Properties (REFPROP) tool provided by National Institute of Standards (NIST). A MATLAB $^{\circledR}$ function application provided by the NIST REFPROP program were used to obtain the properties and evaluate energy analysis at each steady-state engine operating points obtained from the DoE test matrix. 


\section{CHAPTER 4 WHRS SIMULATION MODEL}

\subsection{Introduction}

An approach put forward in designing a waste heat recovery model moreover depends on the quality of heat source available over defined temperatures ranges during engine operations. Using Rankine power cycles working on different organic fluids have been widely considered and studied for extracting useful work from heavy-duty diesel engines (Latz et al., 2012). Therefore, for this study to lead into estimating possible thermal management strategies as proposed, a theoretically approached waste heat recovery system was modeled for different cases of heat sources, and suitable working fluids.

\subsection{WHRS Design}

The proposed design consists of four major components to complete the standard Rankine cycle and generate useful work for the cycle working with specific working fluid. Figure 14 illustrates a basic schematic of the Rankine cycle. For this study, in order to achieve maximum thermal energy recovery from the engine's different possible paths, the cycle was designed to extract heat from two different sources. The heat exchangers are identified in the model as $\mathrm{HX}_{1}$ and $\mathrm{HX}_{2}$. The state between any two sub-systems components of the Rankine cycle are evaluated as pinch-point (steadily operating) condition, meaning the process and the properties does not vary. The states are labeled from 1 to 5 , defining the thermodynamic condition of the working fluid at specific state as it passes through individual components in the Rankine cycle. 


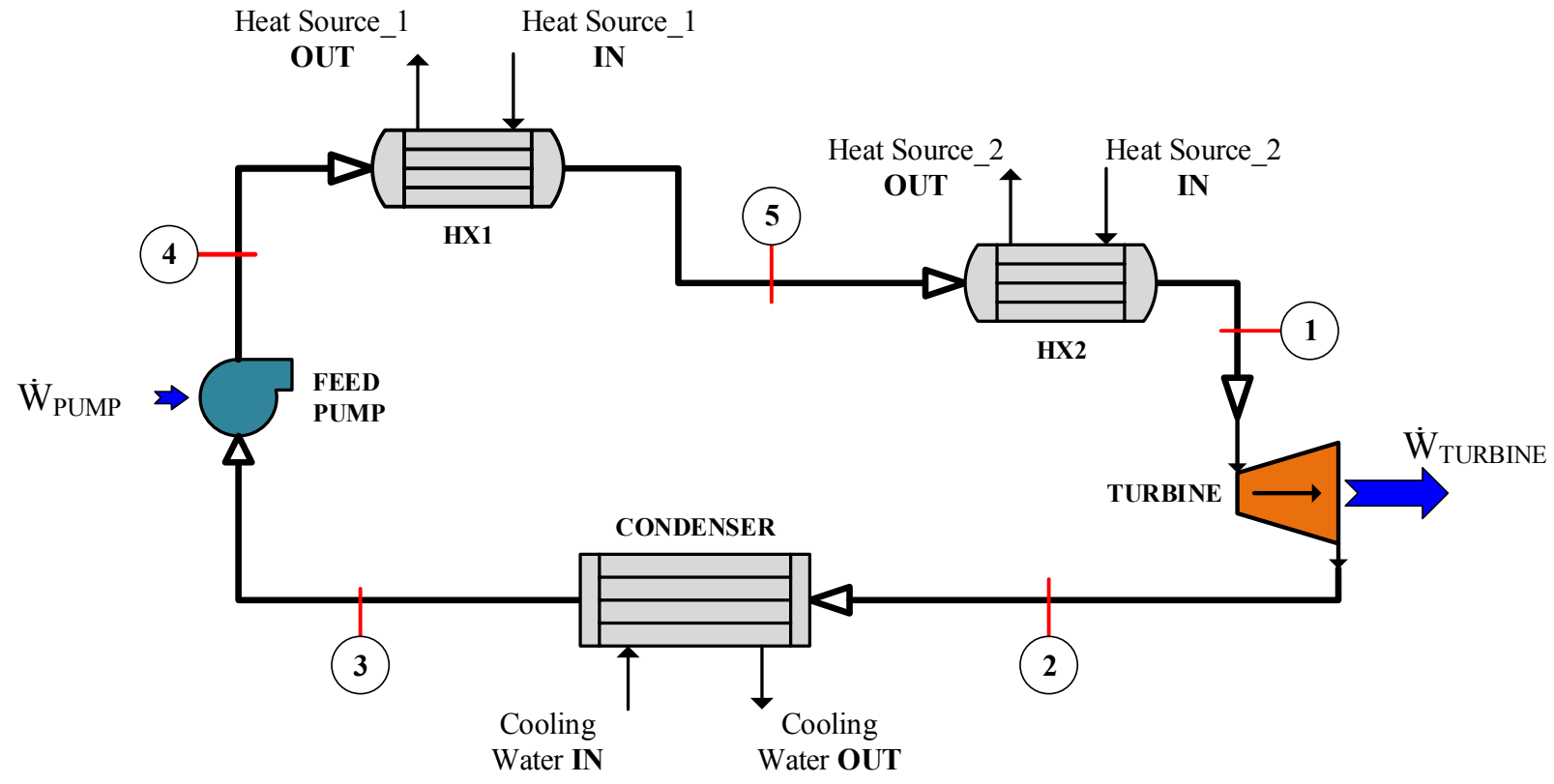

Figure 14. Layout of proposed Rankine cycle waste hear recovery system with energy recovery from two heat source

Detailed processes of proposed components and the methods used in evaluating the thermodynamic performance in the Rankine cycle are provided in the sections below:

\section{I. $\quad$ Feed Pump}

The feed pump is the main circulating mechanism of the Rankine cycle system. The pump compresses the working fluid from initial pressure of the cycle at state 3 to reach the system pressure condition at state 4 . The working fluid condition outlet of the pump state 4 is evaluated using Eq. (14)

$$
h_{4}=\frac{\left(h_{4 s}-h_{3}\right)}{\eta_{p u m p}}+h_{3}
$$

where, $\eta_{\text {pump }}$ is the isentropic pump efficiency. The enthalpy of the working fluid at state $3, h_{3}$ is calculated using condenser outlet temperature and pressure, which is known from the initial system 
characteristic assumption. From isentropic assumption, $h_{4 s}$ is evaluated using the relation $\left(\mathrm{s}_{3}=\right.$ $\mathrm{S} 4 \mathrm{~s})$.

Based on the type of pump selected for the design, the maximum pressure and the mass flow rate of the system is defined. For this study, a pump having similar characteristics used by AVL Powertrain Engineering, Inc. (Teng et al., 2011) and Cummins, Inc. (Nelson, 2008) in their WHR system demonstration for heavy-duty application were considered to make a realistic and practical model. For defining the system flow rate ranges and maximum pump pressure, pump performance curve from a Tuthill pump (Model 1L 25.4mm) was used. The performance plot is attached in APPENDIX A.

The power required by the pump to do work on the fluid passing through is calculated by performing an energy balance for a control volume enclosing the pump as shown by Eq. (15).

$$
\dot{W}_{\text {pump }}=\dot{m}_{W F}\left(h_{4}-h_{3}\right)
$$

where, $\dot{m}_{W F}$ is the mass flow rate of the working fluid.

\section{II. $1^{\text {st }}$ Stage Heat Exchanger}

The pressurized working fluid at state 4 was designed to pass through the $1^{\text {st }}$ stage heat exchanger (HX1). The heat transferred into the working fluid is highly dependent on the heat exchanger design and the flow rate of the working fluid passing through the heat exchanger. This heat exchanger acts as the pre-heater in heating the working fluid before it enters the $2^{\text {nd }}$ stage heat exchanger. The heat exchanger characteristic assumed for this study is a counter-flow shell and tube heat exchanger. For model simplicity, a negligible pressure drop for the working fluid flowing through the heat exchanger was assumed. 
The pre-heater was evaluated based on the outlet properties at state 5 which is calculated by performing an energy balance for the control volume over the heat exchanger alone with assuming no heat loss to the surroundings. Eq. (16) shows the method used for obtaining enthalpy at state 5 .

$$
h_{5}=\frac{\dot{Q}_{H X 1}}{\dot{m}_{W F}}+h_{4}
$$

where, $\dot{m}_{W F}$ is the mass flow rate of the working fluid, and $\mathrm{h}_{4}$ is the enthalpy at state 4 obtained from Eq. (14). $\dot{Q}_{H X 1}$ is the total heat transferred into the work fluid, and calculated using the effectiveness-NTU method. This method is an alternative to log mean temperature difference (LMTD) method when only the inlet temperatures in the heat exchangers are known and is provide by Eq. (17) (Incropera et al., 2007).

$$
\dot{Q}_{H X 1}=\varepsilon C_{\min }\left(T_{4}-T_{\text {SourceInlet_HX1 }}\right)
$$

where, $\varepsilon$ is the heat exchanger effectiveness and is assumed a value based on literature. $\mathrm{T}_{4}$ is the temperature of the working fluid at state 4 , and $T_{\text {SourceInlet_HX1 }}$ is the temperature of the hot fluid at the engine sourcel entering the $1^{\text {st }}$ stage heat exchanger. $C_{\min }$ represents the heat capacitance and is calculated by multiplying mass flow rate and specific heat capacity of the respective fluid. $C_{\min }$ is either equal to the heat capacitance of the working fluid or heat source fluid. The criteria to obtain $C_{\min }$ is given by the following conditions:

$$
\begin{aligned}
& \text { if, } \mathrm{C}_{\text {cold (working fluid) }}<\mathrm{C}_{\text {hot (heat source fluid) }} \text { then } \mathrm{C}_{\min }=\mathrm{C}_{\text {cold (working fluid) }} \\
& \text { else if, } \mathrm{C}_{\text {cold (working fluid) }}>\mathrm{C}_{\text {hot (heat source fluid) then } \mathrm{C}_{\min }=\mathrm{C}_{\text {hot (heat source fluid) }}}
\end{aligned}
$$




\section{III. $\quad 2^{\text {nd }}$ Stage Heat Exchanger}

The pre-heated working fluid at state 5 is then allowed to enter into the $2^{\text {nd }}$ stage heat exchanger (HX2). The heat transferred into the working fluid is once again dependent on the heat exchanger design and the flow rate of the working fluid passing through the heat exchanger which is the same flow rate as was in the HX1. The function of this heat exchanger is to basically extract enough energy into the working fluid to attain complete vaporization at state 1 before entering the turbine inlet. The heat exchanger characteristic assumed for this study is a counter-flow shell and tube heat exchanger. No pressure loss through the heat exchanger was assumed.

The outlet of the $2^{\text {nd }}$ stage heat exchanger is evaluated by performing an energy balance for the control volume over the heat exchanger alone, and also assuming no heat loss to the surroundings. Eq. (18) shows the method used for obtaining enthalpy at state 5.

$$
h_{1}=\frac{\dot{Q}_{H X 2}}{\dot{m}_{W F}}+h_{5}
$$

where, $\dot{\mathrm{m}}_{\mathrm{WF}}$ is the mass flow of the working fluid. The enthalpy at state $5, \mathrm{~h}_{5}$ is obtained from Eq. (16). Provided by Eq. (19), $\dot{Q}_{H X 2}$ is the amount of heat transferred into the work fluid and calculated using similar method as mentioned in the $1^{\text {st }}$ stage heat exchanger process.

$$
\dot{Q}_{H X 2}=\varepsilon C_{\min }\left(T_{5}-T_{\text {SourceInlet_HX2 }}\right)
$$

where, $\varepsilon$ is the heat exchanger effectiveness which is assumed a constant value. $T_{5}$ is the temperature of the working fluid at state 5 , and $T_{\text {SourceInlet_HX2 }}$ is the temperature of the hot fluid

of the engine source 2 entering the $2^{\text {nd }}$ stage heat exchanger. $C_{\min }$ is evaluated the same method as mentioned in $1^{\text {st }}$ stage heat exchanger. 


\section{Turbine}

The turbine is incorporated in a Rankine cycle to extract mechanical (rotational) work from the working fluids which is at a higher energy state. The high pressure and temperature fluid is then allowed to pass through the turbine where the fluid expands through the process and discharges to a lowered pressure at state 2 . The working fluid condition outlet of the turbine at state 2 is evaluated using Eq. (21).

$$
h_{2}=h_{1}+\left(h_{1}-h_{2 s}\right) \cdot \eta_{\text {turbine }}
$$

where, $\eta_{\text {turbine }}$ is the isentropic turbine efficiency. The enthalpy of the working fluid at state $1, h_{1}$ is obtained from Eq. (18). From isentropic assumption, $h_{2 s}$ is evaluated using the relation $\left(\mathrm{s}_{1}=\right.$ $\left.\mathrm{s}_{2 \mathrm{~s}}\right)$.

Assuming no heat transfer to the surrounding, performing an energy balance over the turbine's control volume gives the work generated by the turbine, and is illustrated by Eq. (21).

$$
\dot{W}_{\text {turbine }}=\dot{m}_{W F}\left(h_{1}-h_{2}\right)
$$

where, $\dot{m}_{W F}$ is the mass flow rate of the working fluid.

\section{Condenser}

At the final stage of the Rankine cycle a condenser is a used to condense the working fluid discharged from the turbine to a liquid phase state and low temperature. The condenser is a heat exchanger where it aids in dissipating the fluid heat at state 2 to a required state 3 set purposely for the system. Although condenser physical design was not approached for the study, it was assumed that the condenser would perform with a characteristic to meet the desired condition 
before the feed pump. Condenser size and performance characteristics were kept into consideration in assuming the condenser-out temperature. It was also assumed that there was no pressure loss through the heat exchanger.

Due to the condenser inlet (State 2) still being at superheated vapor conditions, adding a recuperator designed to reject heat back to the cycle before the pre-heater at state 4 would help in cooling down the vapor before the condenser inlet. This would also favor in sizing the condenser and increase the overall cycle performance. However, introducing a recuperator in the WHR system model would add complexity to the model and requires advanced level of iterative approach in solving the thermodynamic cycle problem, and was outside the scope of this study. For simplicity, hence a recuperator was not considered for this study.

\subsection{WHRS Model Efficiency}

The overall system efficiency of the Rankine cycle simulated for steady-state engine operating points are evaluated based on the energy balance over control volume enclosing the entire system. The efficiency is calculated by taking the ratio of the useful work extracted from the system to the total input heat energy into the system. The thermal efficiency of the Rankine cycle is hence represented by the following relation:

$$
\eta_{\text {thermal }}[\%]=\left(\frac{\dot{W}_{\text {turbine }}-\dot{W}_{\text {pump }}}{\dot{Q}_{H X 1}+\dot{Q}_{H X 2}}\right) 100 \%
$$

The system performance obtained from above relation is also compared to the Carnot cycle efficiency. The Carnot cycle efficiency for the cycle is achieved based on the maximum temperature, $\mathrm{T}_{\mathrm{H}}$ and minimum temperature, $\mathrm{T}_{\mathrm{L}}$ for the Rankine cycle, and is provided by the Eq. (23). 


$$
\eta_{\text {carnot }}[\%]=1-\frac{T_{L}}{T_{H}}
$$

\subsection{WHRS Model Assumptions}

In modeling the Rankine cycle waste heat recovery system, key assumptions were introduced in order to perform steady-state thermodynamic analysis. Based on the scope of the project, and to estimate a realistic and practical application, standard characteristics of the system components were obtained from studies demonstrating similar work. Table 3 lists the characteristics and assumptions applied for simulation.

Table 3. ORC-WHR system characteristics

\begin{tabular}{|r|c|}
\hline Working Fluid Flow Rate Range & $5-35 \mathrm{LPM}$ \\
\hline Evaporation Pressure & $14 \mathrm{bar}$ \\
\hline Condensation Temperature & $36^{\circ} \mathrm{C}$ \\
\hline Turbine Efficiency & $75 \%$ \\
\hline Pump Efficiency & $65 \%$ \\
\hline Heat Exchanger Effectiveness & $70 \%$ \\
\hline
\end{tabular}

\subsection{WHRS Fluid Selection}

Considering the system's component size along with keeping cost and environmental aspects in mind, selecting the right working fluid for the Rankine cycle is an important step in overall performance of the WHR system (Bae et al., 2011). Numerous studies related to engine waste heat recovery have been investigated with comparing the performance of different organic fluid types for Rankine cycle waste heat recovery system implemented on heavy-duty diesel vehicle applications (Arunachalam et al., 2012). 
The applicability and performance of a working fluid in a Rankine cycle depends highly on the fluid characteristics. Saturation vapor curve is one of the important fluid characteristics in selecting an organic fluid. The organic fluids are classified into dry, wet, and isentropic based on the saturation vapor curve in a T-s diagram. Fluids having dry characteristics exhibit positive saturation vapor slope where the working fluid would still remain in vapor phase even after the expansion process, and hence avoiding the possibility of fluid condensation when passing through the turbine. This would also benefit in designing the system without requiring extra superheating of the working fluid. In the case of wet fluids, which are characterized by negative saturation vapor curve, would possibly require excess super heating before the turbine to avoid the fluid condensation. The T-s diagram showing the characteristics of each working fluid are graphically illustrated in Figure 15.
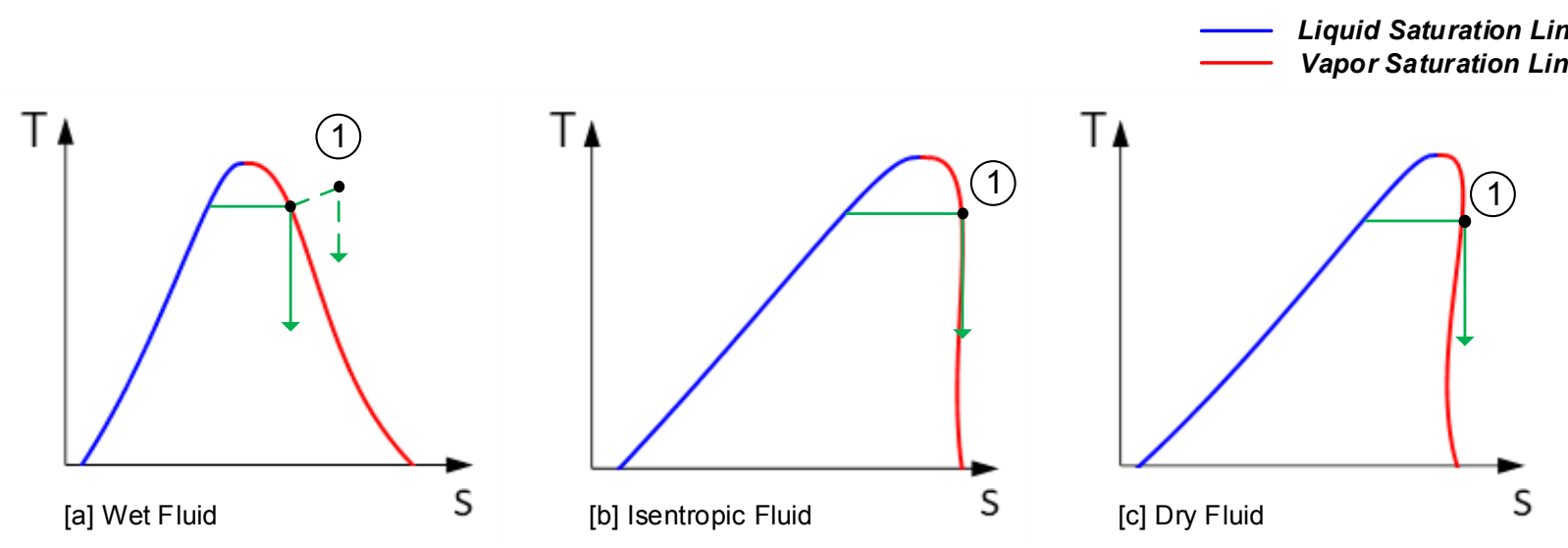

Figure 15. Classification of working fluid on T-s diagram

Three common working fluids, R245fa, R123 and R134a were investigated for this study. Identified as suitable fluids from Cummins, AVL and DOE Supertruck programs. Comparison of thermodynamic properties along with safety and aspects in terms of environmental are summarized in Table 4 below. 
Table 4. Properties of considered working fluids (Wang et al., 2011, Latz et al., 2012)

\begin{tabular}{lccc}
\cline { 2 - 4 } & R245fa & R123 & R134a \\
\hline Fluid Type & Dry & Dry & Wet \\
Critical Temperature & $154^{\circ} \mathrm{C}$ & $183.7^{\circ} \mathrm{C}$ & $101.1^{\circ} \mathrm{C}$ \\
Critical Pressure & $36.6 \mathrm{bar}$ & $36.5 \mathrm{bar}$ & $40.6 \mathrm{bar}$ \\
Flammability & None & None & None \\
Toxicity & Low & High & High \\
Global Warming Potential (GWP) & 950 & 120 & 1300 \\
Ozone Depletion Potential (ODP) & 0 & 0.02 & 0 \\
\hline
\end{tabular}

\subsection{ORC-WHRS Simulation Setup}

Standard organic Rankine cycle was developed in MATLAB ${ }^{\circledR}$ using steady state model analysis. Thermodynamics properties of specific states were called using function applications inbuilt in MATLAB ${ }^{\circledR}$ provided by the NIST REFPROP program. The model analyzed for each individual subsystem based on thermodynamic principles of energy balance and applying assumptions as mentioned earlier. Given below are the simulation steps carried in sequence for performing the calculations at each states:

STATE 3: The calculation for the model starts at state 3 with a pre-determined cycle condition set by the condenser temperature $\left(36^{\circ} \mathrm{C}\right)$ at liquid state and initially selecting the highest flow rate of the working fluid i.e. 35LPM based on the selected pump characteristics.

STATE 4: The system pump pressurizes the working fluid from state $\rightarrow$ state4 to reach the evaporation pressure at $14 \mathrm{bar}$. State 4 is known from the two thermodynamic properties, pressure and entropy (isentropic pump efficiency from assumed value).

STATE 5: Enthalpy at state 5 is calculated based on the amount of heat transferred in the HX1, mass flow rate of the working fluid and the condition at state 4. A condition was also set 
where the inlet working fluid temperature does not exceed the inlet temperature of the hot fluid. If the condition is not met, the simulation goes to the next engine operating point and restarts at state 3.

STATE 1: Similarly, enthalpy at state 1 is calculated based on the amount of heat transferred in the HX2, mass flow rate of the working fluid and the condition at state 5. At this state the simulation checks for the fluid thermodynamic condition. Depending on the type of working fluid selected, two different limiting approaches were set to reach the state 1 condition. For the dry working fluids (R245fa and R123), state 1 condition was constrained to be at saturated vapor line, while for the wet fluid (R134a), state 1 was allowed to superheat further to an extent where sate 2, after the turbine, would fall on the saturation vapor line. If the above conditions are not met then simulation starts with the next mass flow rate of the working fluid from state 3 . Hence, the maximum cycle temperature is limited to the saturation temperature and pressure at state 1. The schematics of T-s diagram given by Figure 16 and Figure 17 with respected thermodynamic states, represents the approach for simulating two different types of working fluid.

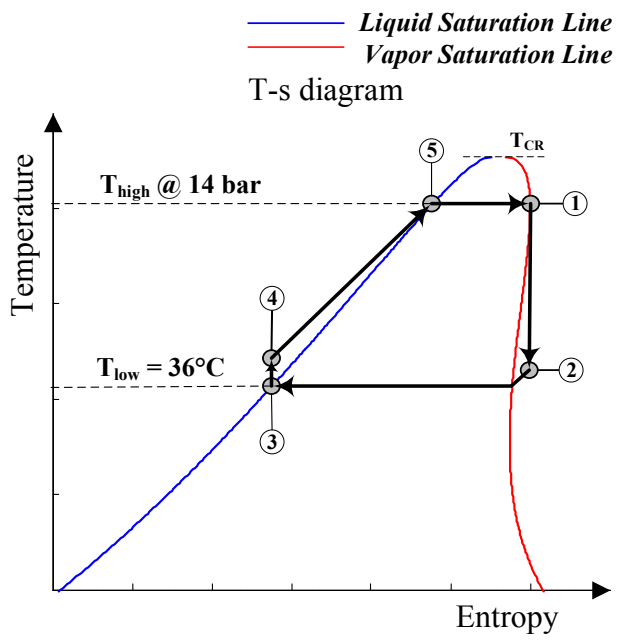

Figure 16. T-s diagram showing process flow for dry fluid 


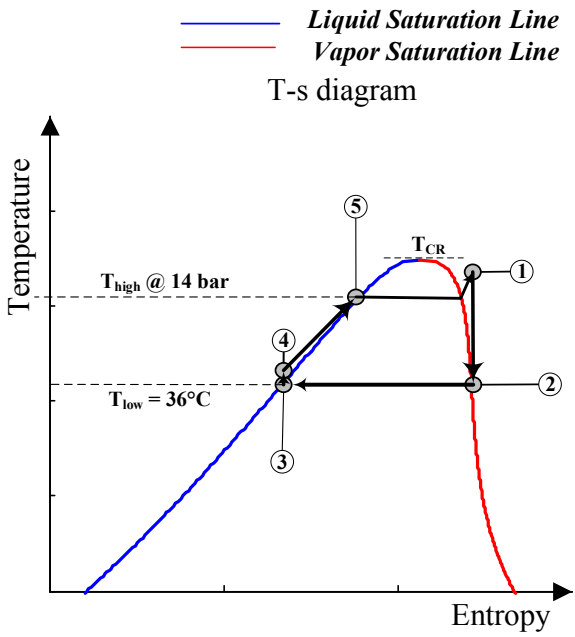

Figure 17. T-s diagram showing process flow for wet fluid

STATE 2: Once the conditions for state 1 are met, then the process continues in calculating state 2. As mentioned earlier, the pressure outlet of the turbine is forced to be the same as the condenser pressure. With the isentropic expansion assumption $\left(\mathrm{s}_{1}=\mathrm{s}_{2}\right)$, enthalpy at state is calculated.

The ORC-WHRS simulation model was analyzed for three different organic fluids and four different engine heat source configuration with two heat exchanger systems placed in series. Table 5 represents the matrix with total of twelve model study configurations.

Table 5. ORC-WHRS model heat source and working fluid configuration

\begin{tabular}{|c|c|c|}
\hline \multirow{2}{*}{ Working Fluids } & $\mathbf{1}^{\text {st }}$ Stage [HX1] & 2 $^{\text {nd }}$ Stage [HX2] \\
\hline \multirow{2}{*}{$\mathrm{R} 245 \mathrm{fa} / \mathrm{R} 123 / \mathrm{R} 134 \mathrm{a}$} & CAC & EGR \\
\cline { 2 - 3 } & CAC & Exhaust Post SCR \\
\cline { 2 - 3 } & EGR & Exhaust Post SCR \\
\cline { 2 - 3 } & Exhaust Post SCR & EGR \\
\hline
\end{tabular}




\section{CHAPTER 5 RESULTS AND DISCUSSIONS}

\subsection{Introduction}

This chapter illustrates the major results obtained for the study. The chapter is divided into three sections based on the objective of the evaluation. Preliminary data analysis was made to ensure confident in the data collected from the experimental work performed for the study. All the instrumented data were collected in continuous basis, and was averaged over the 2 minute trail time for each test point operated to achieve steady-state conditions. Analysis and discussion of averaging the data over the 2 minutes and the uncertainty of this approach are also mentioned below.

\subsection{Data Analysis}

\subsubsection{Comparison of DoE Methods}

As two methodologies were used in designing the test matrix under the engine lug curve, the raw fuel flow rate data were analyzed in order to understand the difference in operating behavior of the engine when no repeats were taken. Curve fitting process with a second order fit was used for the 25 steady state points for fuel mass rate $(\mathrm{g} / \mathrm{s})$ data obtained from each of the two DoE designs, Latin Hyper Cube and Gaussian Process ISME Optimal. Two dependent inputs, speed in (rpm) and torque in (ft-lbs) were used to obtain the response fuel mass rate in $(\mathrm{g} / \mathrm{s})$.

Table 6. Summary of the $2^{\text {nd }}$ order curve fitting model for the two design methods

$$
\text { Coefficient of Determination } \quad \text { Root Mean Square Error }
$$

$\left(\mathbf{R}^{2}\right)$ (RMSE)

\begin{tabular}{|ccc}
\hline DoE Design 1 & 0.9966 & 14.41 \\
DoE Design 2 & 0.9994 & 6.2 \\
\hline
\end{tabular}


Table 6 provides a summary of the curve fitting, where both the designs showed good correlation for the response with respect to the two inputs. In order to compare the difference in the two models, the Design 2 fuel values were predicted using the same (speed and torque) inputs of Design 1. Figure 18 illustrates a scatter plot of the predicted fuel as a function of engine power, comparing the two DoE designs. The result obtained once again shows that they correlates well with respect to the engine power. From the lack of fit test performed, resulted in a P-value $<0.001$, shows that there is no significant difference (with significance level of 0.05 ) between the two design methods approached for the study. It also shows that most of the fuel variation are seen at the lower engine power, and tends to gradually decrease as engine power increases, with an average difference of $\sim 2 \%$ as shown in Figure 19. It also shows that DoE 1 consistently has higher prediction than compared to DoE 2 because of the applied second order fit on DoE 1 results which had higher overall fueling rates.

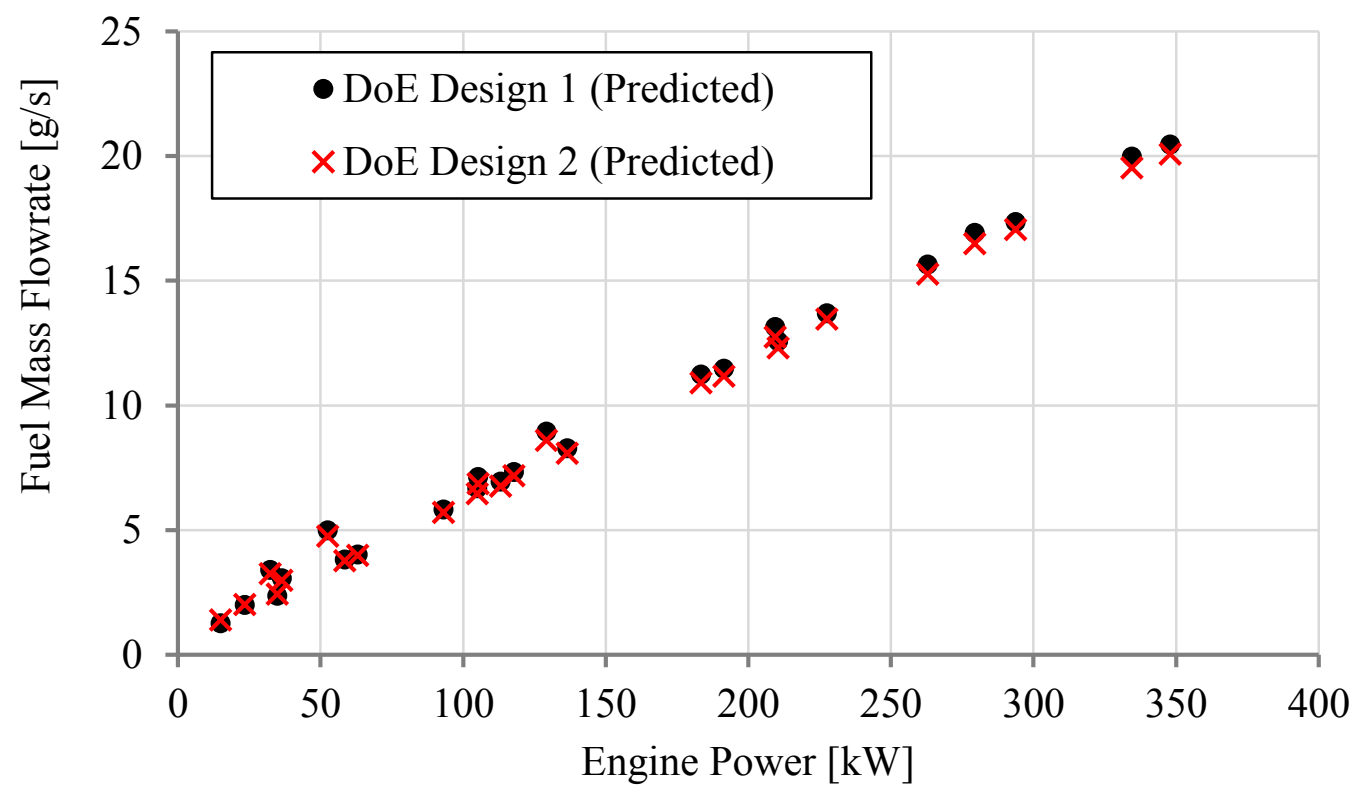

Figure 18. Comparison of the predicted fuel $[\mathrm{g} / \mathrm{s}]$ for two DoE designs 


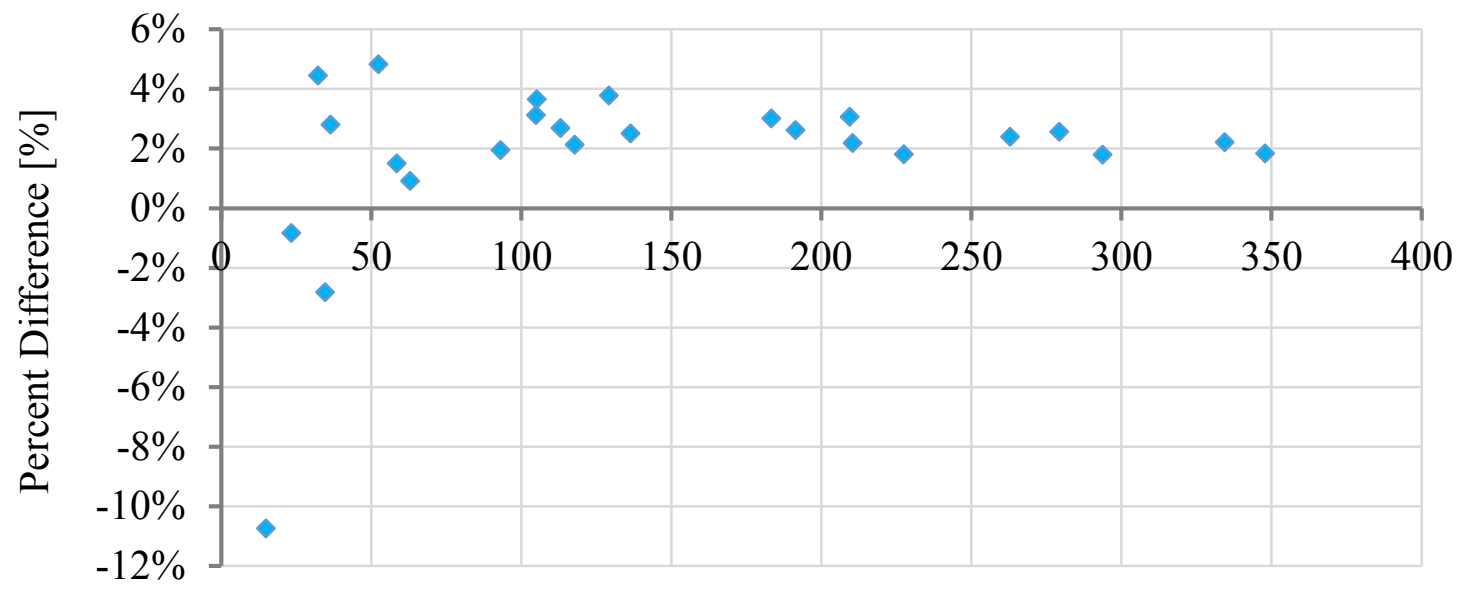

Engine Power $[\mathrm{kW}]$

\section{Figure 19. Percent difference of the prediction fuel $[\mathrm{g} / \mathrm{s}]$ for two DoE designs}

\subsubsection{Analysis of Energy Data}

As the DoE method comparison provided good correlation and no significant difference in collecting the data with two different ways, all the 50 data points along with the 3 ESC points were statistically analyzed together for variation in the energy outputs results obtained from experiment performed. A regression analysis with respect to engine power was applied as the preliminary analysis to point any unusual trends in the data collected. Following results provides such analysis for the major energy components:

\section{Exhaust Energy}

A linear regression applied to the rate of exhaust energy as a function of engine power data to analyze the trend and variation in the data is given by Figure 20. The regression summary shows an $R^{2}$ of 0.969 for the fit with RMSE of 10.58. Rate of exhaust energy at two operating points (@) $129.2 \mathrm{~kW}$ and $279.3 \mathrm{~kW}$ engine power) indicated by blue cross in the figure were calculated to be outside the $95 \%$ confidence interval of the linearly fitted curve. It is to be noted that any two combination of speed and torque could provide the same engine power point, and hence variation 
in the energy results such as exhaust energy response depends upon engine speed or torque. At different speed and torque combination to meet the engine power demand, engine control effects and strategies at different operating points affects pressure, temperature and mass flow rate passing through the exhaust lines along with the turbocharger. Likewise, strategic events such as EGR, VGT and combustion could potentially play a significant role in variation in rate of exhaust energy.

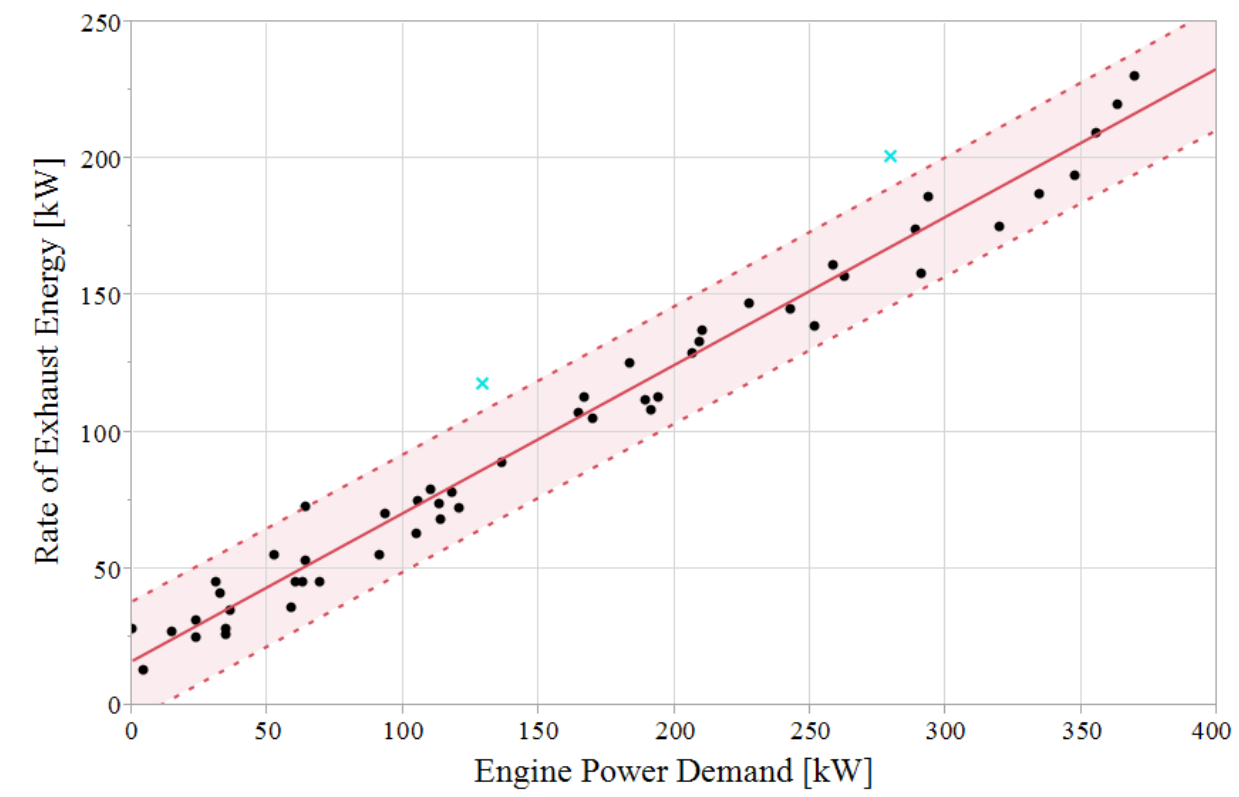

Figure 20. Data analysis of Exhaust energy rate by Engine Power Demand

\section{Coolant Energy}

Similarly, applied linear regression relating to coolant energy to power demand is shown in Figure 21 where statistical summary show an $\mathrm{R}^{2}$ of 0.8898 for the fit with RMSE of 7.293. Coolant energy at one operating point (@290.8 kW engine power) indicated by blue cross in the figure were calculated to be outside the $95 \%$ confidence interval of the linearly fitted curve. Variation in rate of coolant energy could potentially come from thermal response of the engine components where the two minute stabilization time will affect the averaged value of the measurement. Higher variation of data points at the low power engine operation could also result 
from thermal history effect mainly when operating a point at lower engine speed and load consecutively operating after a high engine speed and load combination. For such conditions the two minute stabilization time may not be sufficient for the temperatures to reach a stable reading. Further discussion on the steady-state stabilization analysis are provided in next section.

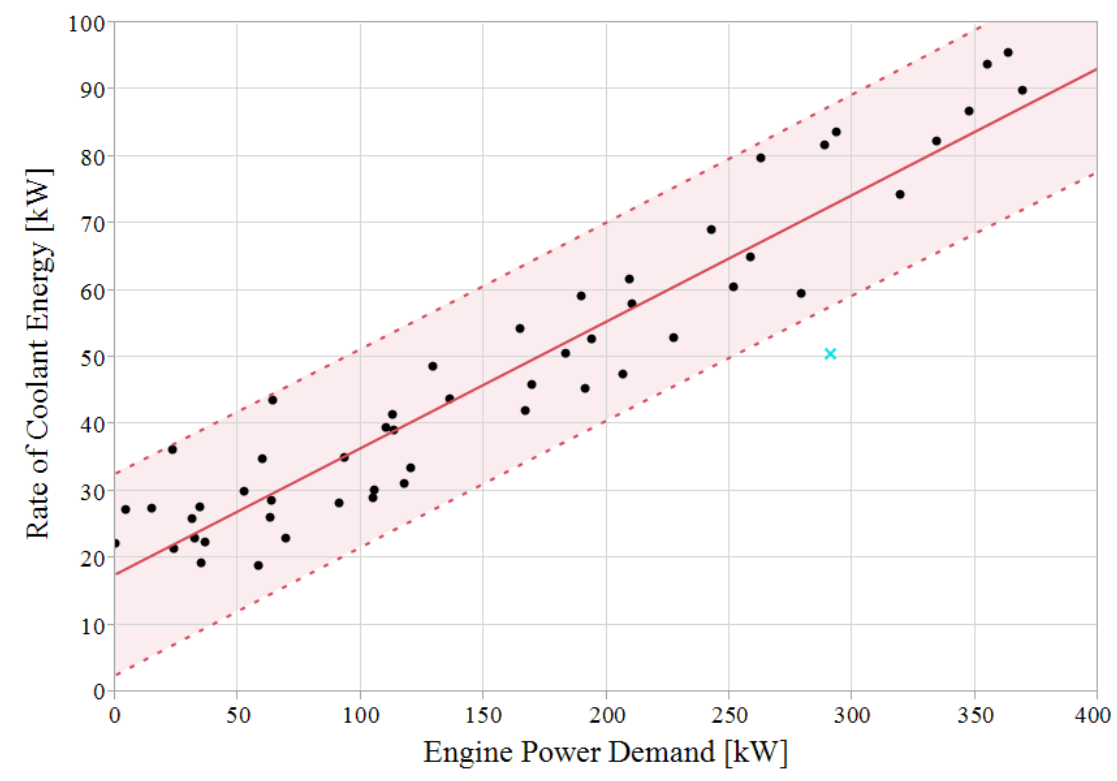

Figure 21. Data analysis of Coolant energy rate by Engine Power Demand

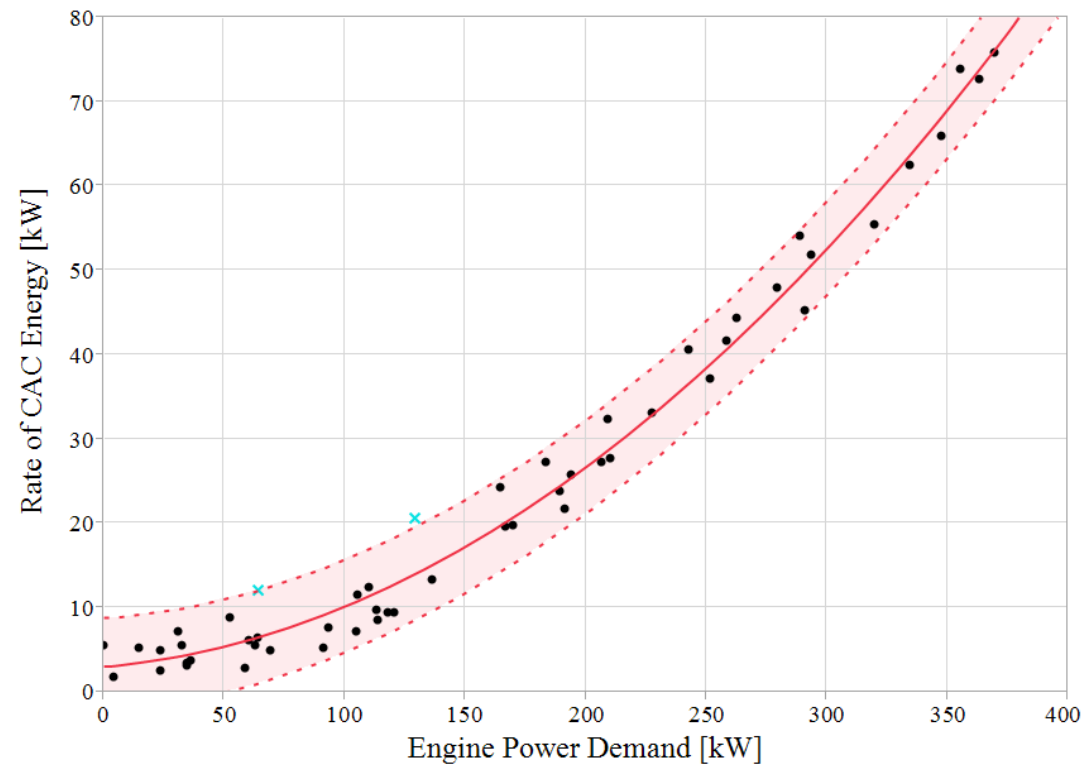

Figure 22. Data analysis of CAC energy rate by Engine Power Demand 


\section{CAC Energy}

The rate of charge air cooler energy with respect to engine power showed different correlation as compared to other energy analysis reviewed earlier. A second order polynomial curve was fitted through the data to better estimate the relation between the CAC energy rate and engine power demand. Figure 22 shows the second order fit with shaded area as the confidence intervals. An $\mathrm{R}^{2}$ of 0.9849 and RMSE of 2.695 was calculated for the fit. It indicates that two points operated at $64.1 \mathrm{~kW}$ and $129.2 \mathrm{~kW}$ were outside the confidence interval.

\subsubsection{Steady-State Temperature Analysis}

This section examines the continuous temperature data for select points in order to understand thermal history effects and influence of data averaging over the steady-state engine operation. Figure 23 provides the temperature profile for first four modes, where the mode 1 is an idle $(0 \mathrm{~kW})$ operation. Each mode represents 120 seconds of steady-state operating with 20 seconds of transition period in between modes. In the 120 seconds of steady-state operation, the temperature trend and stabilization period within the modes differ based on the prior operation. In the initial period of each mode for EGR gas in/out, post-turbo, post/pre CAC, temperature trends to increase at faster rate, and then gradually levels at mush slower rate of increase. On the other hand, post-SCR showed a different temperature behavior and the profiles also was not consistent based on the operating mode. This is due to the nature heat transfer in thermal mass of the aftertreatment system which includes both DPF/DOC and SCR. Transport delay plays an important role in heat transfer inside the aftertreatment system, and hence differing in the temperature behavior. 


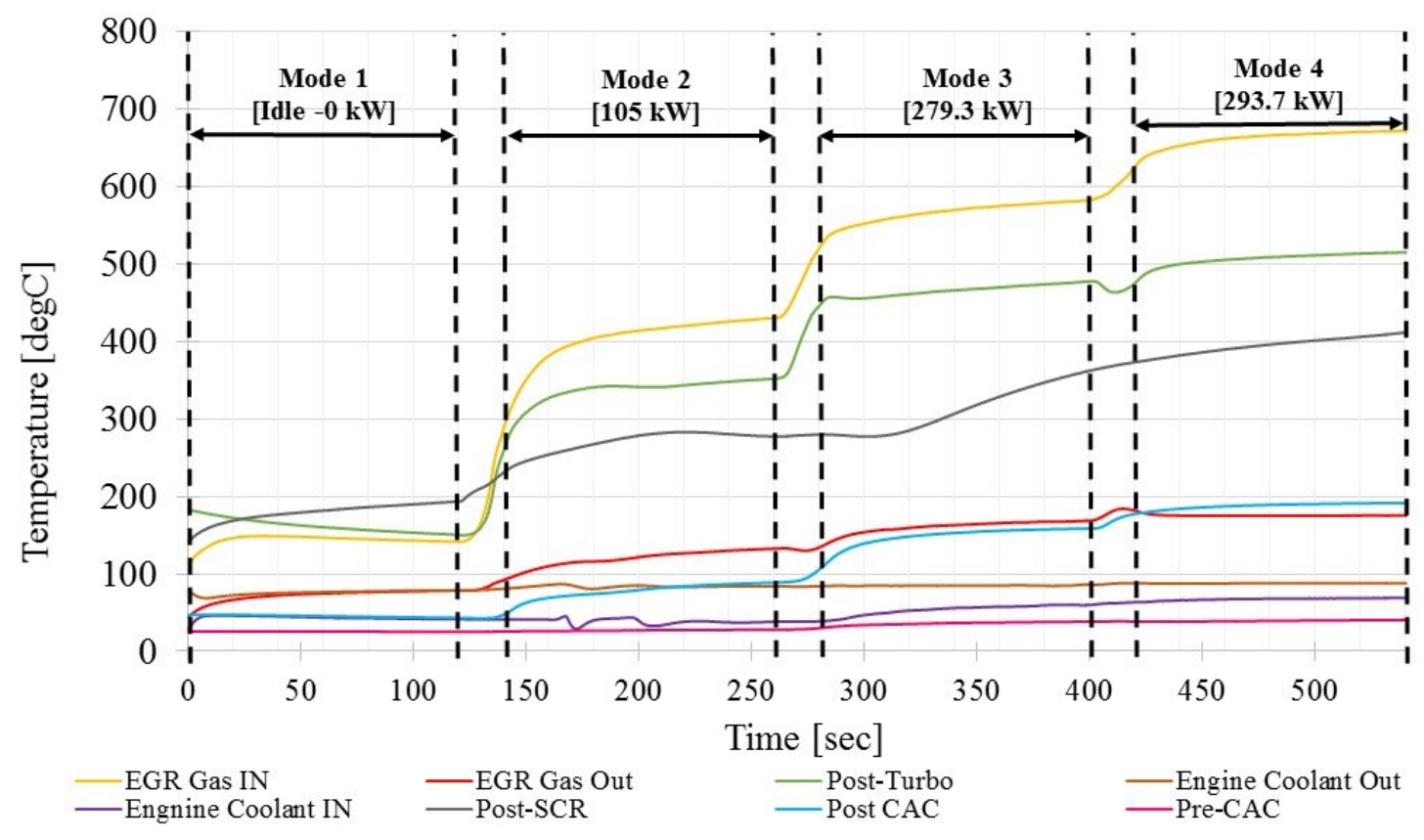

Figure 23. Continuous temperature profile for select modes

Table 7 provides the summary showing the average, standard deviation and coefficient of variation $(\mathrm{COV})$ for the major temperature parameter for two minute steady-state operation of the selected modes. Upon observation for the EGR cooler measurement, temperature of EGR gases entering the cooler showed low $\mathrm{COV}$ of $\sim 3.8 \%$ (averaged of the four modes) compared to the temperature of gases leaving the cooler with COV of $\sim 5.8 \%$ (averaged of the four modes). Similar variation trends were also observed for engine coolant leaving and entering the engine or in other words, engine coolant entering and leaving the coolant heat exchanger. Temperature of the engine coolant leaving the engine showed significantly low $\mathrm{COV}$ of $\sim 1.4 \%$ while engine coolant entering the engine showed higher $\mathrm{COV}$ of $\sim 6.7 \%$ (averaged of four mode). Once again this higher variance could be from the thermal inertia of the heat exchanger, and hence would require longer time for a stable temperature reading. The $\mathrm{CAC}$ temperature profiles of the air entering and leaving the CAC heat exchanger shows an opposite trend compared to the EGR and coolant. The post-CAC temperature which is of the air leaving the CAC heat exchanger showed low $\mathrm{COV}$ of $\sim 2.6 \%$ 
(averaged of four modes) compared to the temperature of pre-CAC with a COV $\sim 6.2 \%$. This shows that the air cooled heat exchanger such as the CAC air stabilizes sooner than the water heat exchangers (EGR and coolant coolers). The post-turbo temperatures showed on averaged of $\sim 3.4 \%$ COV with mode 1 and 2 having higher averaged COV of $\sim 5.2 \%$, and mode 2 and 3 having a lower averaged $\mathrm{COV}$ of $\sim 1.5 \%$. Overall for all parameters, mode 1 and 2 showed higher variation in the temperature, meaning at low engine power demands, the modes had higher difference in stabilizing the temperature within two minutes of the steady-state operation. The effect of thermal history could be interpreted when moving into mode $2(105 \mathrm{~kW})$ from mode 1 (idle $0 \mathrm{~kW})$, where due to bigger difference in the rise of temperature, it takes longer time for the temperatures to stabilize. Mode 4 showed the least variation in the temperature for almost all the temperature parameters.

Table 7. Summary of temperature for the select ( 2 minutes) modes

\begin{tabular}{|c|c|c|c|c|c|c|c|c|c|}
\hline & $\begin{array}{c}\text { EGR } \\
\text { Gas IN }\end{array}$ & $\begin{array}{c}\text { EGR } \\
\text { Gas } \\
\text { OUT }\end{array}$ & $\begin{array}{c}\text { Engine } \\
\text { Coolant } \\
\text { Out }\end{array}$ & $\begin{array}{c}\text { Engine } \\
\text { Coolant } \\
\text { In }\end{array}$ & $\begin{array}{l}\text { Post - } \\
\text { Turbo }\end{array}$ & $\begin{array}{l}\text { Post - } \\
\text { SCR }\end{array}$ & $\begin{array}{l}\text { Pre- } \\
\text { CAC }\end{array}$ & $\begin{array}{l}\text { Post- } \\
\text { CAC }\end{array}$ \\
\hline & & \multicolumn{8}{|c|}{$[\operatorname{degC}]$} \\
\hline \multirow{4}{*}{ Avergae } & Mode1 & 143.8 & 72.2 & 75.7 & 43.5 & 162.1 & 179.2 & 45.4 & 25.5 \\
\hline & Mode2 & 403.2 & 119.7 & 83.6 & 38.7 & 336.5 & 270.2 & 77.5 & 27.0 \\
\hline & Mode3 & 566.1 & 160.5 & 84.8 & 53.5 & 465.5 & 311.1 & 148.5 & 36.0 \\
\hline & Mode4 & 662.2 & 175.4 & 87.9 & 67.4 & 506.5 & 394.6 & 187.8 & 39.3 \\
\hline & & & & & & & & & \\
\hline \multirow{4}{*}{ Std.Dev } & Mode1 & 6.0 & 6.9 & 2.7 & 2.1 & 8.8 & 11.3 & 1.3 & 0.1 \\
\hline & Mode2 & 29.6 & 10.1 & 1.4 & 3.3 & 16.7 & 13.8 & 9.5 & 0.7 \\
\hline & Mode3 & 13.2 & 7.7 & 0.3 & 6.1 & 7.2 & 29.3 & 11.4 & 2.0 \\
\hline & Mode4 & 9.7 & 0.9 & 0.1 & 1.4 & 7.7 & 10.6 & 3.5 & 0.7 \\
\hline & & & & & & & & & \\
\hline \multirow{4}{*}{$\mathrm{COV}$} & Mode1 & $4.2 \%$ & $9.6 \%$ & $3.6 \%$ & $4.8 \%$ & $5.4 \%$ & $6.3 \%$ & $2.9 \%$ & $0.4 \%$ \\
\hline & Mode2 & $7.4 \%$ & $8.5 \%$ & $1.6 \%$ & $8.5 \%$ & $5.0 \%$ & $5.1 \%$ & $12.2 \%$ & $2.6 \%$ \\
\hline & Mode3 & $2.3 \%$ & $4.8 \%$ & $0.4 \%$ & $11.4 \%$ & $1.6 \%$ & $9.4 \%$ & $7.7 \%$ & $5.6 \%$ \\
\hline & Mode4 & $1.5 \%$ & $0.5 \%$ & $0.1 \%$ & $2.1 \%$ & $1.5 \%$ & $2.7 \%$ & $1.9 \%$ & $1.9 \%$ \\
\hline
\end{tabular}

The two minutes steady-state operation data for the select modes were also analyzed for two different time periods, first 20 seconds and last 20 seconds of the temperatures data. Table 8 , 
and Table 9, provides the summary for the averaged, standard deviation and COV. It is clearly observed that evaluating the first 20 seconds of the data showed higher variation in the temperature profiles while evaluating the last 20 seconds of the data showed low variation. The low variation with COV less than $1 \%$ for most of the parameters and modes shows that the temperature change is small, and therefore be considered has a stable reading.

The goal of the test plan was to achieve steady-state conditions for the 53 operating points under the lug curve. An analysis of the individual measurements depicted that the temperatures did not reach a true steady state condition. One of the approach for approximating a steady state temperature is using appropriate polynomial fits for measured data. As a conservative approximation of temperatures, the entire two minutes of each modes were averaged instead of using any trend fits or considering only a certain time period from the mode.

Table 8. Summary of temperature for the select (first 20 seconds) modes

\begin{tabular}{|c|c|c|c|c|c|c|c|c|c|}
\hline & $\begin{array}{c}\text { EGR } \\
\text { Gas IN }\end{array}$ & $\begin{array}{c}\text { EGR } \\
\text { Gas } \\
\text { OUT } \\
\end{array}$ & $\begin{array}{c}\text { Engine } \\
\text { Coolant } \\
\text { Out }\end{array}$ & $\begin{array}{c}\text { Engine } \\
\text { Coolant } \\
\text { In }\end{array}$ & $\begin{array}{l}\text { Post - } \\
\text { Turbo }\end{array}$ & $\begin{array}{l}\text { Post - } \\
\text { SCR }\end{array}$ & Pre-CAC & $\begin{array}{l}\text { Post- } \\
\text { CAC }\end{array}$ \\
\hline & & \multicolumn{8}{|c|}{$[\operatorname{deg} C]$} \\
\hline \multirow{4}{*}{ Avergae } & Mode1 & 134.9 & 59.0 & 71.0 & 43.8 & 177.1 & 158.9 & 47.1 & 25.5 \\
\hline & Mode2 & 346.4 & 102.0 & 83.2 & 41.0 & 304.6 & 244.9 & 61.2 & 26.0 \\
\hline & Mode3 & 542.9 & 146.3 & 84.6 & 42.2 & 455.4 & 278.7 & 126.8 & 32.4 \\
\hline & Mode4 & 643.9 & 176.7 & 87.7 & 64.7 & 492.5 & 377.8 & 181.2 & 38.3 \\
\hline & & & & & & & & & \\
\hline \multirow{4}{*}{ Std.Dev } & Mode1 & 9.7 & 6.0 & 2.2 & 4.1 & 3.0 & 7.5 & 0.1 & 0.1 \\
\hline & Mode2 & 26.2 & 5.2 & 1.4 & 0.0 & 17.7 & 6.3 & 6.4 & 0.2 \\
\hline & Mode3 & 7.7 & 5.8 & 0.1 & 2.6 & 2.0 & 0.9 & 9.7 & 1.2 \\
\hline & Mode4 & 6.7 & 1.6 & 0.1 & 0.9 & 6.3 & 2.5 & 1.9 & 0.1 \\
\hline & & & & & & & & & \\
\hline \multirow{4}{*}{$\mathrm{COV}$} & Mode1 & $7.2 \%$ & $10.1 \%$ & $3.0 \%$ & $9.3 \%$ & $1.7 \%$ & $4.7 \%$ & $0.2 \%$ & $0.2 \%$ \\
\hline & Mode2 & $7.6 \%$ & $5.1 \%$ & $1.7 \%$ & $0.1 \%$ & $5.8 \%$ & $2.6 \%$ & $10.5 \%$ & $0.6 \%$ \\
\hline & Mode3 & $1.4 \%$ & $3.9 \%$ & $0.2 \%$ & $6.2 \%$ & $0.4 \%$ & $0.3 \%$ & $7.7 \%$ & $3.6 \%$ \\
\hline & Mode4 & $1.0 \%$ & $0.9 \%$ & $0.1 \%$ & $1.3 \%$ & $1.3 \%$ & $0.7 \%$ & $1.0 \%$ & $0.2 \%$ \\
\hline
\end{tabular}


Table 9. Summary of temperature for the select (last 20 seconds) modes

\begin{tabular}{|c|c|c|c|c|c|c|c|c|c|}
\hline & $\begin{array}{c}\text { EGR } \\
\text { Gas IN }\end{array}$ & $\begin{array}{c}\text { EGR } \\
\text { Gas } \\
\text { OUT }\end{array}$ & $\begin{array}{c}\text { Engine } \\
\text { Coolant } \\
\text { Out } \\
\end{array}$ & $\begin{array}{c}\text { Engine } \\
\text { Coolant } \\
\text { In } \\
\end{array}$ & $\begin{array}{l}\text { Post - } \\
\text { Turbo }\end{array}$ & $\begin{array}{l}\text { Post - } \\
\text { SCR }\end{array}$ & $\begin{array}{l}\text { Pre- } \\
\text { CAC }\end{array}$ & $\begin{array}{l}\text { Post- } \\
\text { CAC }\end{array}$ \\
\hline & & \multicolumn{8}{|c|}{$[\operatorname{degC}]$} \\
\hline \multirow{4}{*}{ Avergae } & Mode1 & 142.2 & 78.0 & 78.5 & 41.7 & 151.7 & 191.6 & 43.5 & 25.4 \\
\hline & Mode2 & 428.0 & 131.3 & 83.8 & 37.5 & 350.0 & 278.6 & 87.8 & 28.0 \\
\hline & Mode3 & 580.4 & 167.6 & 85.1 & 59.8 & 475.5 & 355.2 & 157.9 & 38.2 \\
\hline & Mode4 & 671.1 & 175.2 & 88.0 & 68.7 & 514.1 & 408.6 & 191.3 & 40.4 \\
\hline & & & & & & & & & \\
\hline \multirow{4}{*}{ Std.Dev } & Mode1 & 0.5 & 0.3 & 0.2 & 0.2 & 0.8 & 1.1 & 0.2 & 0.0 \\
\hline & Mode2 & 1.4 & 0.7 & 0.0 & 0.4 & 1.1 & 0.9 & 0.6 & 0.1 \\
\hline & Mode3 & 1.1 & 0.5 & 0.6 & 0.2 & 1.1 & 4.4 & 0.3 & 0.1 \\
\hline & Mode4 & 0.4 & 0.0 & 0.0 & 0.2 & 0.5 & 1.7 & 0.2 & 0.1 \\
\hline \multirow{4}{*}{$\mathrm{COV}$} & Modo 1 & $020 /$ & 0.40 & 020 & 0406 & $060 /$ & 060 & 050 & $00 \%$ \\
\hline & Mode2 & $\begin{array}{l}0.5 \% \\
0.3 \%\end{array}$ & $\begin{array}{l}0.4 \% \\
0.6 \%\end{array}$ & $\frac{0.2 \%}{0.0 \%}$ & $\frac{0.4 \%}{0.9 \%}$ & $\begin{array}{l}0.0 \% \\
0.3 \%\end{array}$ & $\begin{array}{l}0.0 \% \\
0.3 \%\end{array}$ & $0.5 \%$ & $0.0 \%$ \\
\hline & Mode3 & $0.2 \%$ & $0.3 \%$ & $0.7 \%$ & $0.3 \%$ & $0.2 \%$ & $1.2 \%$ & $0.2 \%$ & $0.3 \%$ \\
\hline & Mode4 & $0.1 \%$ & $0.0 \%$ & $0.0 \%$ & $0.2 \%$ & $0.1 \%$ & $0.4 \%$ & $0.1 \%$ & $0.3 \%$ \\
\hline
\end{tabular}

\subsection{Energy Audit}

The energy audit results for the data collected from the MY 2011 Mack MP8 engine dynamometer testing are summarized in terms of individual energy distribution to the input fuel energy, as based on energy balance applied over steady state operation. Figure 24 gives the percent energy distribution with respect to the input fuel for all 53 steady-state engine operated points as a function of engine power. Since, this thesis focuses at major recoverable energy based on relevant studies, the accounted/measured energies such as the brake work, exhaust, coolant, and CAC energy values were only considered for the discussion. The remainder of the unaccounted/nonmeasured energies which are lumped as other losses are obtained from subtracting the sum of four accounted losses from the total input fuel energy. The unaccounted losses have shown to include engine friction (excluding the friction heat taken by the coolant), pumping, convection heat from engine surface, oil sump, crankcase, and other losses (Heywood, 1988). 
From the energy distribution Figure 24, at lower engine power operation, more variability in energy distribution per input fuel energy are observed. This could be due to engine stability at low speed and torque operations (lower power demand), and effects of thermal history as discussed earlier in the previous section. It also shows that at lower power demand operations, less percentage of fuel energy are converted to brake work while majority of the fuel energy is shown to be transported by the exhaust and coolant. At increasing engine power operations, the energy distribution tends to be stabilizing with engine operating at better work conversion efficiency. Similarly, less variability are also observed within the individual energy distribution at higher engine power demand. The "saw" like pattern observed in Figure 24, depicted distinctly at lower engine power operations, are the result of varying correlation between the engine speed and torque with respect to energy distribution. It could also be understood that an engine power can be reached with no one particular combination of speed and torque, hence resulting in different energy flows.

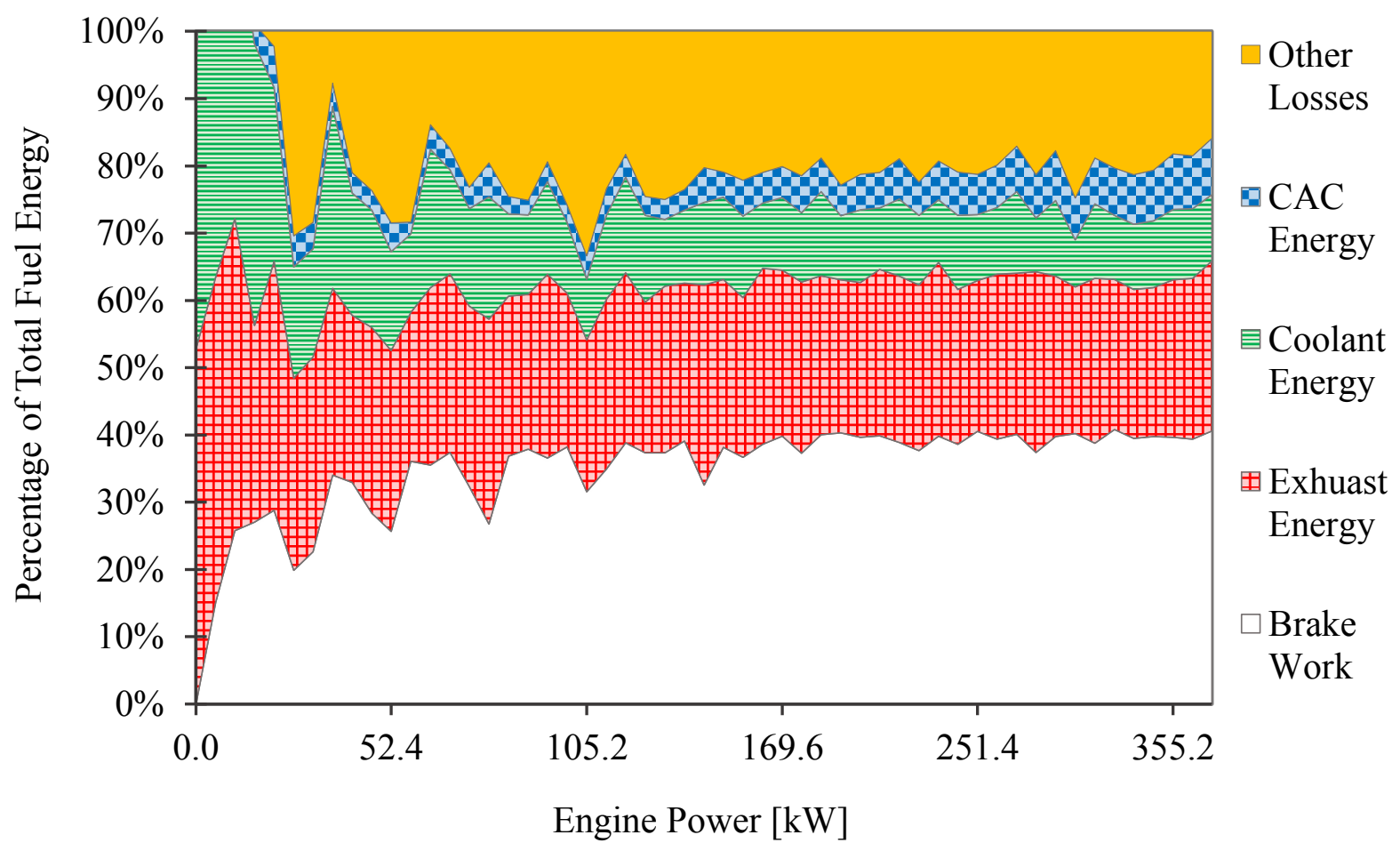

Figure 24. Relative energy distribution with respect to total fuel energy 
Figure 25 shows the energy distribution with respect to input fuel energy for a select three operating points from the collected steady-state data set. Results show that about ( $40 \%)$ of the input fuel energy is converted to brake work, while majority of the fuel energy $(\sim 25 \%)$ is lost through in terms of engine exhaust heat. Out of the three major energy flow in terms of losses looked at in this study, part of input energy taken by CAC resulted in lowest, showing on average $6 \%$

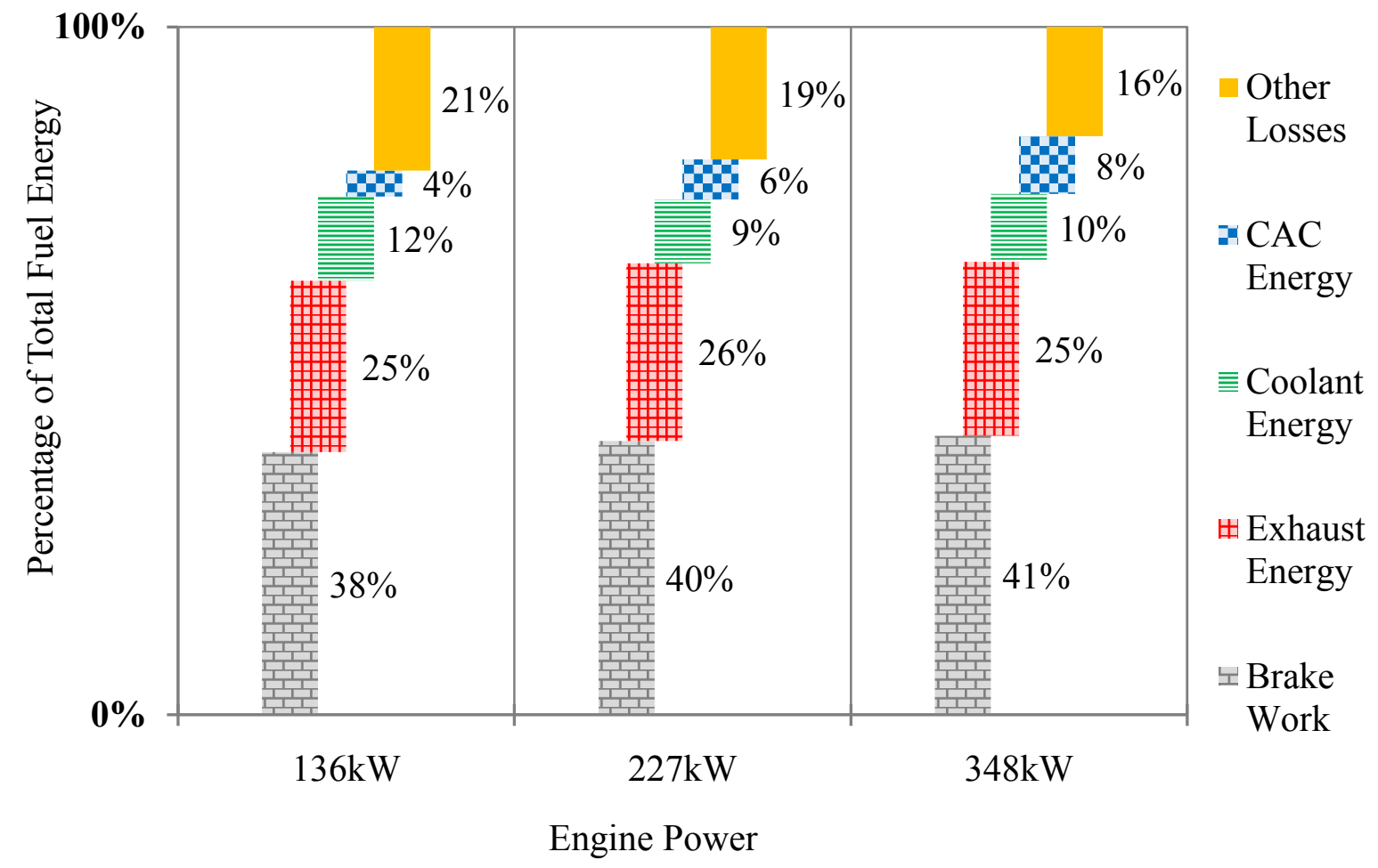

Figure 25. Relative energy distribution with respect to total fuel energy for select operating
points

Figure 26 shows the rate of energy for the individual energy distribution: exhaust, coolant and $\mathrm{CAC}$ as a function of engine power. It clearly shows that exhaust energy has the highest magnitude of recoverable potential as compared to coolant and CAC. It also shows that higher energy rate could be recovered at higher engine power demand from the exhaust energy. Both coolant and CAC rate of recoverable energy tends to increase at a same rate as engine power 
increases. The highest recoverable rate energy from the three engine losses of $363 \mathrm{~kW}$ was calculated at the maximum power $(369.4 \mathrm{~kW})$ among the 53 operating points.

The goal of the energy analysis was to show the potential heat sources which could be used for ORC-WHR system. But on the other hand, it would not be a probable solution to look at extracting energy from the exhaust right after the post-turbo as from the very fact that part of the energy is aimed to provide thermal operation of the after-treatment system located downstream. However, based on the energy analysis conducted after the post-SCR, it appears that there is still suitable heat available in the exhaust gas stream relatively at high temperature $\left(300-400^{\circ} \mathrm{C}\right)$, as shown for all operating points in Figure 27.

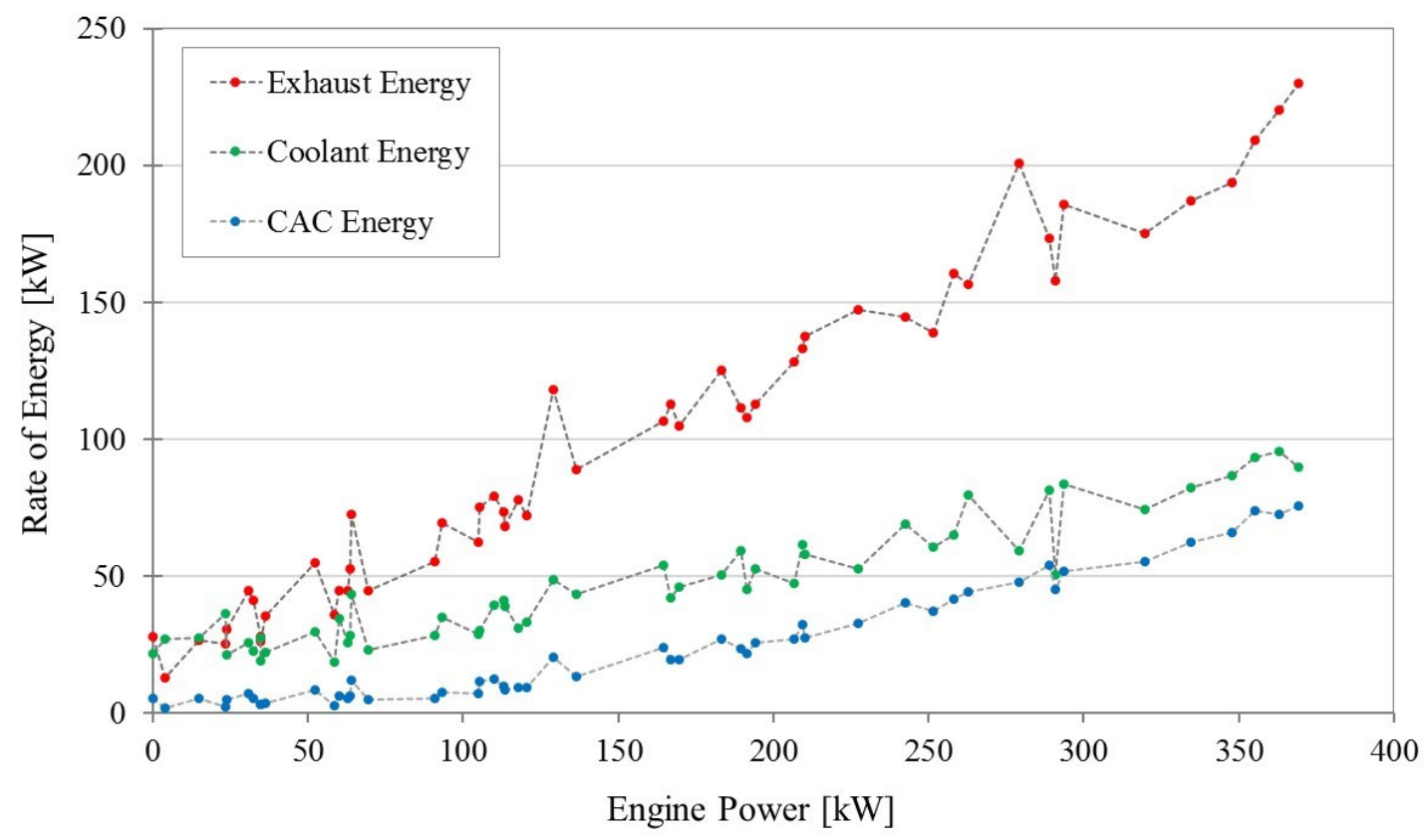

Figure 26. Energy distribution of the total accounted heat loss from exhaust, coolant and CAC 


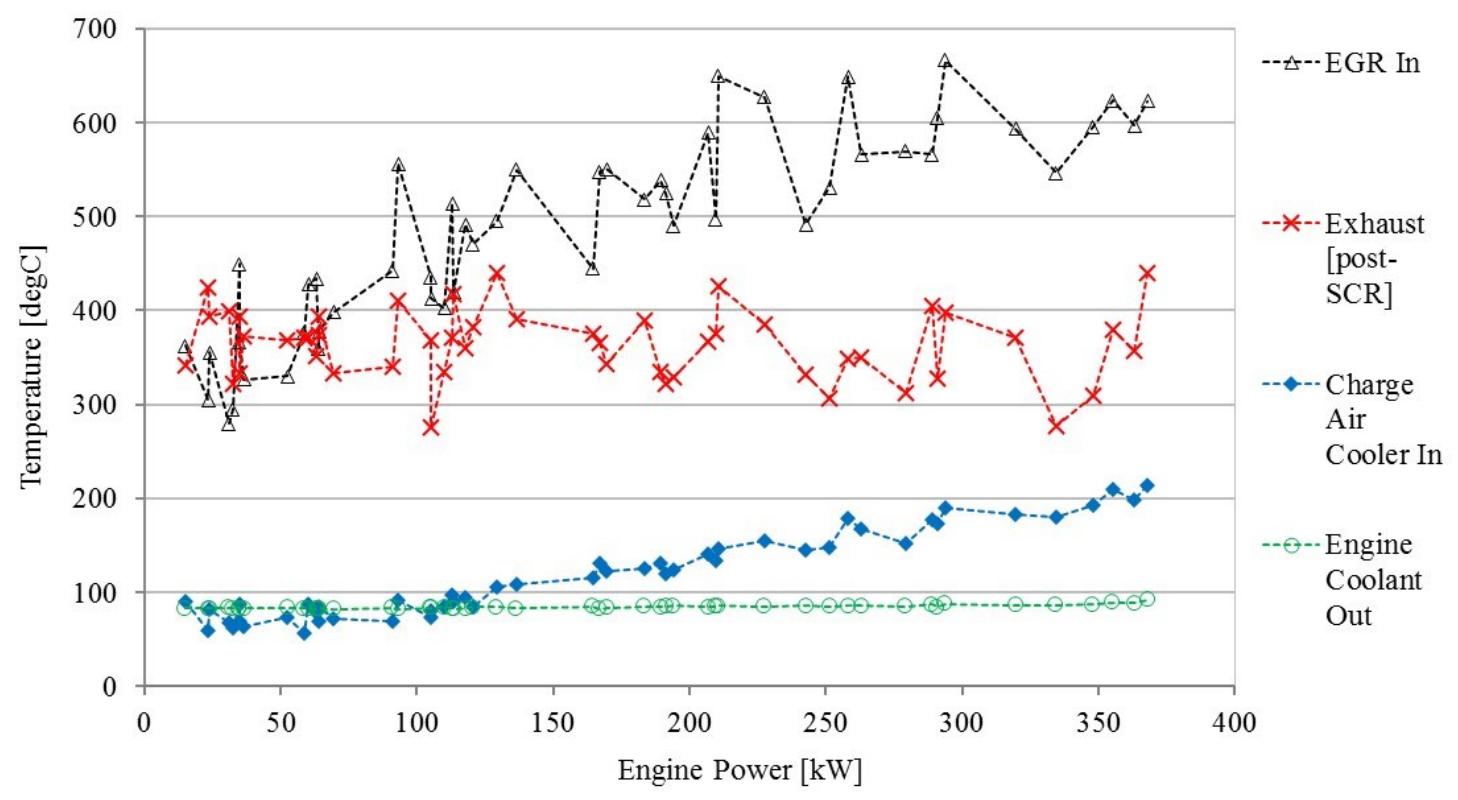

Figure 27. Comparison of temperature profile for all operating points

Figure 28 shows the magnitude of the rate of exhaust energy after the turbo and after the SCR, plotted as a function of engine power. It shows that there is still high amount of energy available after the SCR system. From Figure 27, it also shows that the exhaust energy that could be recoverable after the post-SCR is considered to be high quality compared to coolant and CAC. At couple of operating points, especially at lower power demands, the rate of exhaust energy postSCR is seen to be higher than the total engine exhaust energy. This could possibly be due to thermal history effects and thermal inertia of the aftertreatment systems as discussed earlier in the steadystate data analysis section.

Figure 29 shows the magnitude of the rate of EGR energy as a function of engine power. Since EGR cooler uses engine coolant for cooling down the recirculated exhaust gases entering the cooled intake stream, from the result it shows that engine coolant carries a portion of the EGR heat. However, the coolant is measured to be a low grade heat source due to the availability of heat at low fluid temperatures, consistently seen at an average temperature of $84^{\circ} \mathrm{C}$ for most of the 
operating points as can be observed in Figure 27. While, EGR heat source are considered to be high quality heat (above $400^{\circ} \mathrm{C}$ ), it could be said that harvesting heat directly at the EGR cooler could be more beneficial than using the engine coolant alone.

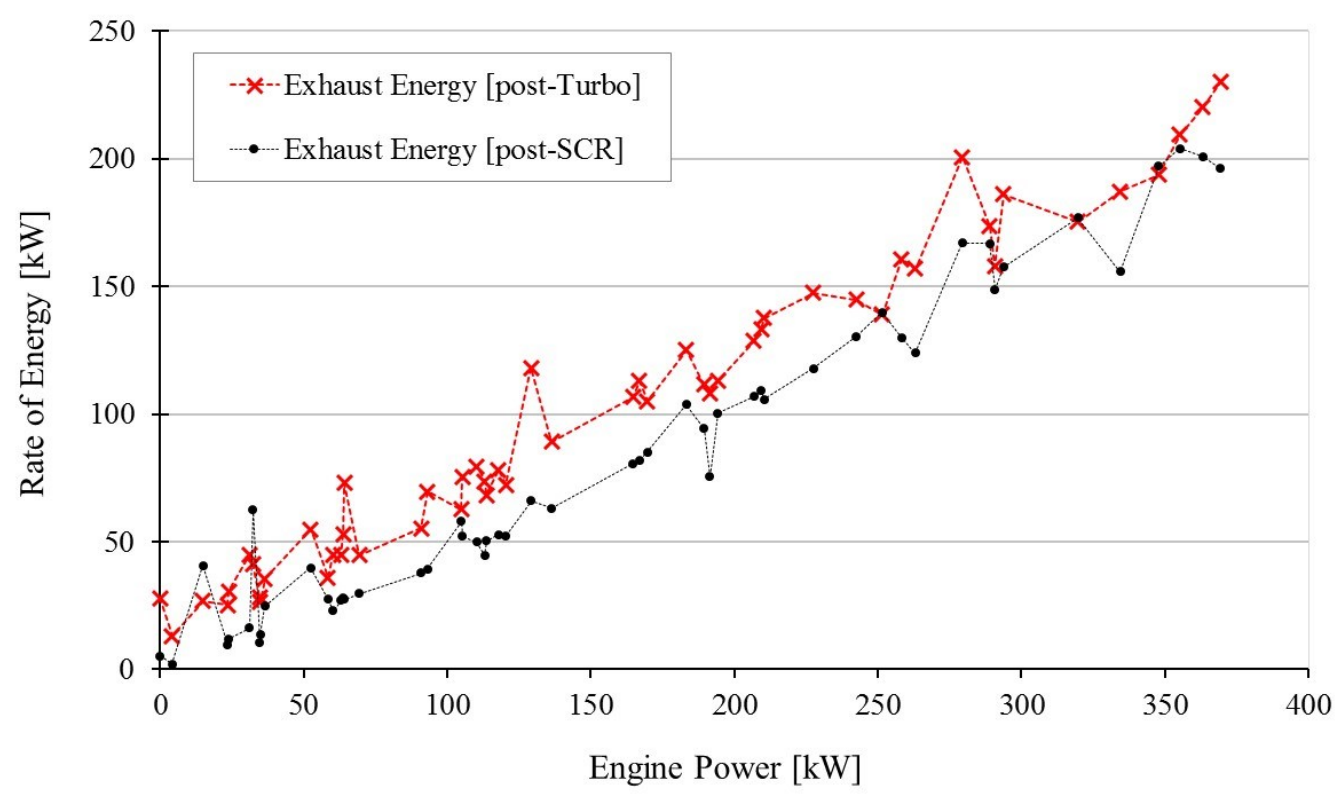

Figure 28. Exhaust energy post-turbo and post-SCR

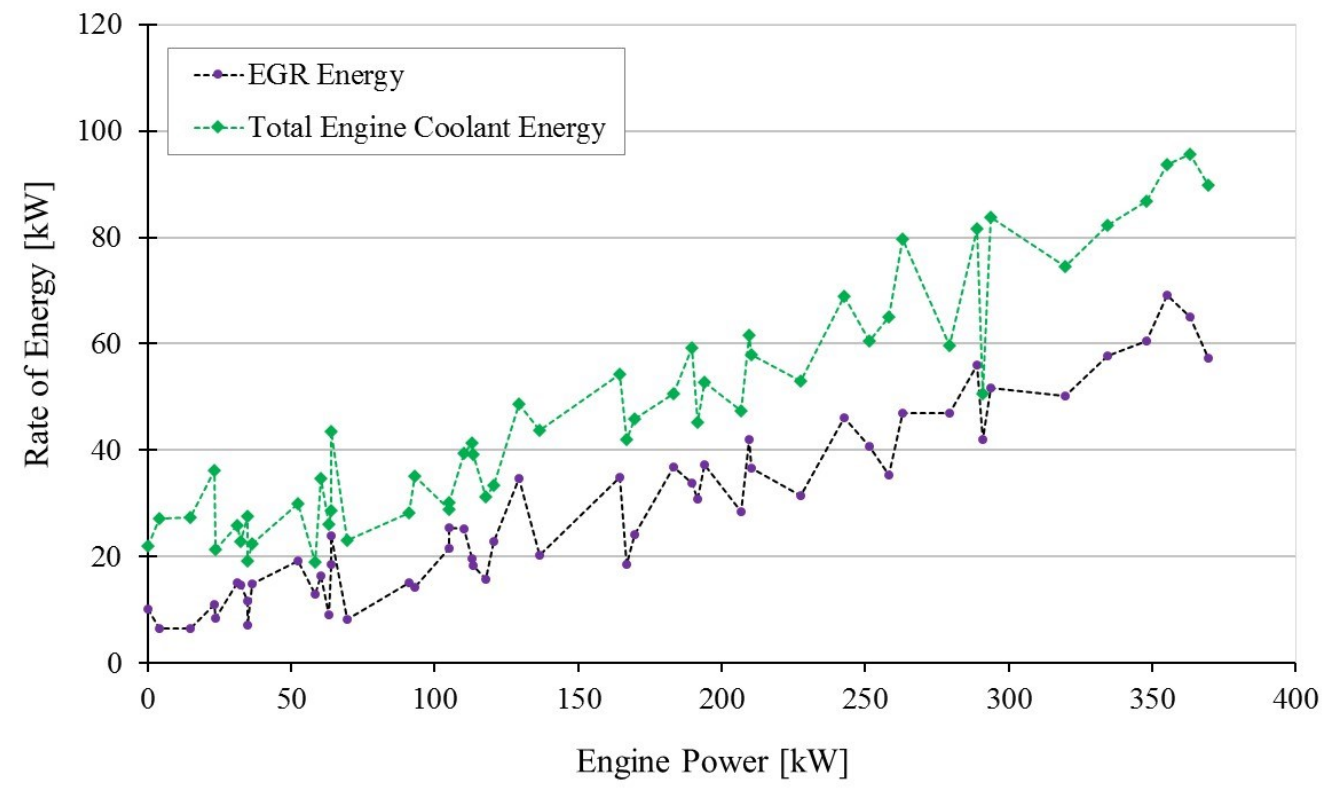

Figure 29. Total coolant energy including EGR energy 


\subsection{ORC-WHRS Results}

\subsubsection{Working Fluid Comparison}

Figure 30 shows the comparison of total output work generated by different working fluids for the model configured with two input heat sources; HX1 (exhaust post-SCR) and HX2 (EGR). It is clearly observed that all three fluids exhibits increasing cycle output with increase in engine power demand. Similar trend as of the exhaust and EGR energy seen during the energy analysis earlier. Working fluid, R123 showed the best performance with the maximum cycle power $(24.6 \mathrm{~kW})$ generated at the highest engine power operating point $(369 \mathrm{~kW})$. R245fa showed similar performance as compared R123. The maximum power $(19.9 \mathrm{~kW})$ for the fluid was achieved at the same highest operated engine power. The cycle simulated with R134a fluid generated the lowest cycle output $(6.22 \mathrm{~kW})$ at maximum operated power.

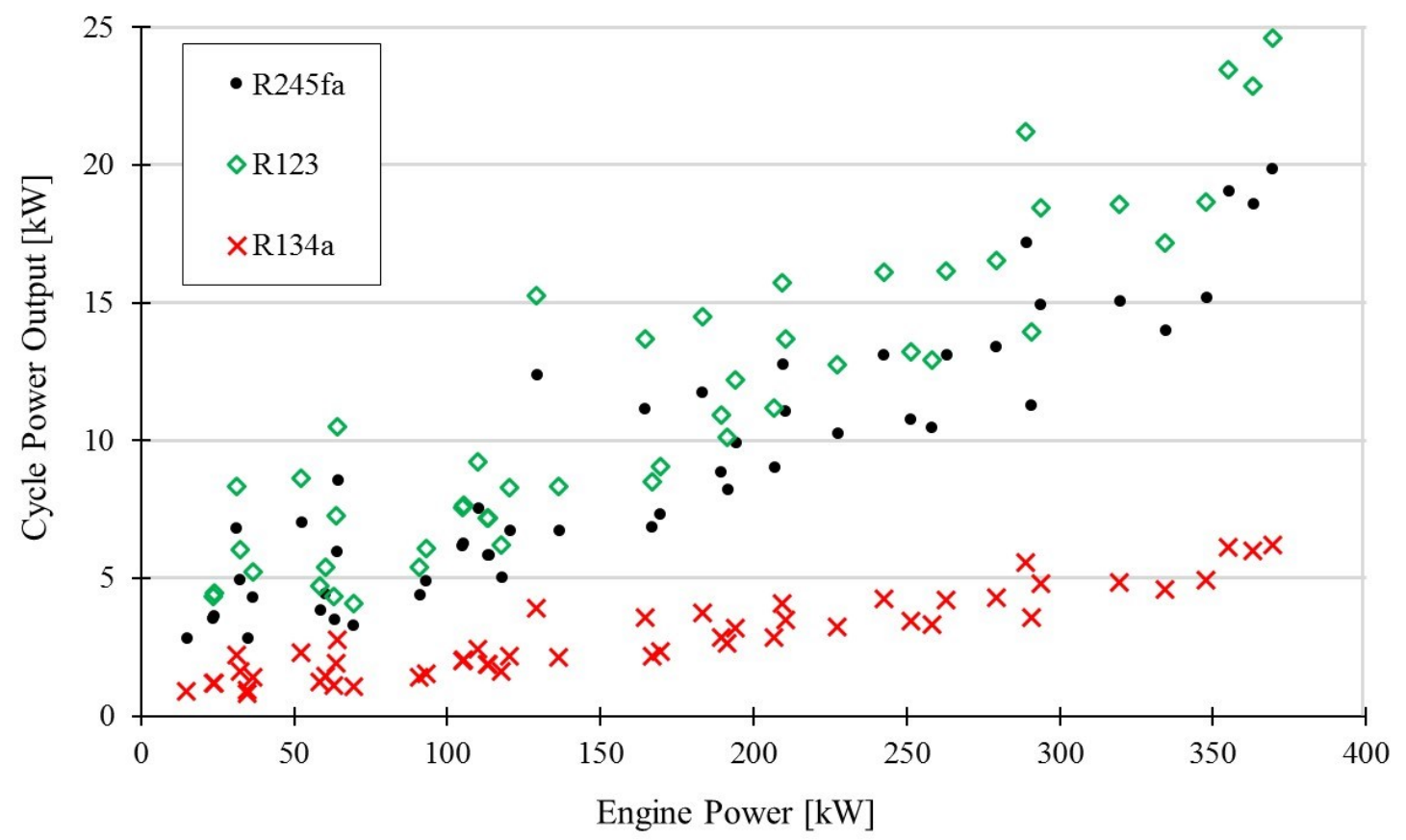

Figure 30. HX1 [Exhaust] - HX2 [EGR] Waste Heat Recovery for different working fluids 


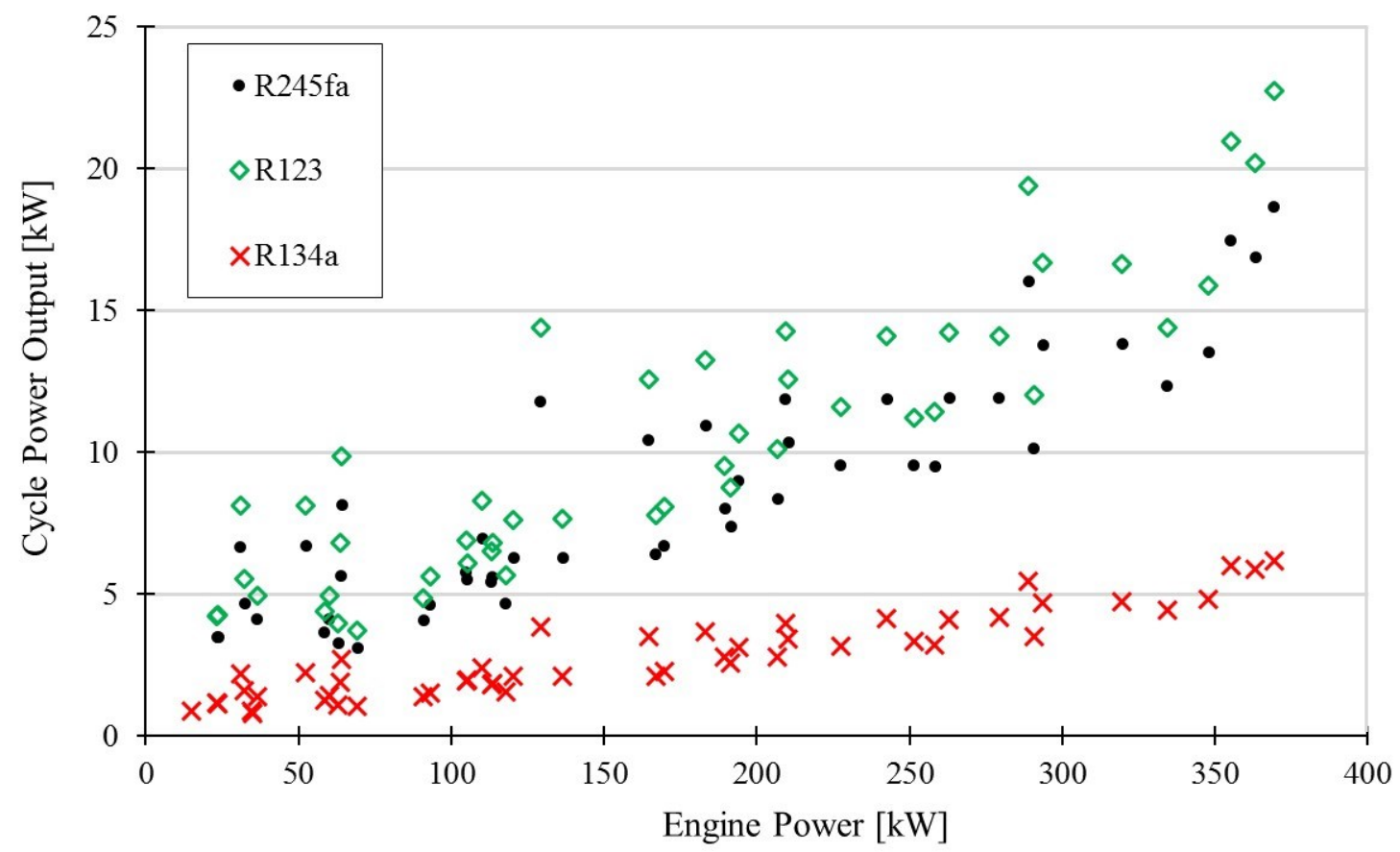

Figure 31. HX1 [EGR] - HX2 [Exhaust] Waste Heat Recovery for different working fluids

Figure 31 shows the working fluid comparison for the cycle output configured with using HX1 (EGR) and HX2 (exhaust post-SCR) as the two heat sources. Similar trends were observed for the performance as compared to the previous configuration. Comparing the three working fluids, the maximum cycle power of $22.7 \mathrm{~kW}$ for R123, $18.7 \mathrm{~kW}$ for R245fa, and $6.16 \mathrm{~kW}$ for R134a were generated at maximum engine operated power of $369 \mathrm{~kW}$.

Figure 32 shows the working fluid comparison for the cycle output configured with using HX1 (CAC) and HX2 (exhaust post-SCR) as the two heat sources. Once again, similar trends were observed for the performance as compared to the previous two configurations. The maximum cycle power of 23.2kW for R123, 19.1kW for R245fa, and 6.3kW for R134a were generated at maximum engine operated power of $369 \mathrm{~kW}$.

Figure 33 shows the working fluid comparison for the cycle output configured with using HX1 (CAC) and HX2 (EGR) as the two heat sources. For the defined configuration, less number 
of points are shown in the figure since the cycle was not able to meet the thermodynamic conditions to generate power, especially at lower engine speed/load conditions. Comparing the three working fluids, the maximum cycle power of $15 \mathrm{~kW}$ for R123, $12.3 \mathrm{~kW}$ for R245fa, and $2.5 \mathrm{~kW}$ for R134a were generated at maximum engine operated power of $363.2 \mathrm{~kW}$. Since, the availability of the EGR heat source was higher at $363.2 \mathrm{~kW}$ than at the maximum engine power operating condition, the cycle output generated was also observed higher. The cycle was not able to generate turbine work for majority of the operated points, mostly at lower speed/ load operating points due to insufficient energy to excite the working fluid to meet the cycle conditions.

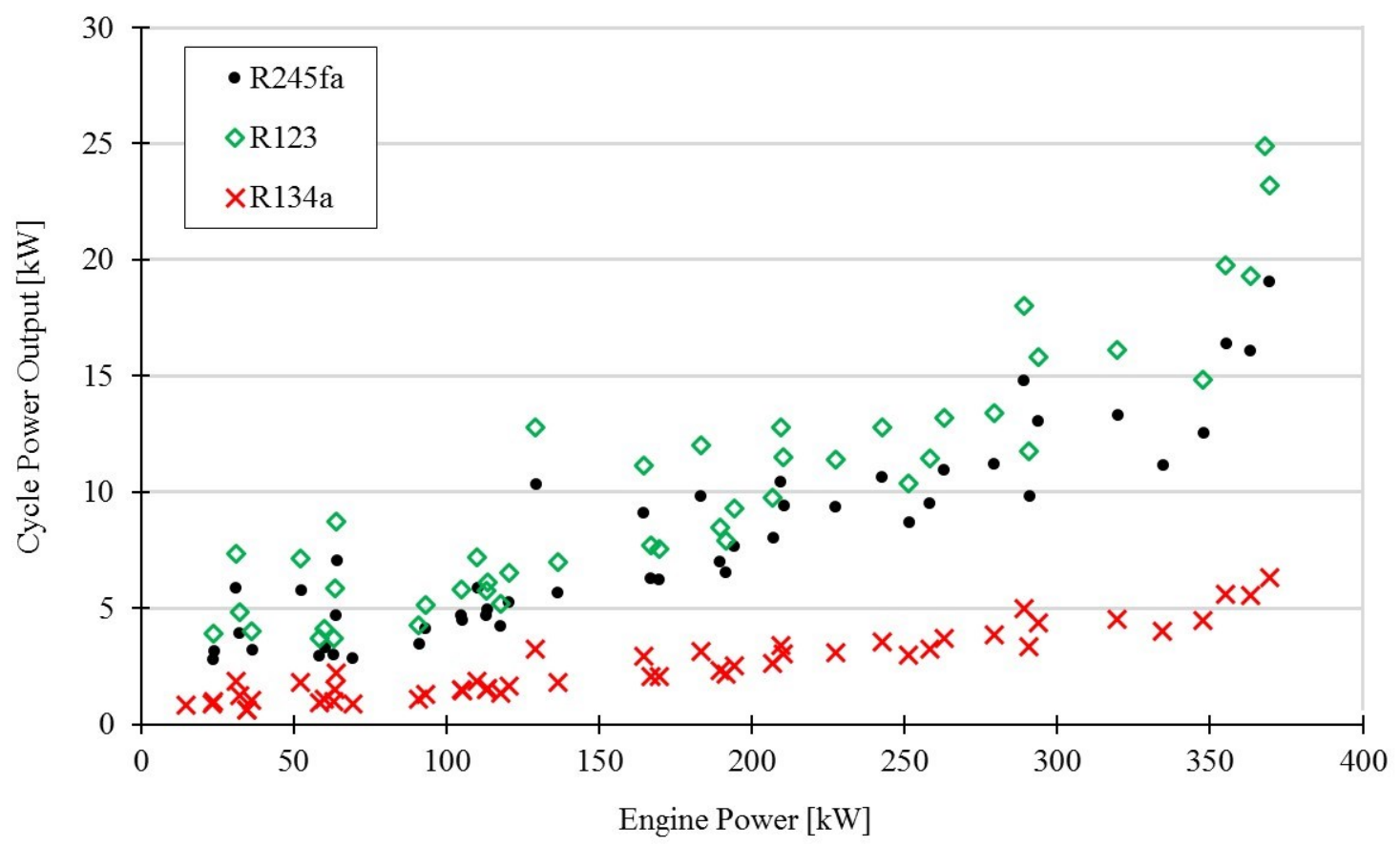

Figure 32. HX1 [CAC] - HX2 [Exhaust] Waste Heat Recovery for different working fluids 


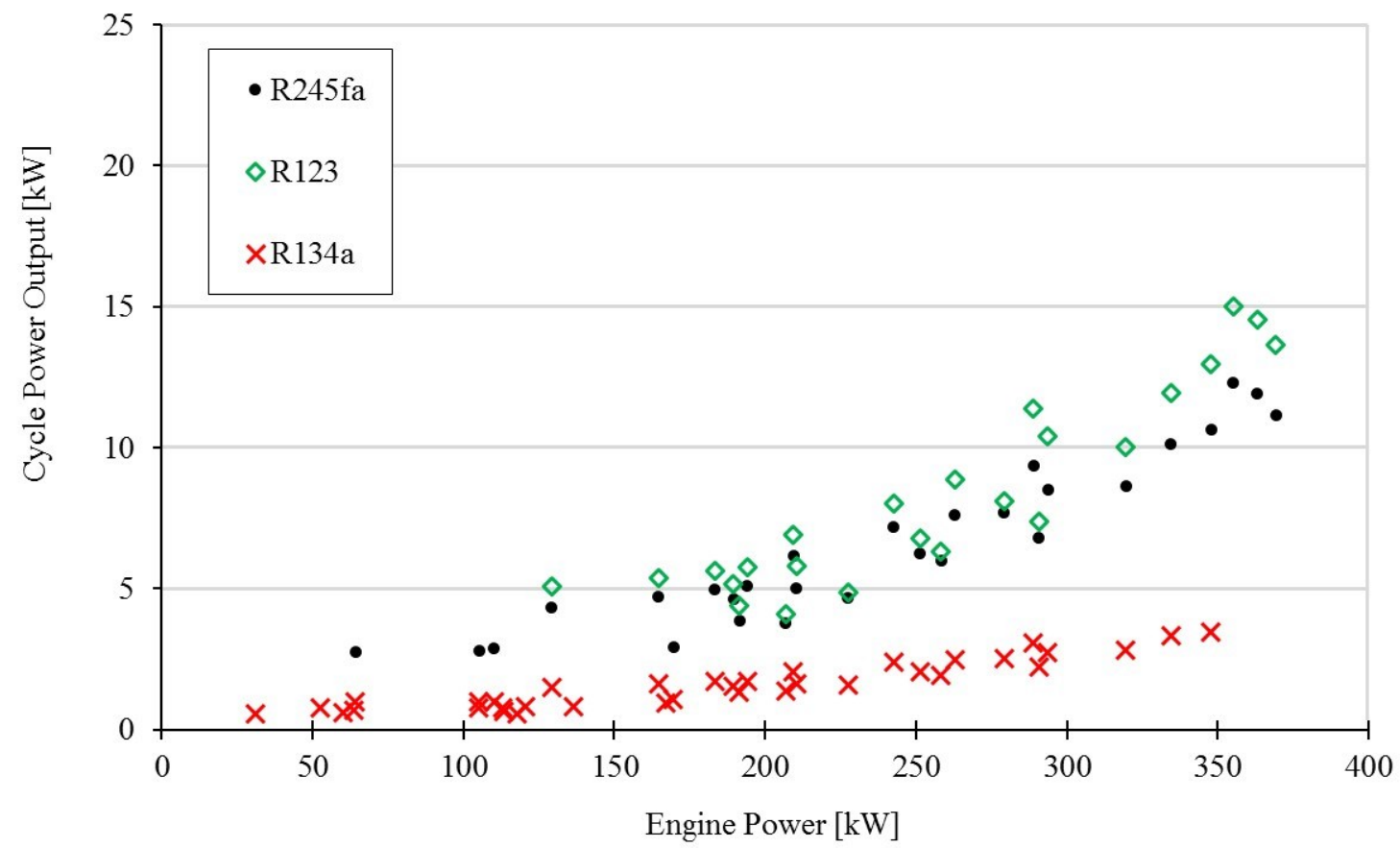

Figure 33. HX1 [CAC] - HX2 [EGR] Waste Heat Recovery for different working fluids

For the designed model with different heat source configuration, R123 and R245fa fluids provided the optimal performance. Reiterating, the cycle analyzed were based on the same system boundaries and thermodynamic conditions for all three fluids. However, better performance for R134a could potentially be achieved for the same heat sources if the evaporation pressure is increased. This would require design of a high pressure pump that could lead to potential issues related to durability and system cost. Comparison of the thermal efficiency along with the Carnot cycle efficiency of the system operating between the source and sink are provided by Table 10 . Under the system's different maximum cycle temperature (evaporator) with the same minimum temperature (condenser) for the three fluids, R123 resulted in the highest Carnot cycle efficiency of $22.9 \%$ with an actual efficiency of $13.5 \%$. R134a showed the actual cycle efficiency of only $2.1 \%$, while the idle efficiency was also low (3.4\%). The efficiency for R134a resulted in such low 
efficiency values was due to the cycle operating for a small temperature differences between the condenser $\left(\mathrm{T}_{\mathrm{L}}\right)$ and the evaporator $\left(\mathrm{T}_{\mathrm{H}}\right)$.

Table 10. Thermal cycle efficiency of ORC-WHRS model

\begin{tabular}{lccc}
\cline { 2 - 4 } & R123 & R245fa & R134a \\
\hline Carnot Cycle Efficiency & $22.9 \%$ & $18.2 \%$ & $3.4 \%$ \\
Actual Cycle Efficiency & $13.5 \%$ & $10.8 \%$ & $2.1 \%$ \\
\hline
\end{tabular}

\subsubsection{Heat Source Comparison}

Figure 34, Figure 35, and Figure 36 provides comparisons of the system performance based on four different proposed heat source configuration. With respect to all three fluid types, configuration with using post-SCR exhaust for the HX1 and EGR for the HX2 showed the best system performance than compared to other three. While, the configuration with using the two heat source, charge air cooler (CAC) for the HX1 and EGR for the HX2 showed the lowest system performance, and the simulation results also had the lowest amounts of points generated (below $150 \mathrm{~kW}$ engine power) out of the 53 defined points. This shows that at lower engine operating conditions, CAC and EGR sources would not be able to generate an useful work out of the design Rankine cycle.

Likewise, the energy recovered from outlet of the SCR assist in pre-heating the working fluid going through the first stage heat exchanger (HX1), and then utilizes the high quality heat from the EGR circuit in the second stage heat exchanger (HX2). This results in sufficient energy for the working fluid to reach the saturated vapor condition, relatively at higher working fluid mass flow rate which consequently provides better performance from the turbine. 


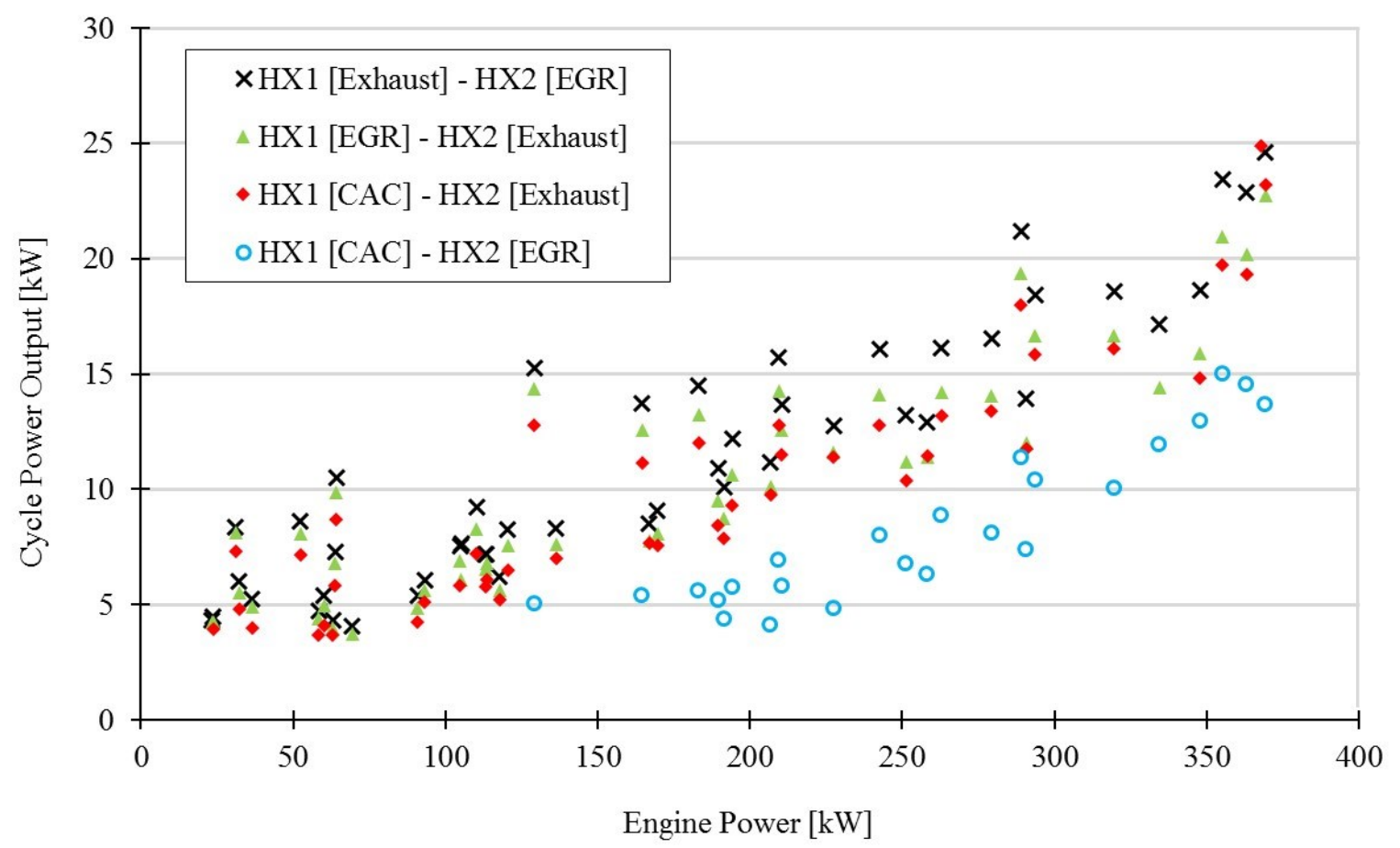

Figure 34. WHRS cycle output for different heat source configuration using R123

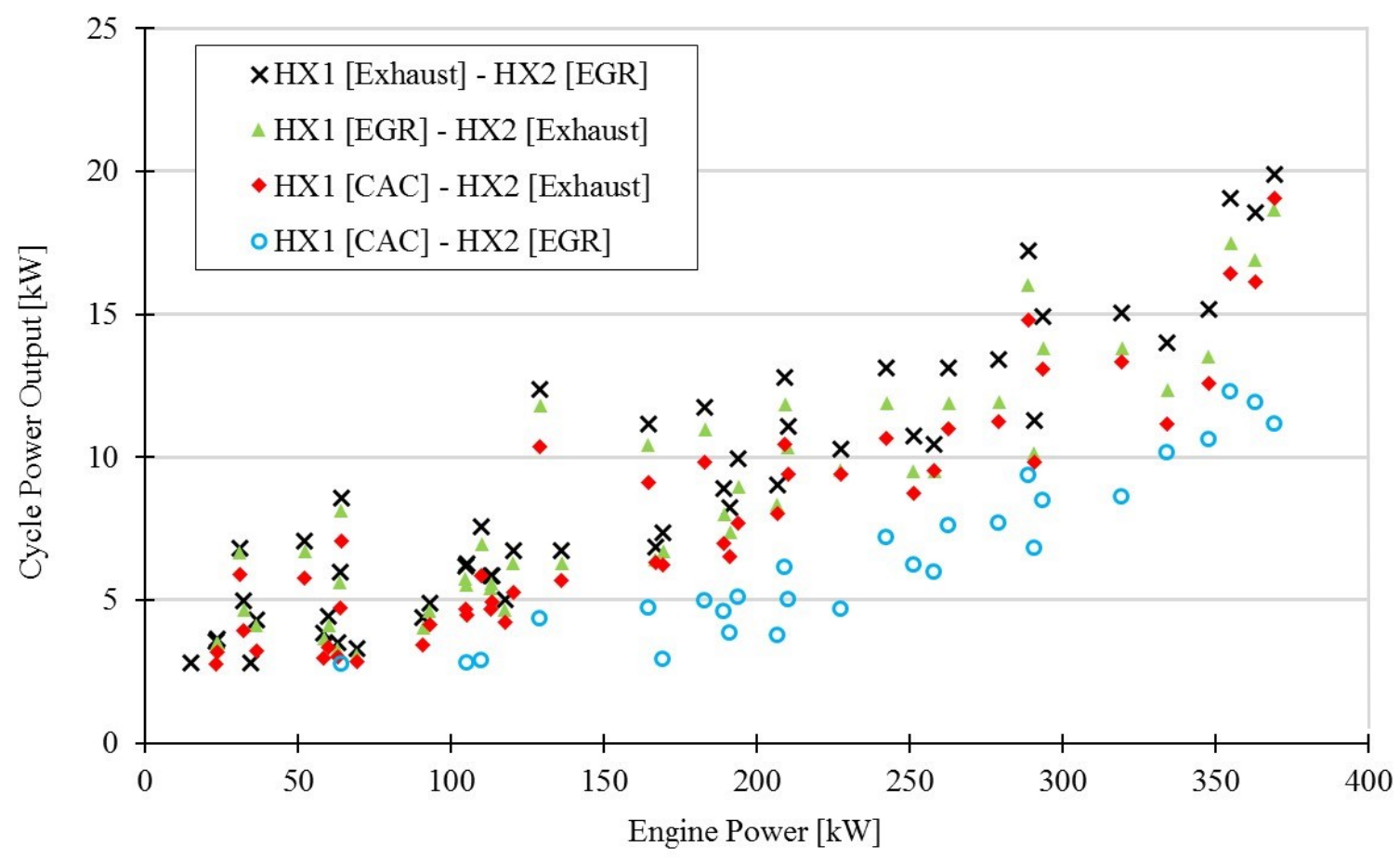

Figure 35. ORC-WHRS cycle output for different heat source configuration using R245fa 


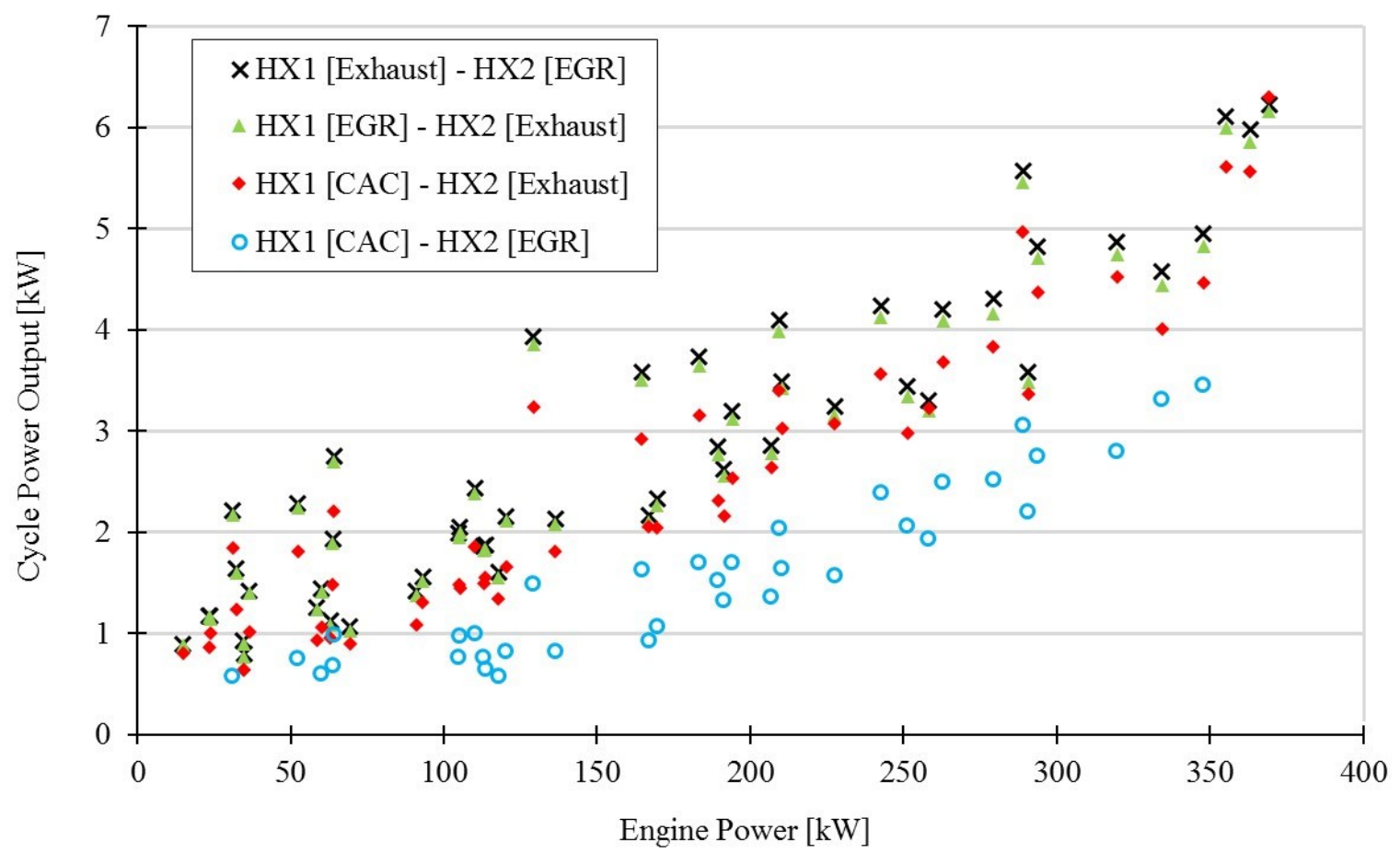

Figure 36. ORC-WHRS cycle output for different heat source configuration using R134a

It is to be noted from the above shown results that even though the ORC-WHRS models were able to simulate cycle power output at lower engine power demands, it would be misleading to represent ORC-WHRS output potential at lower engine operating conditions, mostly at lower speed/load points because of the variability observed during the measurement of the energy distribution. The availability for the Rankine cycles to generate output work was also limited due to the specified flow rate ranges which was pre-defined for the model based upon the selected pump characteristics. 


\section{CHAPTER 6 THERMAL MANAGEMENT POTENTIAL}

\subsection{Introduction}

As the primary goal of this study was to understand the utilization of a WHRS as a strategy for thermal management of an after-treatment system in reducing NOx levels, the study further investigates into the dynamic operation of a heavy-duty diesel engine from an actual vehicle testing results. This chapter details the thermal energy analysis from a similar Class-8 HDD vehicle. It also provides description of the methodology used in developing ORC-WHRS maps from the WHRS steady-state basis simulation results, and then used the developed maps to predict the potential WHRS output for a transient operation.

\subsection{Transient Data Source}

A similar Class-8 HDD vehicle equipped with standard DOC/DPF and SCR aftertreatment, tested on a chassis dynamometer testing performed by WVU CAFEE were used for this part of study. The vehicle specifications are provided in Table 11.

Table 11. Vehicle Specification

\begin{tabular}{|l|l|}
\hline Vehicle Manufacturer & Mack Trucks Inc. \\
\hline Vehicle Model & CXU613 \\
\hline Vehicle model year & 2011 \\
\hline Engine Model & MP8 $-445 \mathrm{C}$ \\
\hline Displacement (L) & 12.8 \\
\hline After-treatment system & DPF-SCR \\
\hline GVWR & $52,000 \mathrm{lbs}$ \\
\hline
\end{tabular}

Results obtained from a transient test cycle, known as Urban Dynamometer Driving Schedule (UDDS) with a specific cold-start test was used for the analysis. As the vehicle was not instrumented for the purpose of performing a complete energy audit, limited parameters were only 
evaluated. Parameters such as vehicle speed, engine speed, engine load, and post/pre SCR exhaust temperatures were obtained from the ECU logged channels.

The above mentioned vehicle chassis testing was also performed with using the WVU's Heavy Duty Transportable chassis dynamometer lab, capable of performing emission measurements. A full scaled constant volume sampler (CVS) tunnel designed and maintained as per CFR 40 Part 1065 were used as the primary method in emission sampling and measurement. The exhaust mass flow rates needed for the purpose of this study were obtained from the data reduced as per CFR 40 Part 1065 method.

\subsection{Transient Cycle Energy Analysis}

A continuous time traced profile of vehicle speed and temperature before the SCR for the UDDS cycle is presented in Figure 37. On the basis of literature reviews, minimum temperature of $200^{\circ} \mathrm{C}$ was considered to be the threshold limit for the SCR inlet condition. It shows that during initial driving period (from start of the cycle to about 180 seconds) the temperature before the SCR system are below the threshold temperature which is represented by the red dotted lines in the figure. It also observed that the temperature falls below $200^{\circ} \mathrm{C}$ for about 40 seconds after a longer idle duration. Once the vehicle starts operating at a higher vehicle speed and long driving activity, the temperature tends to stay well above the threshold limit.

Maintaining the necessary pre-SCR temperatures above $200^{\circ} \mathrm{C}$ requires additional thermal energy. The additional required energy for the selected transient cycle to reach the threshold limit was evaluated using the mass flow rate of the exhaust, and the difference between the enthalpies at pre-SCR and the threshold temperature. The transient exhaust energy rate traces evaluated before the SCR and exhaust energy at $200^{\circ} \mathrm{C}$ for the UDDS cycle are shown in Figure 38. The 
additional heat required (shown by the green shaded region) to meet the threshold temperature of $200^{\circ} \mathrm{C}$ is the potential aim to be employed by the thermal management strategy in this study.

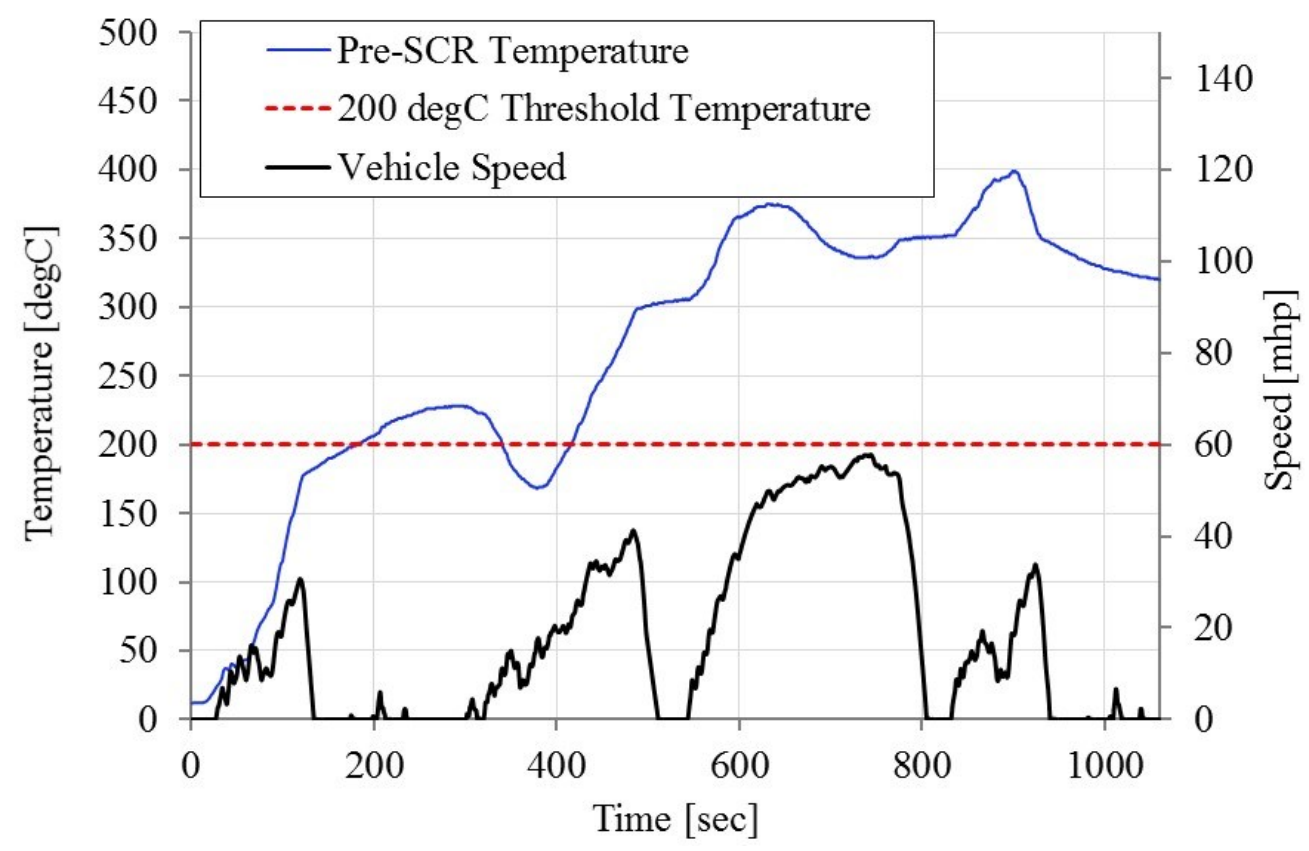

Figure 37. Pre-SCR temperature profile from a cold-start UDDS cycle vehicle-chassis test results

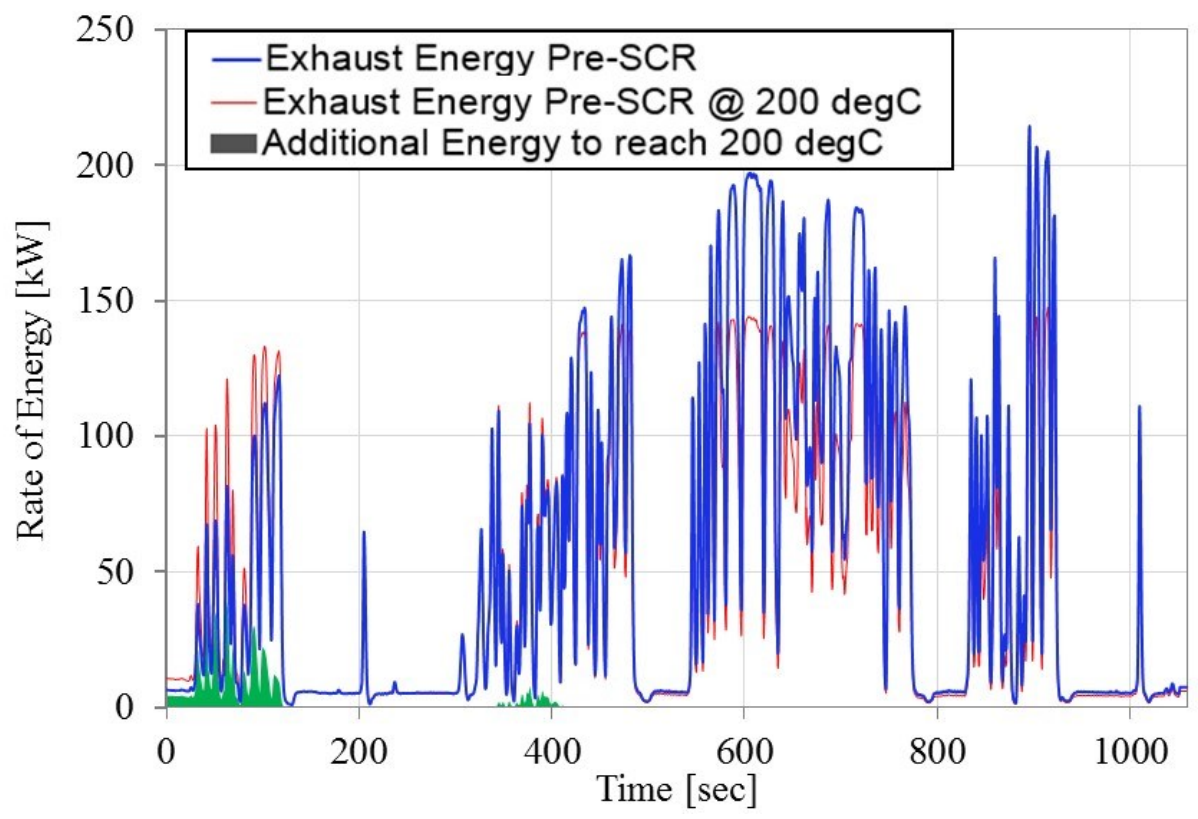

Figure 38. Pre-SCR exhaust energy thermal analysis on the UDDS cycle vehicle-chassis test results 


\subsection{ORC-WHRS Mapping}

In order to quantify the power generated by an ORC-WHRS model for the selected UDDS cycle, a complete instrumentation would have been required. The data collected from chassis vehicle testing included post-SCR temperatures and exhaust flow rates but no EGR temperatures. Hence, simulating the developed ORC-WHRS model in MATLAB ${ }^{\circledR}$ was not possible, but instead surface maps were generated for predicting the ORC-WHRS power output for the selected UDDS cycle.

Curve fitting tools were used to predict the ORC-WHR system's power output for the transient cycle based on the steady state simulation results. Results from R123 and R245fa fluids employed with HX1(exhaust post-SCR) and HX2(EGR) configuration were specifically used due to the optimum performance that were seen from the results obtained for the Mack MP8 engine. Three influential factors: speed in (rpm), torque in (ft-lbs) and post-SCR exhaust energy in (kW) were used as model inputs in developing the response surface. JMP ${ }^{\circledR}$ software tool was used for developing and analyzing the fitting model.

A second-order model over the steady state results for the three input factors provided reasonable approximation of the response than compared to a linear or higher other polynomials. The second-order model is represented by Eq. (24) (Montgomery, 2009).

$$
y=\beta_{0}+\beta_{1} x_{1}+\beta_{2} x_{2}+\beta_{3} x_{3}+\beta_{11} x_{1}^{2}+\beta_{22} x_{2}^{2}+\beta_{33} x_{3}^{2}+\beta_{12} x_{1} x_{2}+\beta_{13} x_{1} x_{3}+\beta_{23} x_{2} x_{3}
$$

Here, $\mathrm{y}$ is the model output response which is defined as the ORC-WHRS cycle power output, and the model input factors $\mathrm{x}_{1}, \mathrm{x}_{2}$ and $\mathrm{x}_{3}$ are defined with respect to speed, torque and postSCR energy respectively. The $\beta$ 's represents the partial regression coefficients parameters where it dictates the weightage of the input factors and the interactions between the input factors in the 
model. The JMP ${ }^{\circledR}$ software estimates the parameters for the second-order polynomial using the method of least squares. The summary of the parameter estimates for the two working fluid response surface models are provided in APPENDIX - B.

From the fit summary for the two models, an $\mathrm{R}^{2}$ of (0.945) for R123 and (0.955) for R245fa were obtained. It is to be noted that a better prediction of the output response could have been obtained if a fourth input factor EGR were also used in fitting the second-order model.

Figure 39 and Figure 40 presents the predicted response surface of the ORC-WHR system's power output as a contour profile where the horizontal axis represents the engine speed and the vertical axis represents the engine torque. The boundary of the contour map is defined by the obtained points resulted from the ORC-WHRS system operated for specific engine speed/load points.

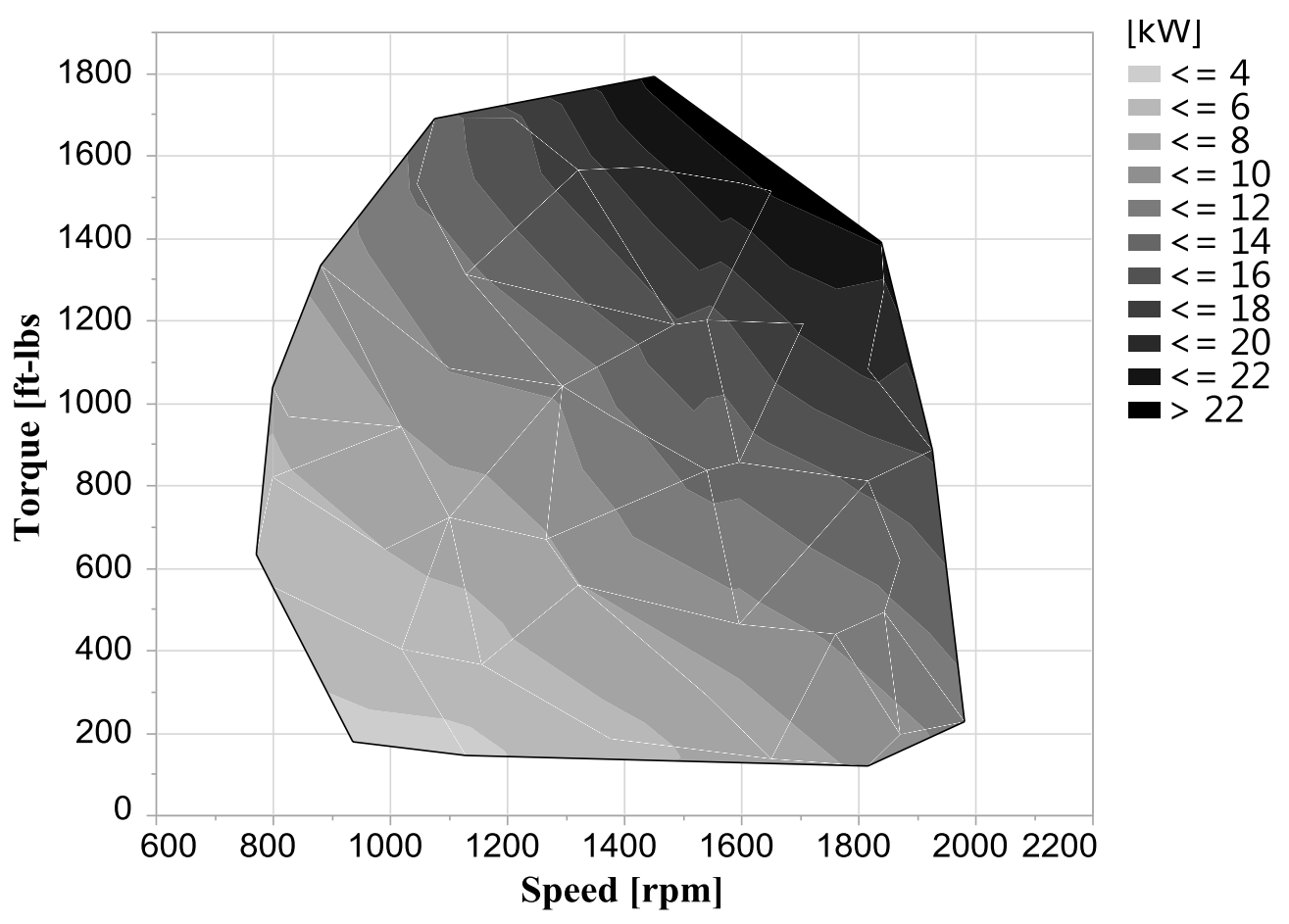

Figure 39. ORC-WHRS cycle output power map for HX1(exhaust post-SCR) and HX2(EGR) using R123 


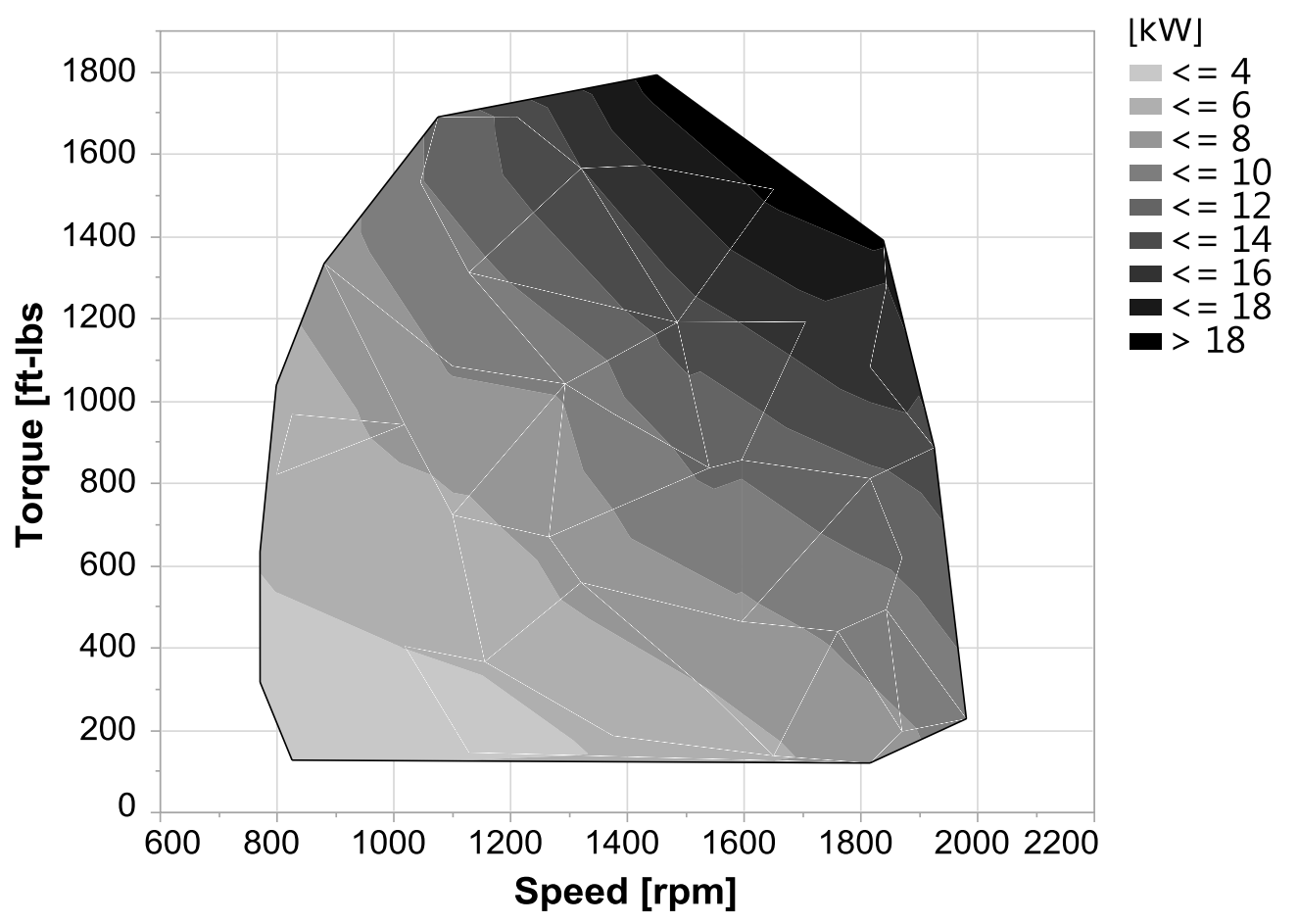

Figure 40. ORC-WHRS cycle output power map for HX1(exhaust post-SCR) and HX2(EGR) using R245fa

\subsection{ORC-WHRS Transient Results}

Respective maps developed for the two working fluids were used to estimate the ORCWHRS cycle power output for the transient process. Transient profiles of the three input factors: engine speed, engine torque and post-SCR energy obtained from the UDDS test data are shown in Figure 41. As mentioned earlier in this study, generating WHR output at low speed and toque condition would not be practical, hence for the study, ORC-WHRS cycle power output were set to zero if the engine operating power was equal to less than $75 \mathrm{~kW}$.

Figure 42 provides the results obtained from the ORC-WHRS, comparing the two working fluids. The estimated cycle output for both R123 and R245fa showed transient correlation with the three input traces. For the transient cycle, the maximum ORC-WHR cycle power output for R123 and $\mathrm{R} 245 \mathrm{fa}$ resulted in $15.1 \mathrm{~kW}$ and $11.6 \mathrm{~kW}$, respectively. 


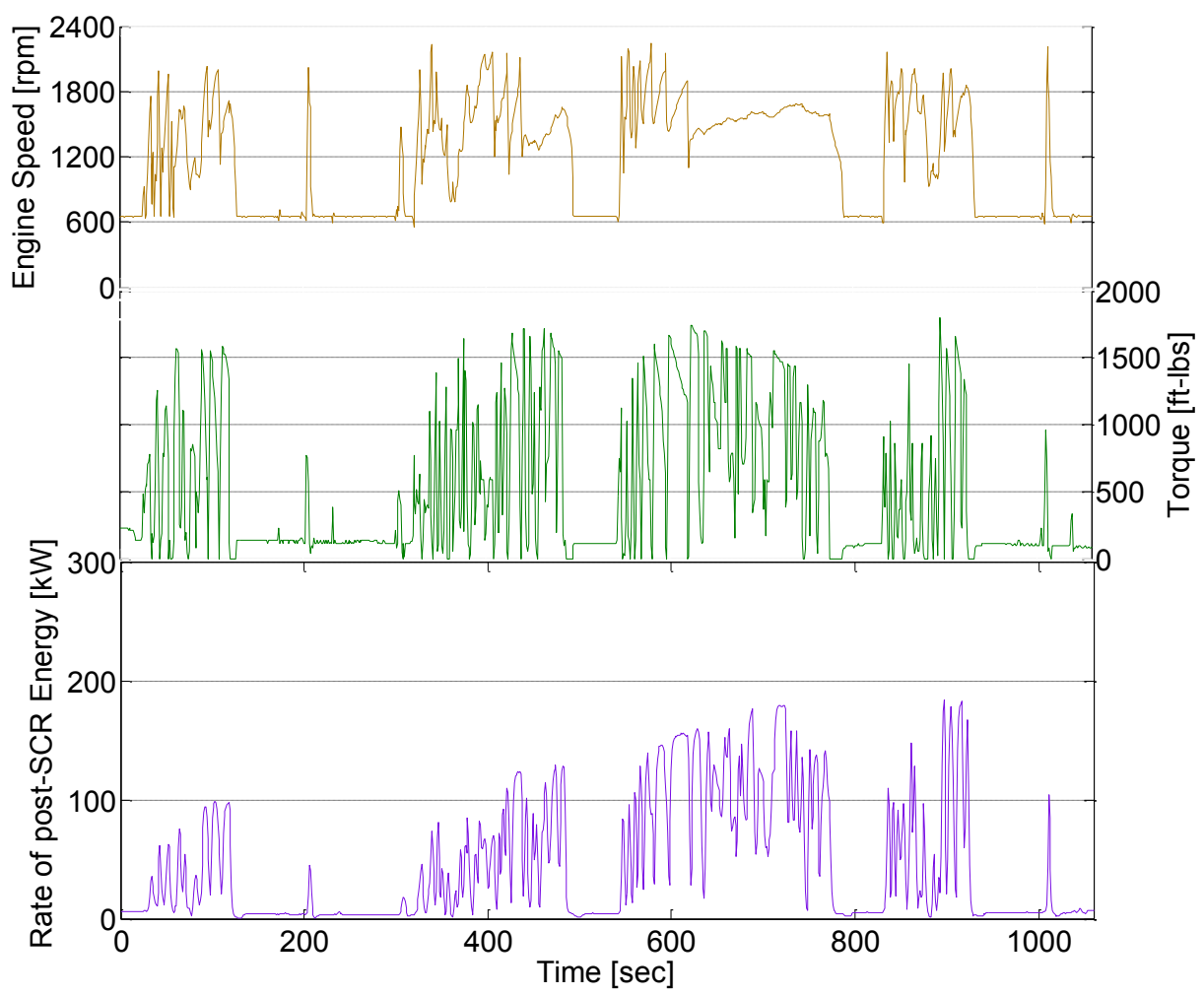

Figure 41. Transient input factor profiles

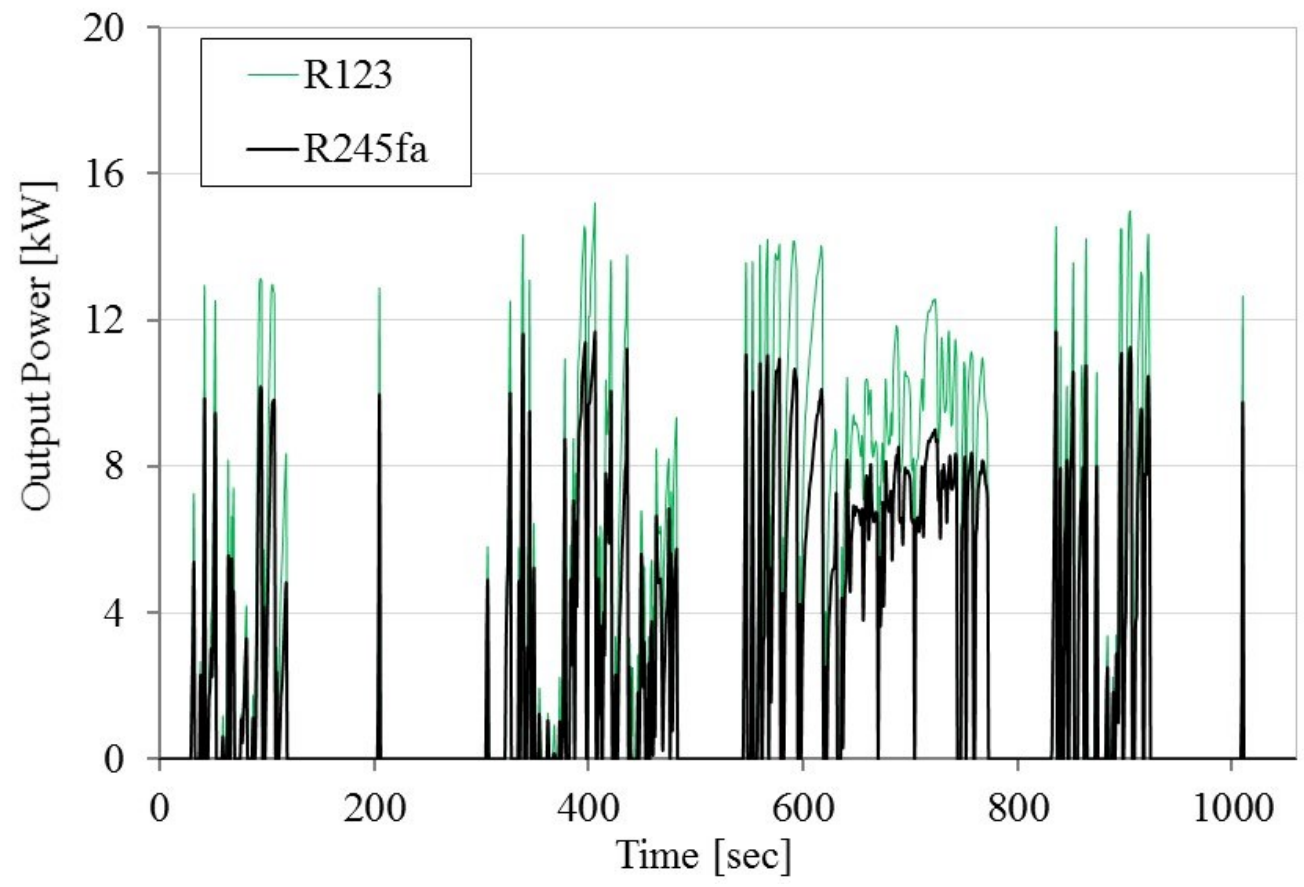

Figure 42. ORC-WHRS power generated for HX1 [Exhaust] - HX2 [EGR] WHRS on UDDS cycle 
In terms of total energy accumulated for the UDDS cycle, both R123 with $0.987 \mathrm{~kW}-\mathrm{hr}$ and R245fa with $0.692 \mathrm{~kW}-\mathrm{hr}$ resulted in exceeding the cumulative energy of $0.432 \mathrm{~kW}$-hr required by the pre-SCR catalysts to reach the threshold temperature of $200^{\circ} \mathrm{C}$ as shown in Figure 43 . R123 and R245fa were able to produce $56.2 \%$ and $37.6 \%$ more energy respectively over the entire UDDS cycle as compared to required thermal energy before the SCR.

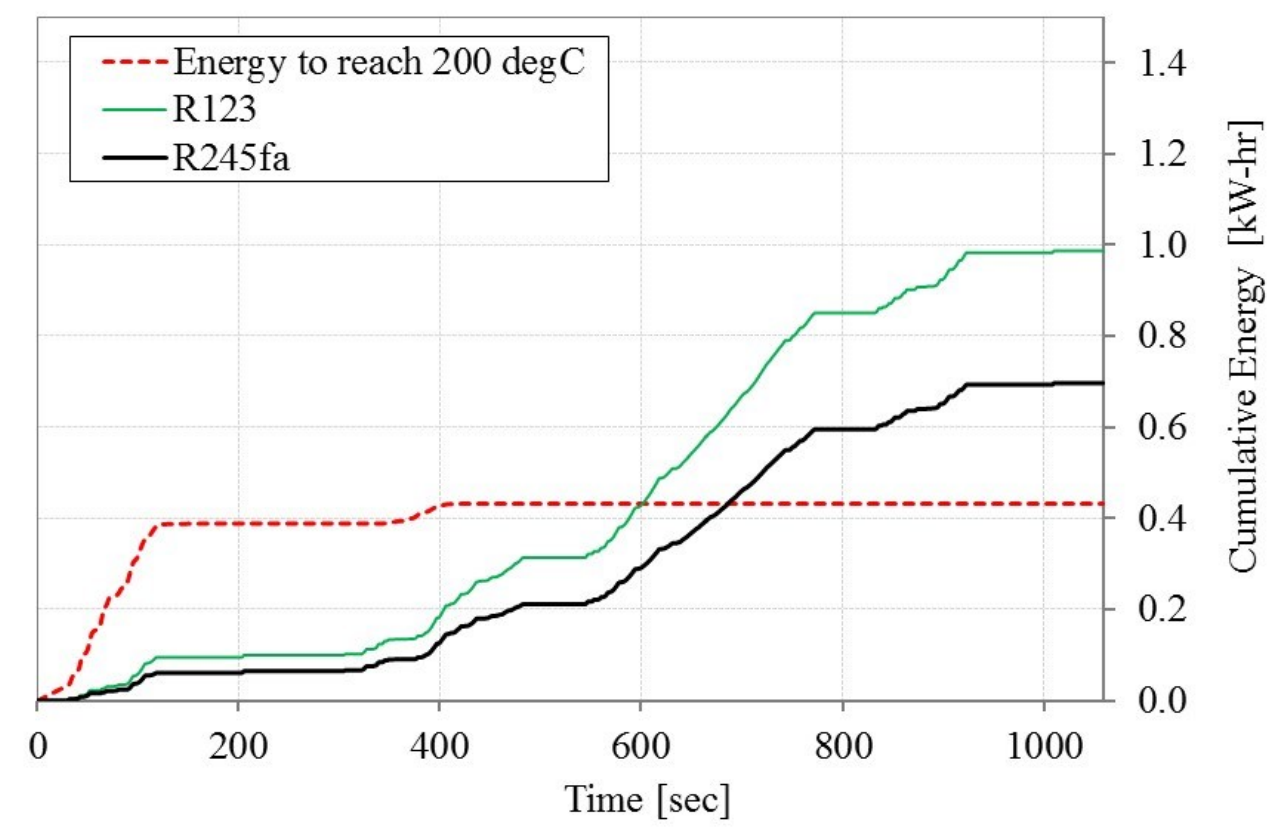

\section{Figure 43. Cumulative energy results using ORC-WHRS output on UDDS cycle}

The results obtained underlines the magnitude of thermal energy in the exhaust system for proper SCR activation, and a potential source provided to sufficiently meet the energy requirement, assuming that all the energy recovered is completely utilized in raising the thermal energy of the exhaust stream before the SCR catalyst. However, during vehicle start-up period there wouldn't be any opportunity in generating power from an ORC-WHRS which could be utilized for thermal management purposes. 


\subsection{Thermal Management Strategy}

This section details the thermal management strategy implementation of an electrically heated SCR catalyst using the power source obtained from the ORC-WHRS development. Figure 44 shows a simple schematic of a vehicle exhaust system integrated for an electrical heater. As a probable control technique, using an electrical heater with power usage from a pre-charged vehicle's internal battery (secondary source) for pre-heating the SCR catalyst during initial warmup period or even before the engine is started, and then utilizing the accumulated energy from the ORC-WHRS for charging the external battery which would be the primary source for the electrical heater. The warm-up phase would consist of warming up the pre-SCR air stream in order for the catalyst to reach its proper operating temperatures.

As control strategy presented in Figure 45 for the first 450 seconds of the UDDS cycle, the catalyst could be pre-heated before the engine starts (key-on), and since there would be no exhaust flow before engine key-on, an external air pump would be required at such events. The pump would also be powered from the same energy source. The duration of the pre-heating time depends upon the temperature requirement of the SCR system.

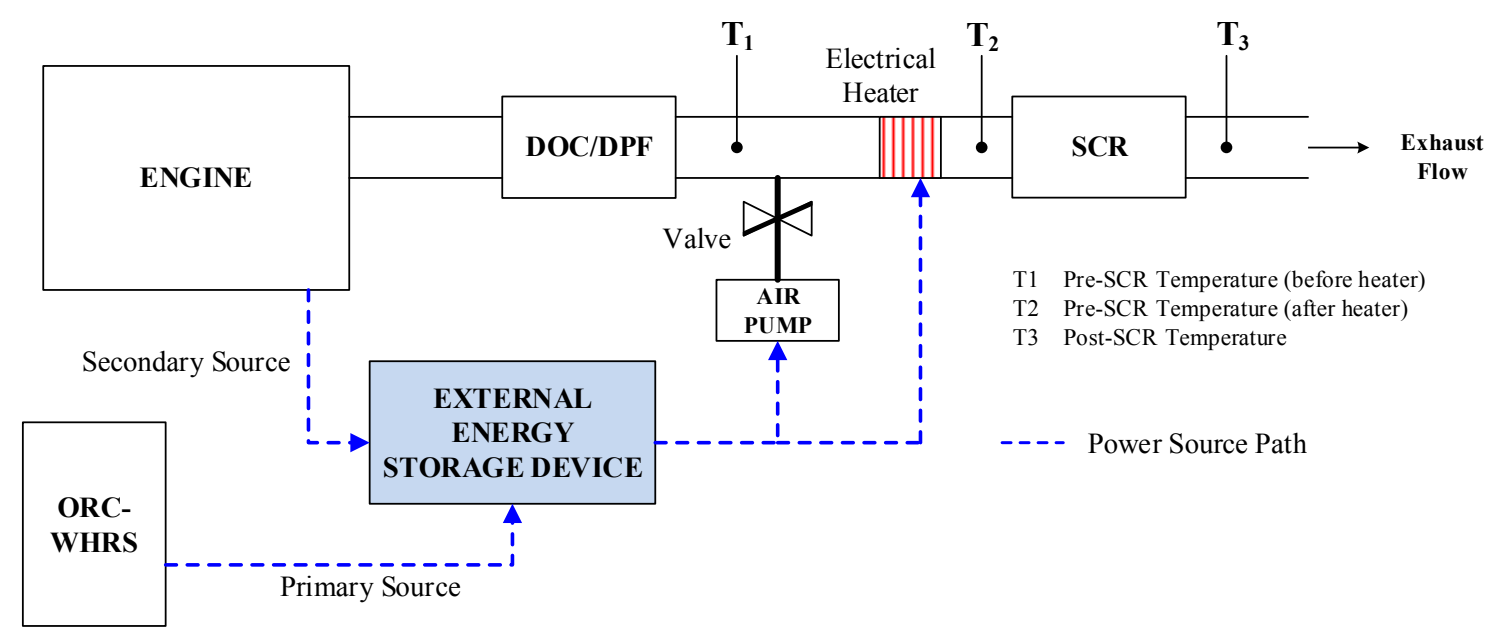

Figure 44. Schematic of a thermal management using ORC-WHRS as the power source 


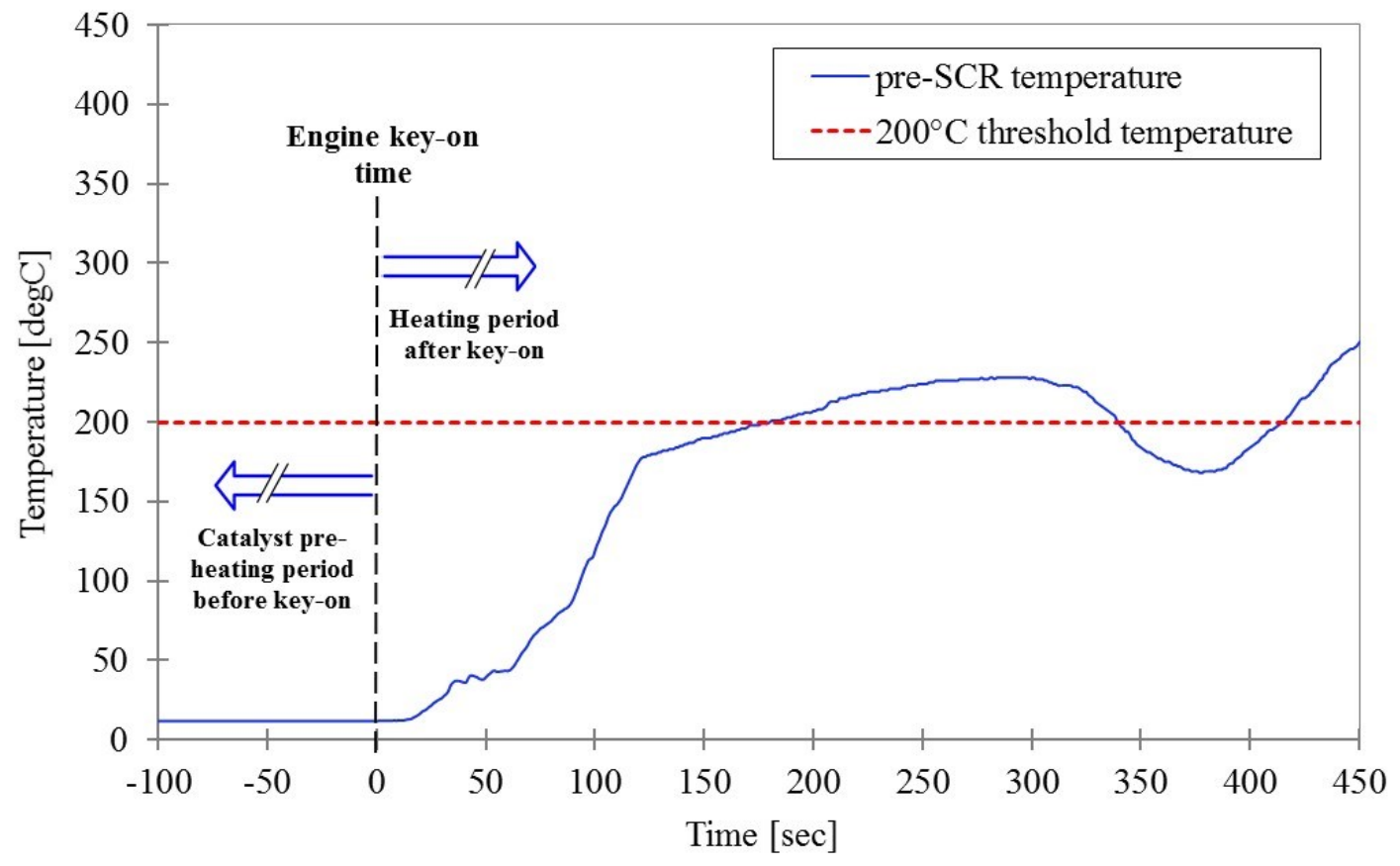

Figure 45. Catalyst pre-heating strategy before and after engine key-on

For implementation of such thermal management strategies, monitoring of internal substrate temperatures would be required as a feedback control: both during pre- and post- engine key-on phases. In real-time based system controls, due to thermal inertia and transport delay, physical-based SCR catalyst models are needed to be investigated and developed for implementing advanced control strategies. Hence, development of system models along with advanced feedback information from different exhaust sensors could be incorporated for managing the thermal state of the SCR system during vehicle warm-up and varying driving conditions. Moreover in the light of this study, the vehicle's primary battery source would only be utilized for the initial warm-up period and rest of the power required for employing the proposed thermal management could solely be consumed from the secondary battery source storing energy obtained from the ORCWHR system: harvesting potential energy from different sources that are considered as losses in a modern heavy-duty diesel engine. 


\section{CHAPTER 7 CONCLUSIONS AND FUTURE WORK}

\subsection{Conclusions}

In this study, a theoretical waste heat recovery system model was approached based on experimental data obtained from MY2011 Mack MP8 heavy-duty diesel engine testing. As a supporting investigation, the preliminary energy analysis applied under wide range of the engine operating over steady state conditions showed that suitable energy could possibly be extracted from the EGR loop exhibiting high quality heat. Likewise, post-SCR exhaust stream and charge air cooler (CAC) circuit also showed potent candidate in heat recovery. This lead to developing an ORC-WHRS model to include two heat exchangers and evaluating different configuration of heat sources. The study also evaluated three different types of organic fluids (R123, R245fa, and R134a) which are seen to be used in relevant works demonstrated in other studies.

Results obtained from a standard ORC-WHRS simulation over the engine operating points showed that R123 and R245fa gave the optimum performance under the selected characteristics and assumptions made within the study. The optimum WHRS cycle performance was achieved by pre-heating the working fluid using the post-SCR exhaust stream, and then using the EGR circuit to further heat the fluid to reach the saturated vapor conditions.

As the main objective of this study was to identify a thermal management approach for maintaining proper SCR operating temperatures during dynamic vehicle operation. Hence, testing results from a vehicle chassis dynamometer study was analyzed in order to estimate the ORCWHRS output on a transient basis. Result showed that R123 and R245fa based ORC-WHRS simulation were able to produce $56.2 \%$ and $37.6 \%$ more energy respectively over the UDDS cycle as compared to required thermal energy required to maintain the pre-SCR temperature at $200^{\circ} \mathrm{C}$. 
This study does realizes that extraction of work from the WHR cycle to be immediately used for thermal management is not possible. However, this study presents a thermal management scenario wherein utilizing an energy storage system for powering an electrical heater and replenishing the energy back through the ORC-WHRS when sufficient engine conditions are achieved.

\subsection{Future Work}

1. On this basis of future work, this study could further investigate into ORC-WHRS potential using actual on-road vehicle data operating on diverse operations.

2. Also possibly look into development of ORC-WHR system for conducting actual experimental work.

3. Research and development into physical-based thermal model of a vehicle exhaust system equipped with aftertreatment devices

4. Development of control strategies applied for optimization of aftertreatment thermal activity under different levels of vehicle operation. 


\section{References}

ARNOLD, S., SLUPSKI, K., GROSKREUTZ, M., VRBAS, G., ROB, C. \& SHAHED, S. M. 2001. Advanced Turbocharging Technologies for Heavy-Duty Diesel Engines. SAE, 2001-01-3260.

ARUNACHALAM, P. N., SHEN, M., TUNER, M., TUNESTAL, P. \& THERN, M. 2012. Waste Heat Recovery from Multiple Heat Sources in HD Truck Diesel Engine using a Rankine Cycle - A Theoretical Evaluation. SAE, 2012-01-1602.

AVADHANUlA, V. K., CHUEN-SEN, L. \& JOHNSON, T. 2013. Testing a 50kW ORC at Different Heating and Cooling Source Conditions to Map the Performance Characteristics. SAE, 2013-011649.

BAE, S., HEO, H., LEE, H. \& LEE, D. 2011. Performance Charateristics of a Rankine Steam Cycle and Boiler for Engine Waste Heat Recovery. SAE 2011-28-0055.

BIRKHOLZ, U. Conversion of Waste Exhaust Heat in Automobile using FeSi2 Thermoelements. 7th International Conference on Thermoelectric Energy Conversion, 1988 Arlington, USA. pp. 124128.

BOSCH, H. \& JANSSEN, F. 1988. Catalytic Reduction of Nitrogen Oxides. Catalysis Today, vol. 2, pp. v.

CAVINA, N., MANCUNU, G., CORTI, E., MORO, D., CESARE, M. D. \& STOLA, F. 2013. Thermal Management Strategy for SCR After Treatment Systems. SAE, 2013-24-0153.

CHANDLER, G. R., COOPER, B. J., HARRIS, J. P., THOSS, J. E., UUSIMAKI, A., WALKER, A. P. \& WARREN, J. P. 2000. An Integrated SCR and Continuously Regenerating Trap System to Meet Future NOx and PM Legislation. SAE, 2000-01-0188.

COZZOLINI, A., BESCH, M. C., KAPPANNA, H., BONSACK, P. \& GAUTAM, M. Waste Heat Recovery in Heavy-Duty Diesel Engines: A Thermodynamic Analysis of Waste Heat Availability for Implementation of Energy Recovery Systems based upon the Organic Rankine Cycle. ASME 2012 International Combustion Engine Division Spring Technical Conference, 2012 Torino, Piemonte, Italy.

ETTIREDDY, P. R., KOTRBA, A. \& SPINKS, T. 2014. Development of Low Temperature Selective Catalytic Reduction (SCR) Catalyst for Future Emissions Regulations. SAE, 2014-01-1520, 2.

GIANNELLI, R., NAM, E., HELMER, K., YOUNGLOVE, T., SCORA, G. \& BARTH, M. 2005. HeavyDuty Diesel Vehicle Fuel Consumption Modeling based on Road Load and Power Train Parameters. SAE, 2005-01-3549.

GIESHOFF, J., SCHÄFER-SINDLINGER, A., SPURK, P. C. \& TILLAART, J. A. A. V. D. 2000. Improved SCR Systems for Heavy Duty Applications. SAE, 2000-01-0189.

GRAVEL, R. 2013. SuperTruck - An Opportunity to Reduce GHG Emissions while Meeting Service Demands [Online]. Asilomar Conference. Available:

http://www.its.ucdavis.edu/files/general/pdf/2013-08-21 Asilomar-2013-Gravel.pdf [Accessed $12 / 02 / 2014]$. 
HEYWOOD, J. B. 1988. Internal Combustion Engine Fundamentals, McGraw Hill.

INCROPERA, F. P., DEWITT, D. P., BERGAN, T. L. \& LAVINE, A. A. 2007. Fundamentals of Heat and Mass Transfer, 6th Edition, John Wiley \& Sons, Inc.

JMP 2012. JMP® Design of Experiments Guide.

JOHNSON, T. V. 2009. Diesel Emission Control in Review. SAE, 2012-01-0368.

KAMASAMUDRAM, K., CURRIER, N., SZAILER, T. \& YEZERESTS, A. 2010. Why Cu- and FeZeolite SCR Catalysts Behave Differently at Low Temperature. SAE, 2010-01-1182.

KEUPER, A., UNGER, H.-M. I., HUANG, J., BRESSLER, H. \& ALBRECHT, W. 2011. Investigations to Achieve Highest Efficiencies in Exhaust Gas After-Treatment for Commercial Vehicles using an SCR system. SAE, 2011-01-2201.

KOEBEL, M., ELSENER, M. \& KLEEMANN, M. 2000. Urea-SCR: A Promising Technique to Reduce NOx Emissions from Automotive Diesel Engines. Catalysis Today, vol. 59, pp. 335-345.

KOEBEL, M., ELSENER, M. \& MADIA, G. 2001. Recent Advances in the Development of Urea-SCR for Automotive Applications. SAE, 2001-01-3625.

KOEBEL, M., MADIA, G. \& ELSENER, M. 2002. Selective Catalytic Reduction of NO and $\mathrm{NO}_{2}$ at Low Temperatures. Catalysis Today, vol. 73, pp. 239-247.

KRÖCHER, O. 2007. Aspects of Catalyst Development for Mobile Urea-SCR Systems - from VanadiaTitania Catalysts to Metal-Exchanged Zeolites. Studies in Surface Science and Catalysis, vol. 171, pp. 261-289.

LATZ, G., ANDERSSON, S. \& MUNCH, K. 2012. Comparison of Working Fluids in both Subcritical and Supercritical Rankine Cycles for Waste-Heat Recovery Systems in Heavy-Duty Vehicles. SAE, 2012-01-1200.

LATZ, G., ANDERSON, S. \& MUNCH, K. 2013. Selecting an Expansion Machine for Vehicle WatseHeat Recovery Systems based on the Rankine Cycle. SAE, 2013-01-0552.

MAJEWSKI, A. W. 2014. Urea Dosing and Injection Systems [Online]. DieselNet. Available: http://www.dieselnet.com/tech/cat_scr_mobile_urea_dosing.php [Accessed 12/02/2014].

MISRA, C., COLLINS, J. F., SAX, T., KRISHNAMURTHY, M., SOBIERALSKI, W., BURNTIZKI, M. \& CHERNICH, D. 2013. In-Use NOx Emissions from Model Year 2010 and 2011 Heavy-Duty Diesel Enigines Eqipped with Aftertreatment Devices. Environmental Science and Technology, vol. 47, pp. 7892-7898.

MONTGOMERY, D. C. 2009. Design and Analysis of Experiments, 7th Edition, John Wiley \& Sons, Inc.

MORAN, M. J. \& SHAPIRO, H. N. 2008. Fundamentals of Engineering Thermodynamics, 6th Edition, John Wiley \& Sons, Inc.

NELSON, C. R. 2008. Waste Heat Recovery for Heavy Duty Vehicle. Cummins Inc.: Steam Power.

NOOR, A. M., PUTECH, R. C. \& RAJOO, S. 2014. Waste Heat Recovery Technologies in Turbocharged Automotive Engine - A Review. Journal of Modern Science and Teechnology, vol. 2, pp. 108119. 
SLUDER, C. S., STOREY, J. M. E., LEWIS, S. A. \& LEWIS, L. A. 2005. Low Temperature Urea Decomposition and SCR Performance. SAE, 2005-01-1858.

STANTON, D. W. 2013. Systematic Development of Highly Efficient and Clean Engines to Meet Future Commerical Vehicle Greenhouse Gas Regulations. SAE, 2013-01-2421.

TALUS, P., TENG, H., HUNTER, G. L., VELDE, B. V. D. \& KLAVER, J. 2011. A Rankine Cycle System for Recovering Watse Heat from HD Diesel Engines - Experimentla Results. SAE 201101-1337.

TENG, H., KLAVER, J., PARK, T., HUNTER, G. L. \& VELDE, B. V. D. 2011. A Rankine Cycle System for Recovering Waste Heat from HD Diesel Engines - WHR System Development. SAE, 2011-01-0311.

TENG, H. \& REGNER, G. 2009. Improving Fuel Economy for HD Diesel Engines with WHR Rankine Cycle driven by EGR Cooler Heat Rejection. SAE 2009-01-2913.

THEENGINEERINGTOOLBOX. Ethylene Glycol Heat - Transfer Fluid [Online]. Available: http://www.engineeringtoolbox.com/ethylene-glycol-d_146.html [Accessed 10/08/2014].

TURHILL. 2000. Performance Curves (Metric) L Series. Available: http://www.tuthillpump.com/dam/2463.pdf [Accessed 09/30/2014].

ULRICH, P., SCHATZ, A. \& KONIECZNY, R. 2012. Advanced Exhaust Gas Thermal Management for Lowest Tailpipe Emissions - Combining Low Emission Engine and Electrically Heated Catalyst. SAE 2012-01-1090.

USEPA. Engine Testing Regulations [Online]. Available: http://www.epa.gov/nvfel/testing/regulations.htm [Accessed 05/10/2014].

WANG, E. H., ZHANG, H. G., FAN, B. Y., OUYANG, M. G., ZHAO, Y. \& MU, Q. H. 2011. Study of Working Fluid Selection of Organic Rankine Cycle (ORC) for Engine Waste Heat Recovery. Energy, 2011-03-041. 


\section{APPENDIX A Pump Characteristics}

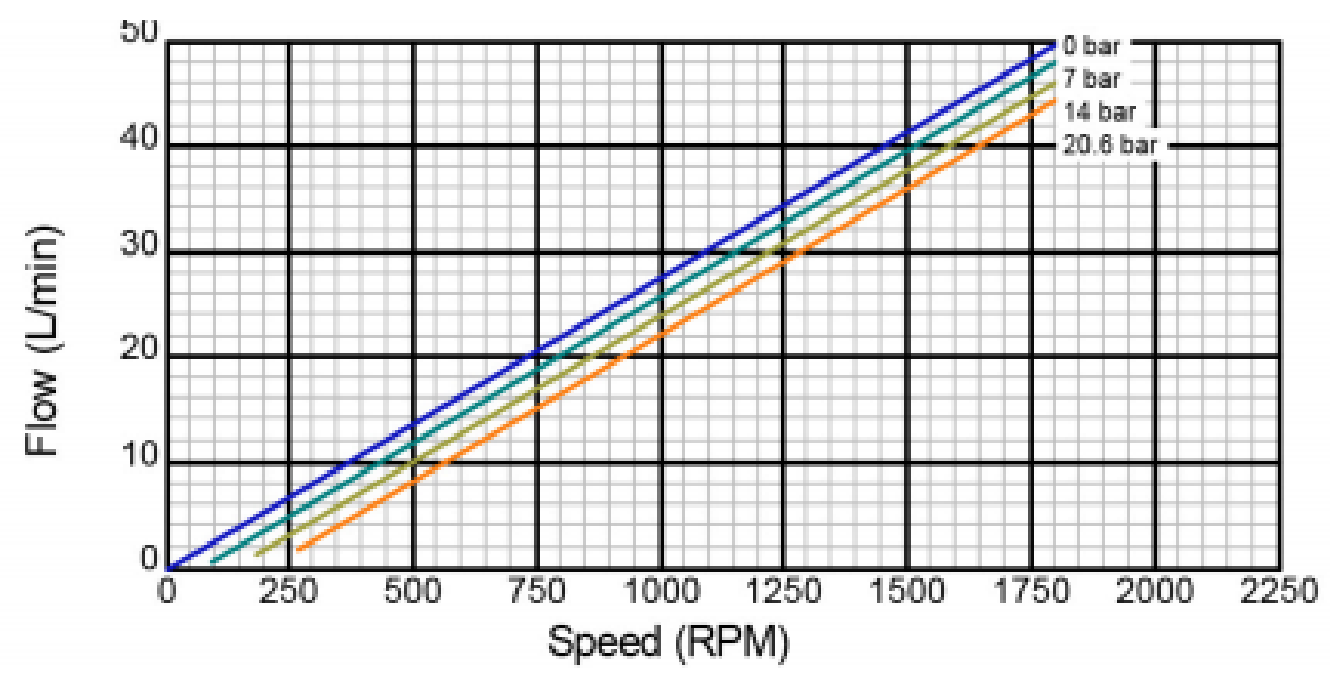

Figure A-1. Performance curve for the selected positive displacement pump (Turhill, 2000) 


\section{APPENDIX B ORC-WHRS Response Surface Results}

Following results provided the model fit summary and results used to predict the ORCWHRS output map for working fluid R123 and R245fa with HX1(post-SCR exhaust) and HX2(EGR) combination. Figure B-1, shows the actual versus predicted for R123 model fit. Table B-1 provides the summary of estimates for the partial regression coefficients parameters in the second order model. The units for speed, torque and post-SCR are defined in terms of rpm, ft-lbs and $\mathrm{kW}$. The table also provides p-values for each parameter term and signifies the parameter significance in the model's response. A low p-value illustrates a higher influence of the parameter in the model obtained. It shows that post-SCR has a significant influence in the model with a pvalue of $0.0281(<$ p-value of 0.05 at $\alpha=5 \%)$. Table B-1. Parameter estimate for second order response model of R123 data.

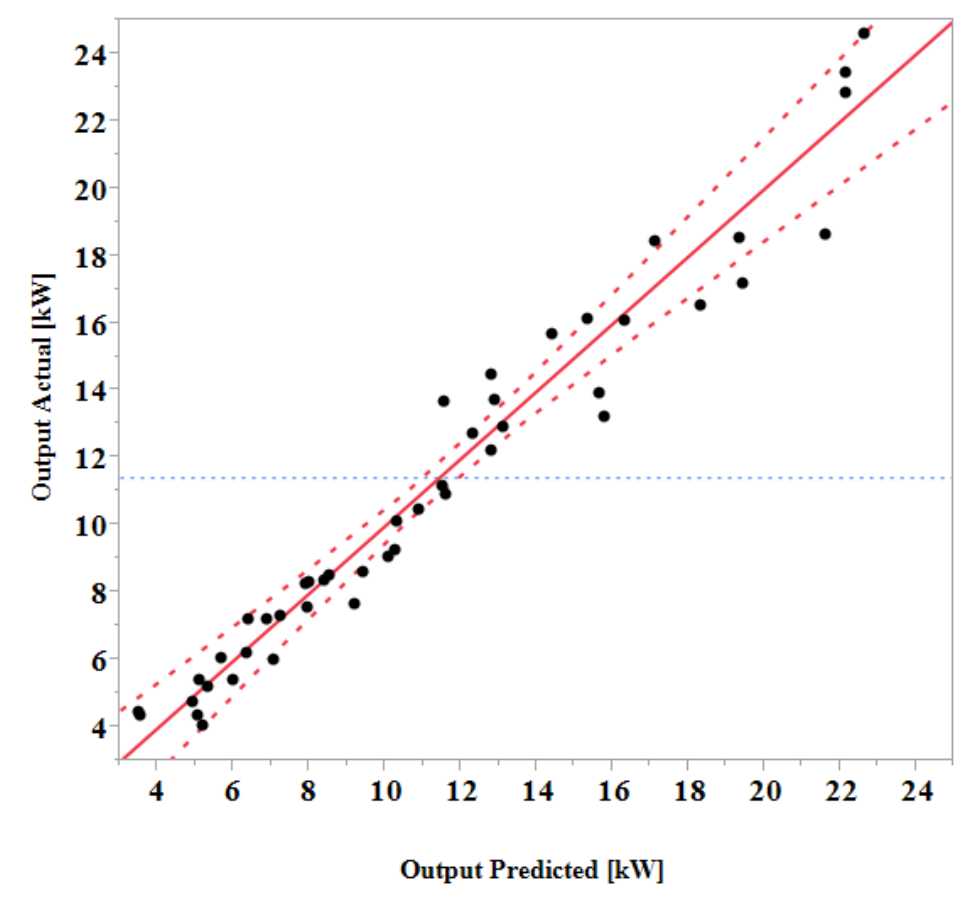

Figure B-1. Actual by predicted plot for second order response model for ORC-WHRS (R123) 
Table B-1. Parameter estimate for second order response model of R123 data

\begin{tabular}{|l|r|r|}
\hline \multicolumn{1}{|c|}{ Model Terms } & \multicolumn{1}{c|}{$\boldsymbol{\beta}$ Estimate } & \multicolumn{1}{c|}{ p-value } \\
\hline Intercept & 4.0638 & 0.5787 \\
\hline Speed [rpm] & -0.00207 & 0.7107 \\
\hline Torque [ft-lbs] & -0.00279 & 0.6041 \\
\hline Post SCR [kW] & 0.076893 & $\mathbf{0 . 0 2 8 1 *}$ \\
\hline (Speed [rpm]-1386.18)*(Speed [rpm]-1386.18) & $-4.18 \mathrm{E}-06$ & 0.9111 \\
\hline (Speed [rpm]-1386.18)*(Torque [ft-lbs]-1087.79) & $-3.37 \mathrm{E}-05$ & 0.6547 \\
\hline (Torque [ft-lbs]-1087.79)*(Torque [ft-lbs]-1087.79) & $-2.65 \mathrm{E}-05$ & 0.4773 \\
\hline (Speed [rpm]-1386.18)*(Post SCR [kW]-193.364) & 0.000113 & 0.7982 \\
\hline (Torque [ft-lbs]-1087.79)*(Post SCR [kW]-193.364) & 0.000257 & 0.5593 \\
\hline (Post SCR [kW]-193.364)*(Post SCR [kW]-193.364) & -0.00054 & 0.6735 \\
\hline
\end{tabular}

Figure B-2. Actual by predicted plot for second order response model for ORC-WHRS (R245fa)

Similarly, Figure B-2 shows the actual versus predicted for R245fa model fit. Table B-2 provides the summary of estimates for the partial regression coefficients parameters in the second order model. From the p-value results for the obtained model, it shows that post-SCR has a significant influence in the model with a p-value of $0.0168(<p$-value of 0.05 at $\alpha=5 \%)$. 


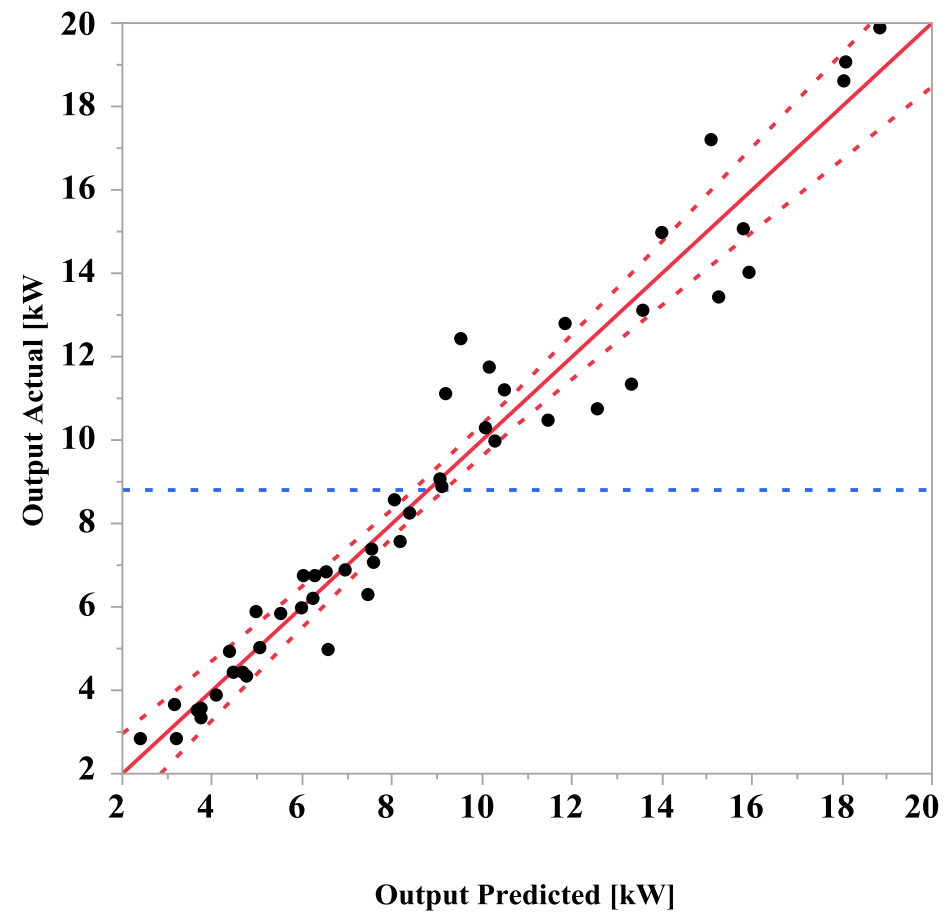

Figure B-2. Actual by predicted plot for second order response model for ORC-WHRS (R245fa)

Table B-2. Parameter estimate for second order response model of R245fa data

\begin{tabular}{|l|r|r|}
\hline \multicolumn{1}{|c|}{ Model Terms } & \multicolumn{1}{c|}{$\boldsymbol{\beta}$ Estimate } & \multicolumn{1}{c|}{ p-value } \\
\hline Intercept & -0.44265 & 0.874 \\
\hline Speed [rpm] & 0.001481 & 0.5286 \\
\hline Torque [ft-lbs] & 0.000979 & 0.6773 \\
\hline Post SCR [kW] & 0.040951 & $\mathbf{0 . 0 1 6 8}$ \\
\hline (Speed [rpm]-1341.78)*(Speed [rpm]-1341.78) & $4.36 \mathrm{E}-06$ & 0.1698 \\
\hline (Speed [rpm]-1341.78)*(Torque [ft-lbs]-839.877) & $-6.86 \mathrm{E}-07$ & 0.9308 \\
\hline (Torque [ft-lbs]-839.877)*(Torque [ft-lbs]-839.877) & $-7 \mathrm{E}-06$ & 0.1932 \\
\hline (Speed [rpm]-1341.78)*(Post SCR [kW]-152.81) & $-2.82 \mathrm{E}-05$ & 0.5779 \\
\hline (Torque [ft-lbs]-839.877)*(Post SCR [kW]-152.81) & $5.44 \mathrm{E}-05$ & 0.427 \\
\hline (Post SCR [kW]-152.81)*(Post SCR [kW]-152.81) & $-2.57 \mathrm{E}-05$ & 0.9128 \\
\hline
\end{tabular}

